\title{
Gender Discrimination: Emotions and Ingroup Strength A Stress and Coping Perspective
}

\section{Ritu Gill}

A Thesis Submitted to the Faculty of Graduate Studies and Research In Partial Fulfillment of the Requirements for the Degree of Doctor of Philosophy

\author{
Department of Psychology \\ Carleton University \\ Ottawa, Ontario
}

October, 2007

(C) Ritu Gill 2007 


$\begin{array}{ll}\begin{array}{l}\text { Library and } \\ \text { Archives Canada }\end{array} & \begin{array}{l}\text { Bibliothèque et } \\ \text { Archives Canada }\end{array} \\ \begin{array}{l}\text { Published Heritage } \\ \text { Branch }\end{array} & \begin{array}{l}\text { Direction du } \\ \text { Patrimoine de l'édition }\end{array} \\ \begin{array}{l}\text { 395 Wellington Street } \\ \text { Ottawa ON K1A 0N4 }\end{array} & \begin{array}{l}\text { 395, rue Wellington } \\ \text { Ottawa ON K1A ON4 }\end{array} \\ \text { Canada } & \begin{array}{l}\text { Canada } \\ \end{array}\end{array}$

Yourfile Votre référence

ISBN: 978-0-494-36786-5

Ourfile Notre référence

ISBN: 978-0-494-36786-5

NOTICE:

The author has granted a nonexclusive license allowing Library and Archives Canada to reproduce, publish, archive, preserve, conserve, communicate to the public by telecommunication or on the Internet, loan, distribute and sell theses worldwide, for commercial or noncommercial purposes, in microform, paper, electronic and/or any other formats.

The author retains copyright ownership and moral rights in this thesis. Neither the thesis nor substantial extracts from it may be printed or otherwise reproduced without the author's permission.
AVIS:

L'auteur a accordé une licence non exclusive permettant à la Bibliothèque et Archives Canada de reproduire, publier, archiver, sauvegarder, conserver, transmettre au public par télécommunication ou par l'Internet, prêter, distribuer et vendre des thèses partout dans le monde, à des fins commerciales ou autres, sur support microforme, papier, électronique et/ou autres formats.

L'auteur conserve la propriété du droit d'auteur et des droits moraux qui protège cette thèse. $\mathrm{Ni}$ la thèse ni des extraits substantiels de celle-ci ne doivent être imprimés ou autrement reproduits sans son autorisation.
In compliance with the Canadian

Privacy Act some supporting forms may have been removed from this thesis.

While these forms may be included in the document page count, their removal does not represent any loss of content from the thesis.
Conformément à la loi canadienne sur la protection de la vie privée, quelques formulaires secondaires ont été enlevés de cette thèse.

Bien que ces formulaires aient inclus dans la pagination, il n'y aura aucun contenu manquant.

\section{Canadä}




\begin{abstract}
The present thesis examined the impact of encountering an acute instance of discrimination on appraisals of the event, emotions, and actions endorsed to contend with it. Two studies were conducted with female first year university participants. Studies 1 $(N=86)$ and $2(N=151)$ exposed women to an experimentally induced situation of gender discrimination. Study 1 examined the effects of experimentally primed emotions (sadness, anger) and expectations for emotional regulation (suppression, expression, control group) on responses to discrimination-based failure feedback on an achievement task. Analyses of variance indicated that, in Study 1, women who were primed to experience anger and encouraged to engage in either emotional suppression or expression, perceived greater discrimination than did angered women who were not provided with such emotional regulation instruction. Contrary to expectations women who were primed to experience anger were more inclined to accept their discriminatory treatment, as on the whole, women perceived all other actions to be ineffective. In light of this finding, Study 2 manipulated perceptions of ingroup strength (strong, weak, control group) and the effects of priming anger (anger, control group) on perceptions of and responses to discrimination. In addition, the moderating influence of gender identification was considered in Study 2. Consistent with expectations, strong group identification and anger resulted in greater recognition of discrimination. Self-reported anger was also found to be related to the endorsement of collective actions. Finally, appraisals of control and efficacy were found the mediate the association between perceived discrimination and action endorsements. Implications of these results for understanding discrimination from a stress and coping perspective were discussed.
\end{abstract}




\section{Acknowledgments}

This has been an amazing journey and I can't believe that it is over! Throughout it all I have been fortunate to be surrounded by a group of wonderful, supportive, and brilliant people.

I thank my thesis advisor, Dr. Kim Matheson, whose commitment and brilliance throughout the years has been inspirational. Kim, your dedication, support, and knowledge of the research has inspired me to be a better researcher. Thank you for being an amazing advisor and role model; I have learned so much from you. Put simply, you rock.

I would also like to express my gratitude to my committee members: Dr. Lloyd Strickland, Dr. Michael Wohl, Dr. Lorraine Dyke, and my external examiner Dr. Mindi Foster. Thank you all for your valuable comments, insight, support, and humor (particularly at stressful times!). A special thanks to Dr. Lloyd Strickland and Dr. Michael Wohl; Dr. Strickland, thank you for your support and insight throughout the years, and encouraging me to explore research from different perspectives. Michael, thank you for your suggestions and help with some of the statistics, especially your humor, which was greatly appreciated during nerve wracking moments!

To my biggest cheerleaders, my family. Mom and Dad, words cannot express how much I thank you for your support, patience, love, and dedication. Mom, thank your for being the strong, independent woman that you are. Dad, thank you for your support and encouragement. You both have made this goal worth achieving, and through your example, make me a better person. To my sister Rupa, potentially, THE biggest 
cheerleader I have and who has been my role model since I was a little girl. Thank your for all of your love, humor, strength, and support. I can't wait until it's your turn!

To my dear labmates and friends, Barb and Chris, thank you for all the lunches, dinners, movies, laughs, and grilling me with the tough questions! Chris, thank you for being my male confederate and for your flare for the dramatics!

Finally, I would like to thank my participants, especially those who would email me after processing the experiment and sharing with me their insights on why they thought they reacted the way they did. You were all an invaluable part of this process. 
Dedication

To Mom, Dad, and Rupa with love. 


\section{Table of Contents}

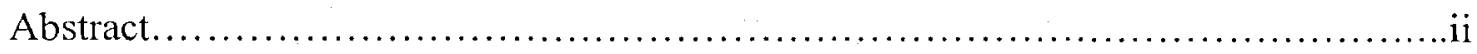

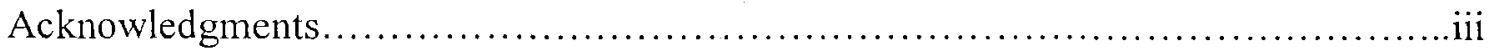

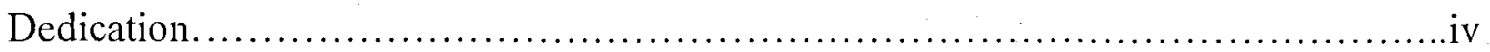

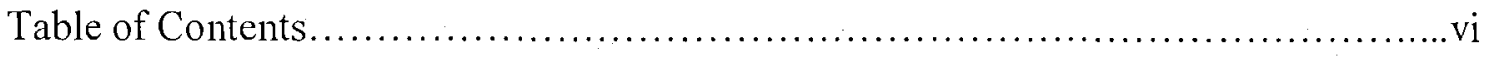

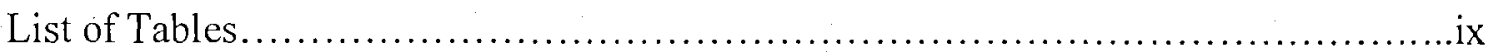

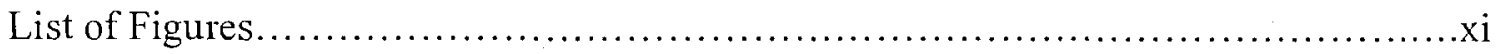

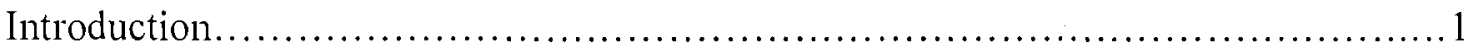

Prejudice \& Discrimination................................................... 4

Group Identification............................................................ 8

Responses to Discrimination: A Stress \& Coping Framework.........................11

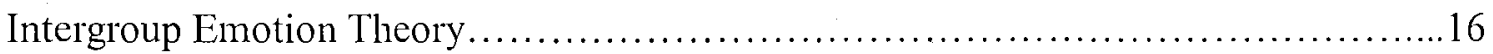

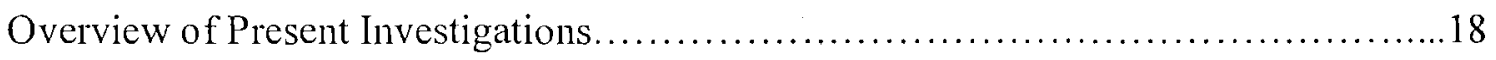

Study 1

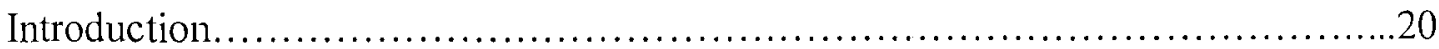

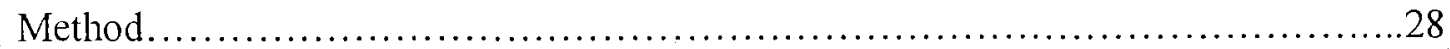

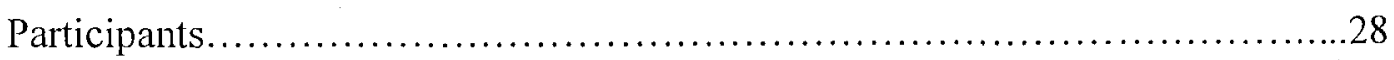

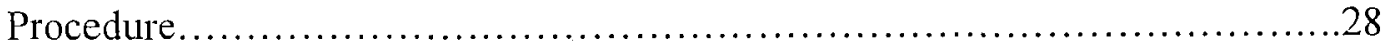

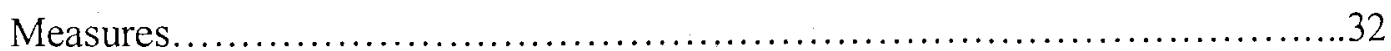

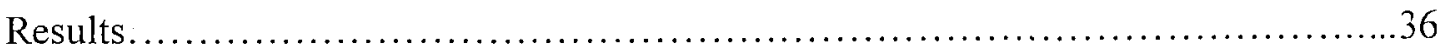

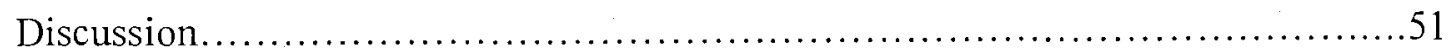

Study 2

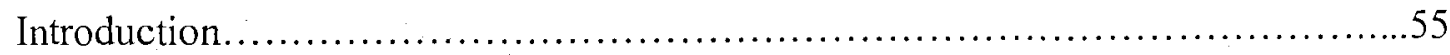




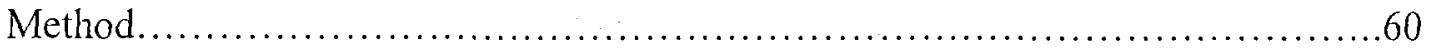

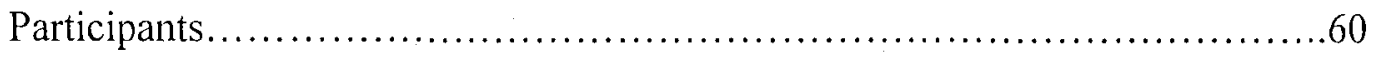

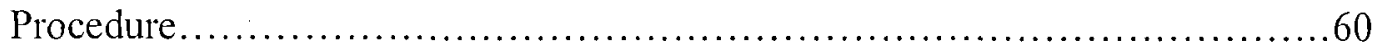

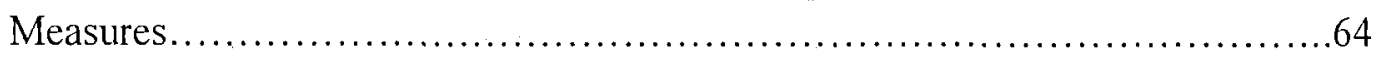

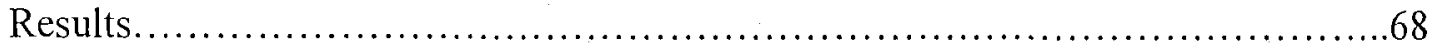

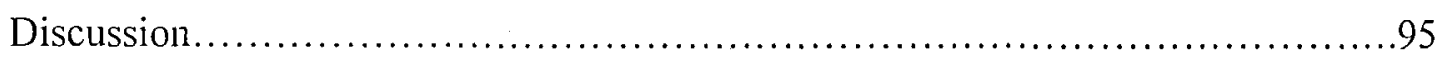

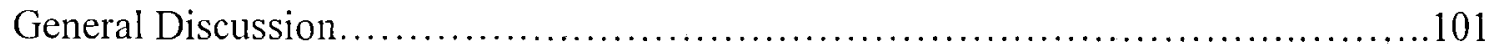

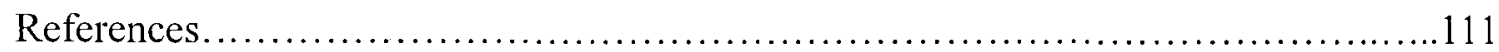

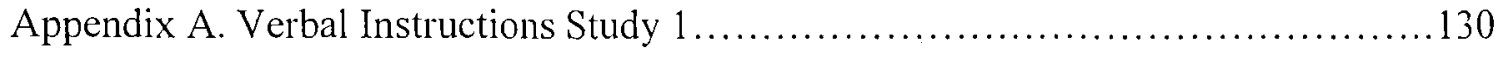

Appendix B. Informed Consent Form Study 1 .....................................133

Appendix C. Story, Sad \& Angry Word Lists.....................................134

Appendix D. Filler Task ..................................................... 137

Appendix E. Emotion Rating Scale ............................................ 138

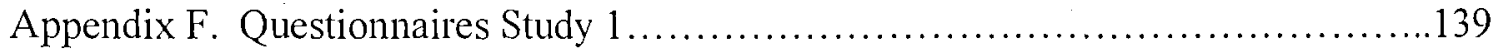

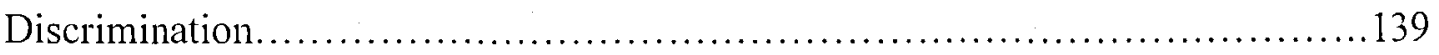

Perceived Control......................................................... 140

Action Efficacy \& Actions......................................................... 141

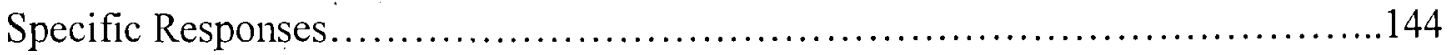

Appendix G. Suspicion Questionnaire.........................................146

Appendix H. Debriefing Study 1 .......................................... 147

Appendix I. Observations by Denis Miller.........................................149

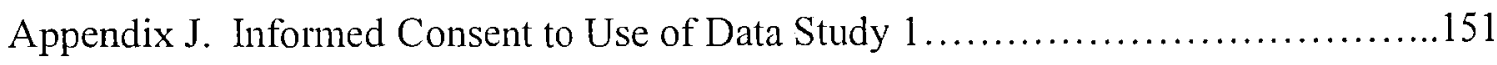

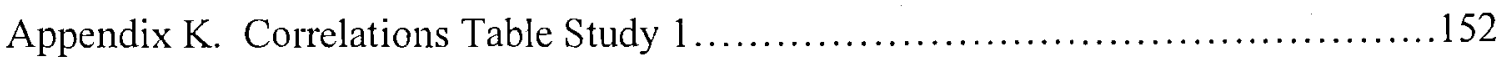


Appendix L. Informed Consent Form \& Demographic Questionnaire Study 2.......155

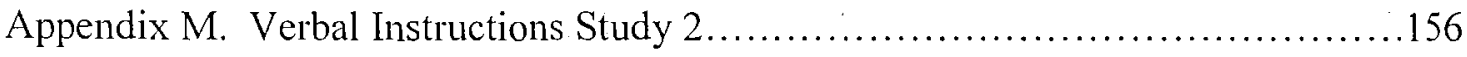

Appendix N. Emotion Manipulation Check....................................157

Appendix O. Strong Ingroup Condition.................................... 158

Appendix P. Weak Ingroup Condition.......................................... 161

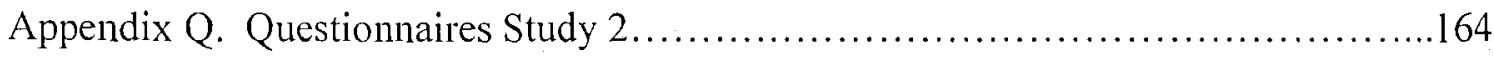

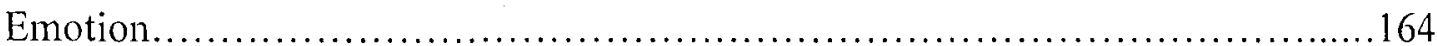

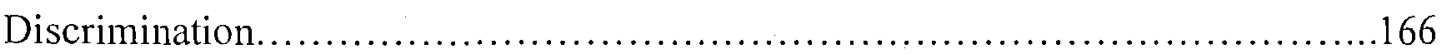

Perceived Control..............................................................

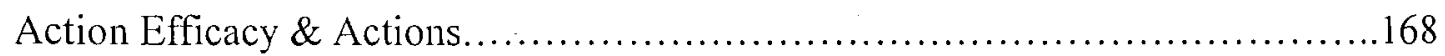

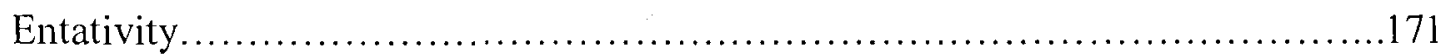

Appendix R. Gender Identity Scale......................................... 172

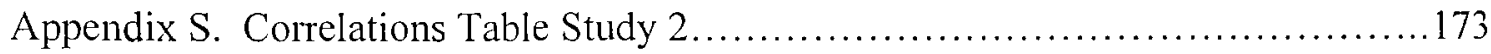

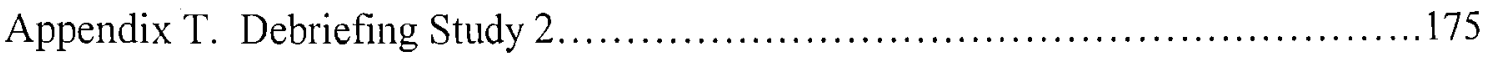

Appendix U. Informed Consent to the Use of Data Study $2 \ldots \ldots \ldots \ldots \ldots \ldots \ldots \ldots \ldots \ldots$ 
List of Tables

1. Means \& Standard Deviations of Self-Reported Emotion Following the Sad \& Angry Emotion Prime Manipulations

2. Means \& Standard Deviations of Personal \& Group

Discrimination for Emotion Primed \& Emotional Regulation. ...

3. Means \& Standard Deviations of Action Endorsements \&

Emotion Prime.

4. Means \& Standard Deviations of Perceived Efficacy of Action

Endorsements in terms of Difficulty in Endorsing Action,

Change Status, \& Procedural Fairness.

5. Correlations between Emotions, Discrimination, Perceived

Control \& Perceived Difficulty of Actions.

6. Mediation of the effect of perceived control on individual confrontation through perceptions of individual confrontation improving personal status and making

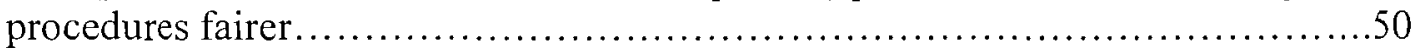

7. Means and Standard Deviations of Self-Reported Anger as a Function of Gender Identity\& Emotional Priming....

8. Means and standard deviations of self-reported anger pre and post-discrimination within Emotional Priming Conditions.

9. Means and Standard Deviations of Perceived

Discrimination as a function of Gender Identity \&

Emotional Priming.

10. Means and Standard Deviations of Personal Mastery and

Perceived Constraints as a function of Ingroup Strength.

11. Means and standard deviations of Perceived Difficulty, Improving Personal Status, and Procedural Fairness of

Actions and Emotional Priming

12. Means \& Standard Deviations of Action Endorsements

13. Correlations between Anger Pre-Discrimination, Perceived Ingroup Strength, Discrimination, Control, \& Action Endorsements 
14. Mediation of the effect of Perceived Discrimination on Individual retest through perceptions of constraints, Individual retest Improving Personal Status and Making Procedures Fairer.

15. Mediation of the effect of Perceived Discrimination on Individual Confrontation through Perceptions of Constraints, Individual Confrontation Improving Personal Status and Making Procedures Fairer.

16. Mediation of the effect of Perceived Discrimination on Collective Retest through Perceptions of Collective Retest Improving Status and Making Procedures Fairer.

17. Mediation of the effect of Perceived Discrimination on Collective Confrontation through Perceptions of Collective Confrontation being Less Difficult, Improving Personal Status, and Making Procedures Fairer.

18. Mediation of the effect of Constraints on Individual Retest through Perceptions of Individual Retest Improving Personal Status and Making Procedures Fairer. 
List of Figures

1. Discrimination Model: Appraisals/Emotions, Identity, Coping...................

2. Model of the Stress Process.............................................. 12

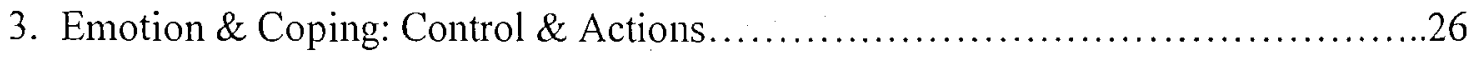

4. Discrimination: Anger \& Ingroup Strength.................................5

5. Mediation of the effect of Perceived Discrimination on Individual Retest through Perceptions of Constraints, Individual Retest Improving Personal Status and Making Procedures Fairer.

6. Mediation of the effect of Perceived Discrimination on Individual Confrontation through Perceptions of Constraints, Individual Confrontation Improving Personal Status and Making Procedures Fairer.

7. Mediation of the effect of Perceived Discrimination on Collective Retest through Perceptions of Collective Retest Improving Personal Status and Making Procedures Fairer.

8. Mediation of the effect of Perceived Discrimination on Collective Confrontation through Perceptions of Collective Confrontation being Less Difficult to Endorse, Improving Personal Status, and Making Procedures Fairer. 


\section{Introduction}

Belonging to a stigmatized group may result in encountering experiences that involve both subtle forms of discrimination that include minor, daily hassles (e.g., followed because you 'look like' a shoplifter), as well as more blatant and sometimes severe forms of discrimination (e.g., assaulted because of ethnic background or sexuality). The prejudicial and discriminatory actions of others constitute a source of acute and chronic stress for members of stignatized groups, whereby experiences of discrimination have been associated with increased symptoms of stress-related pathologies including depression, anxiety, hopelessness, and overall reduced psychological well-being (Baumeister \& Tice, 1990; Branscombe, Schmitt, \& Harvey, 1999; Finch, Kolody, \& Vega, 2000; Kessler; Mickelson, \& Williams, 1999; Krieger, 1999; Krieger \& Sidney, 1996; Matheson, Ofleh, Kelly, \& Anisman, 2004; Ren, Amick, $\&$ Williams, 1999). However, not all members of stigmatized groups are equally negatively affected. The evolution of stress-related disturbances evidenced among members of minority groups are likely moderated by individual difference factors that buffer group members against the negative effects of discrimination.

To evaluate the factors that influence the relation between discrimination experiences and well-being, it may be beneficial to adopt a stress and coping perspective. The general model employed in the present studies (Figure 1) examines discrimination from a stress and coping perspective, along with factors that may influence this process. 


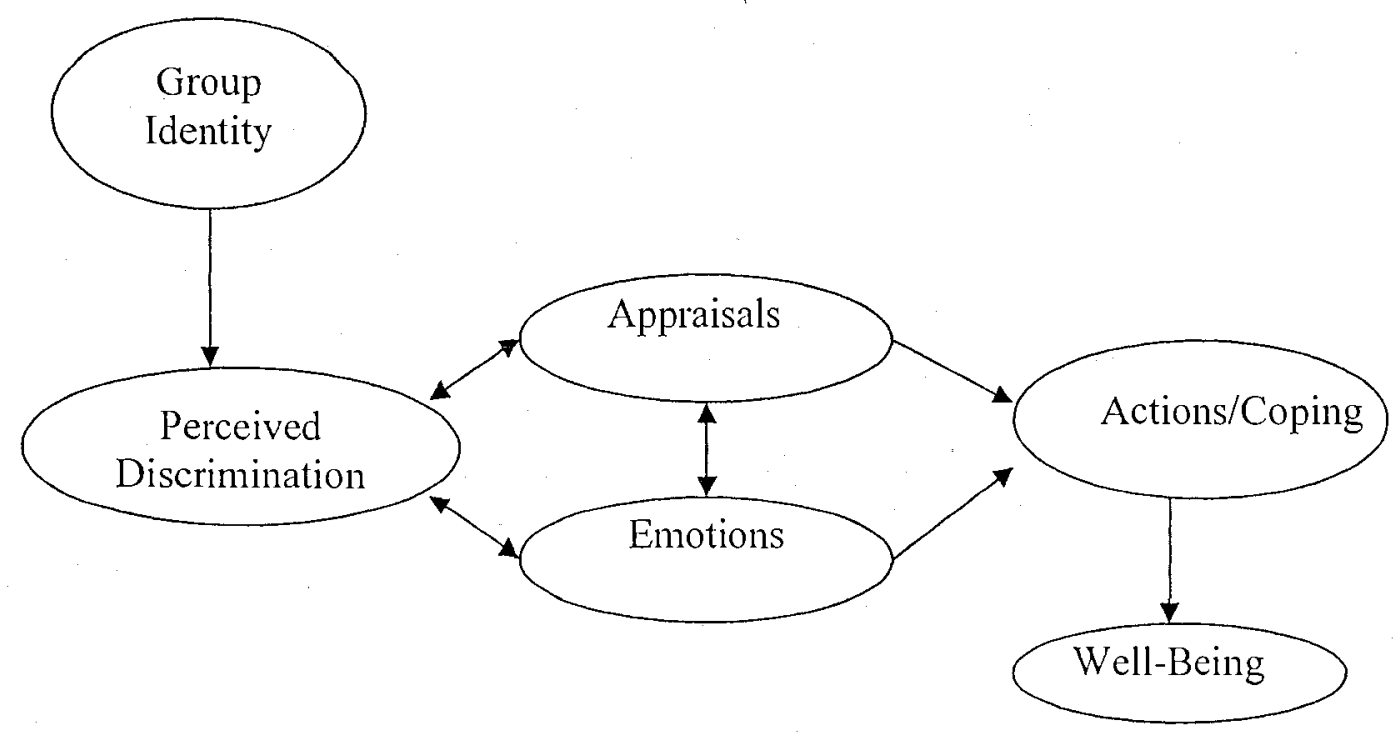

Figure 1. Discrimination Model: Identity, Appraisals/Emotions, Coping

From the perspective of the transactional model of stress and coping (Lazarus \& Folkman, 1984), discrimination can be regarded as a stressor, which the individual appraises and responds to. As important as the nature of the event itself, is the individual's subjective interpretation or appraisal of that event. Given the ambiguity often associated with discriminatory acts, group members may or may not view their experiences as constituting discrimination, and if they do, they must evaluate the extent to which the situation is controllable, whether it has the potential for considerable harm (threat), and whether it is localized or pervasive and hence likely to be encountered again. Notably, appraisals of discrimination may be influenced by individual difference factors such as group identity; for instance, strength of group identification may influence perceptions of discrimination, in that the more individuals identify with their group, the more sensitive they may be to cues pertaining to their stigmatization, and the more likely they are to make attributions of discrimination (Branscombe et al, 1999; Mendoza- 
Denton, Purdie, Downey, \& Davis, 2002; Operario \& Fiske, 2001; Pinel, 1999; Shelton and Sellers, 2000).

Although the original Lazarus and Folkman (1984) model did not include emotional responses as an explicit aspect of the stress and coping process, other theories of emotions have since argued that appraisals give rise to emotions that, in turn, influence how the individual contends with the situation (Frijda, Kuipers, \& ter Schure, 1989; Smith, 1993). Along these lines, recent research on minority group members' reactions to discrimination have noted that the particular emotions derived from individuals' appraisals channel subsequent actions to contend with the event (Smith \& Mackie, 2000; van Zomermen, Spears, Fischer, \& Leach, 2004). According to the intergroup emotions theory (IET; Mackie, Devos, \& Smith, 2000; Smith, 1993; 1999), specific patterns of appraisals may evoke different emotions, which in turn promote particular actions to contend with the event; for example, if the individual appraises his/her group as weak, then fear was elicited by the discrimination event, resulting in an avoidant response (Yzerbet, Dumont, Gordjin, and Wigboldus, 2002). In contrast, appraising an event as unjust (Branscombe et al., 1999), and the group as strong, elicited anger, which was associated with greater endorsement of confrontational or collective actions (Gill \& Matheson, 2006; Mackie et al., 2000; van Zomeren et al., 2004). Although studies have assessed the extent to which appraisals of discrimination are related to more negative affect, the reciprocal relation, wherein women's emotional predispositions may also influence how they appraise a situation has been more limited, despite the fact that some have suggested that appraisals may represent cognitive justifications for particular mood reactions (DeSteno, Dasgupta, Bartlett, \& Cajdric, 2004). 
In applying a stress/coping framework, it is of interest in the present investigation to examine the relations among women's gender identity, discrimination appraisals, emotions, and actions to cope with the event, as these might constitute the processes that ultimately influence the well-being of members of stigmatized groups. Specifically, the focus is on examining the stress response process to discriminatory treatment, as these processes likely have implications for well-being. In the present investigation, Study 1 examined the effects of primed emotions and emotion-focused coping on multiple appraisals of discrimination (including perceived control), and women's endorsement of behavioral responses to change the status quo. The results of this study raised questions regarding the extent to which the intergroup actions emanating from particular emotional reactions might be affected by perceptions of collective strength and ingroup identification. Thus, Study 2 manipulated women's emotions and the collective strength of the group, and assessed the moderating role of women's gender identification on appraisals of discrimination and endorsement of actions to respond to the discrimination.

\section{Prejudice and Discrimination.}

Social stigmas are ubiquitous, as they exist within all societies and cultures in various forms. Social stigmas arise from a variety of characteristics, including body shape, sexual orientation, race, sex, religion, and disability, to name a few. These stigmas may result in the individual being viewed as an 'outsider', providing a basis for prejudice and discrimination. There is growing literature indicating that belonging to a socially stigmatized group is associated with deleterious psychological effects, such as heightened depression, anxiety, and lower self-esteem (Foster, 2000; Landrine, Klonoff, Gibbs, Manning, \& Lund, 1995; Pak, Dion, \& Dion, 1991). The poorer health outcomes 
found across groups may emanate from genetic commonalities, as well as environmental and cultural factors (e.g., diet, activity, social norms) that exacerbate or alleviate particular stress reactions. However, there is also evidence to suggest that stress-related pathologies may be linked to a higher incidence of prejudicial and discriminatory experiences (Dion, Dion, \& Pak, 1992; Kobrynowicz \& Branscombe, 1997; Schmitt, Branscombe, Kobrynowicz, \& Owen, 2002). Self-reported experiences of discrimination have also been associated with physiological pathologies, such as cardiovascular dysfunction and disease (Clark, Andersen, Clark, \& Williams, 2000; James, LaCroix, Kleinbaum \& Strogatz, 1984; Krieger \& Sidney 1996). Branscombe et al. (1999) noted that perceptions that discrimination occurred in the past, along with expectations that it would occur again in the future were particularly likely to be related to decreased wellbeing.

Although these studies demonstrate a link between perceptions of discrimination and well-being, these perceptions may underestimate the extent to which discrimination is, in fact, encountered, given the ambiguity inherent to such experiences. Indeed, a lack of correspondence between perceptions and actual experiences of discrimination has been frequently documented, and is so robust that it has been labelled the personal/group discrimination discrepancy (PGDD), wherein members of stigmatized groups frequently deny that they were personally discriminated against, while concurrently recognizing that the group as a whole experiences discrimination, despite objective indicators that they have been discriminated against (Crosby, 1982, 1984; Foster \& Matheson, 1998, 1999; Taylor, Wright, Moghaddam, \& Lalonde, 1990; Taylor, Wright, \& Ruggiero, 1991). Substantial research has examined cognitive (Major, Quinton \& McCoy, 2002; Rutte, 
Diekmann, \& Polzer, 1994; Twiss, Tabb, \& Crosby, 1991; Zanna, Crosby, \& Lowenstein, 1987) and motivational (Foster, 2001; Hodson \& Esses, 2002; Taylor et al., 1990) bases for the phenomenon.

Cognitive factors point to the uncertainty members of stigmatized groups experience as to whether events are attributable to prejudice and discrimination or to other factors (Crocker, Major, \& Steele, 1998; Crocker \& Major, 1989). This might be due to a lack of comparative information (e.g., how many other group members have had the same experience in this context), or uncertainty concerning the intentions of the possible perpetrator (Twiss, Tabb, \& Crosby, 1989). For example, in a failure situation, negative outcomes could be due to one's inferior qualifications or poor performance relative to others, or alternatively they could be due to prejudice and discrimination based on one's stigmatized group membership. Consequently it may be challenging for members of stigmatized groups to appraise whether the situation constitutes prejudice and discrimination. Indeed, the appraisal process in terms of determining whether an ambiguous event is discriminatory might, in itself, contribute to group members' stress and anxiety.

Motivational factors accounting for the PGDD suggest that minority group members may be motivated to minimize personal experiences of discrimination. An individual may be reluctant to specify the exact source of discrimination, or to pinpoint the 'villain' (Crocker et al., 1998). For instance, a female employee may hesitate to point a finger toward her discriminating male employer in order to avoid, or out of fear of, the potential repercussions of her accusation. As a result, she might minimize the extent to which her experience constitutes discrimination as this allows her to avoid responsibility 
for confronting the situation. Related to this, the disadvantaged individual may be motivated to deny personal discrimination primarily to avoid the dissonance associated with not taking any specific action to address the discrimination (Taylor et al., 1990). Knowing you have been a victim of discrimination but chose not to confront it may produce feelings of anger, sadness, or shame; consequently, it may be easier to minimize such experiences rather than to contend with the otherwise negative affect.

Given the biases that might be associated with whether group members perceive discrimination, it is possible that the relations between reports of discrimination and well-being may be spurious, in that, those individuals who report discrimination may perceive more hassles in general, and it is this general negative evaluation of one's environment that is associated with reduced well-being; however, several studies have found that exposure to racist provocation in a laboratory context led to increased cardiovascular and psychological reactivity, at least among African Americans (Anderson, Myers, Pickren, \& Jackson 1989; Armstead, Lawler, Gordon, Cross, \& Gibbons 1989; Jones, Harrell, Morris-Prather, Thomas, \& Omowale 1996; MorrisPrather, Harrell, Rakale, Leonard, Boss \& Lee, 1996; Sutherland \& Harrell 1986). Thus, although there may be multiple factors influencing perceptions of discrimination, the limited research assessing the effects of actual experiences suggests that such events do indeed have deleterious physical and psychological health effects. Notably, it is possible that relations between perceived discrimination and well-being are attenuated, as many individuals who encounter stressful events that culminate in stress-related pathology may not appraise these events as constituting discrimination. 
Group identification. Although situational factors may contribute to individuals' subjective experience of discrimination (e.g., ambiguity, source of the discrimination), there are also individual difference factors that may play a key role. A substantial body of research demonstrates the importance of whether or not the individual identifies with their group membership, meaning that they view the group as an important aspect of their self-concept (Branscombe et al, 1999; Crocker \& Major, 1989; Mossakowski, 2003; Operario \& Fiske, 2001; Shelton \& Sellers, 2000). Strength of group identification may influence perceptions of discrimination, in that the more individuals identify with their group, the more sensitive they may be to cues pertaining to their stigmatization, and the more likely they are to make attributions of discrimination (Branscombe et al, 1999; Mendoza-Denton et al., 2002; Operario \& Fiske, 2001; Pinel, 1999; Shelton and Sellers, 2000). For instance, Operario and Fiske (2001) found that individuals who reported high ethnic identity perceived greater ethnic discrimination than those with low identification, who tended to overlook the discrimination.

The role of identity in how individuals perceive and experience group-based discrimination is perhaps best understood using the Social Identity Theory (SIT; Tajfel \& Turner, 1979) of intergroup relations. According to SIT, a person has multiple selves that correspond to widening circles of group membership; a social identity involves viewing oneself as a member of a socially defined group or category (e.g., women, Canadian, African American). When group membership is salient, people think of themselves and their attributes in terms of the norms of the group. This social identity can be contrasted to a personal identity, which when salient, results in people thinking of themselves in terms of their unique individual abilities, goals, personality traits, and so on. Compared 
to individuals who are low in social identification, those who are highly identified with their group tend to be more concerned with the group's treatment (Petta \& Walker, 1992), more likely to perceive group-based injustice (Branscombe et al, 1999; Crosby, Pufall, Snyder, O'Connell, \& Whalen, 1989), and to attribute negative outcomes to discrimination when prejudice is ambiguous (Major, Quinton, \& Schmaeder, 2003; Operario \& Fiske, 2001). Thus, individuals with a strong social or group identity may be more motivated to recognize injustices perpetrated against their group, and be more sensitive to the cues and information that facilitate interpreting events as constituting discrimination, as noted earlier.

Group identification also provides a basis for responding to discrimination. Stryker, Owens, and White (2000) suggest that the more important an identity is, the more likely it is that an individual will engage in collective acts to encourage social change for their group. Indeed, more strongly identified women demonstrated a greater degree of involvement on behalf of women and women's issues (Crosby, Todd, \& Worell, 1996; Liss, Crawford, \& Popp 2004). Similarly, Ethier and Deaux (1994) and Ullah (1987) found that in low status groups, members who use the group label to describe themselves (e.g., Hispanic) were more likely to participate in the group's cultural activities and to distinguish themselves from the outgroup. Similar results were observed by Mackie et al. (2000) who found that making ingroup identification salient was associated with greater action taken to respond to the outgroup. Moreover, when the group encounters a threat, collective action was motivated primarily out of concem for one's group (Grant \& Brown, 1995; Kawakami \& Dion, 1993; Simon, Loewy, Sturmer, Weber, Freytag, Habig, Kampmeier, \& Spahlinger, 1998; Simon, Sturmer, \& Steffens, 
2000; Sturmer, Simon, Loewy, \& Jorger, 2003; Tougas \& Veilleux, 1988; Tropp \& Wright, 1999; Walker \& Mann, 1987; Wright \& Tropp, 2002). Thus, group identification appears to be integral in determining how individuals appraise and respond to discrimination.

Given that group identification appears to influence responses to contend with discrimination, this may explain the paradox that highly identified group members are both more sensitive to discrimination and demonstrate greater well-being (Branscombe et al., 1999; Crosby et al., 1989; Mossakowski, 2003). In particular, group identification may be a source of resilience among stigmatized group members. In line with this, group identification has been positively associated with feelings of comfort when interacting with group members (Tropp \& Wright, 2001) with feeling close to group members (Doosje, Ellemers, \& Spears, 1995), and lower feelings of rejection following an identity threat (Branscombe et al., 1999). Thus, for highly identified group members, other members of the group may represent a source of social and emotional support that fosters appropriate actions and provides a resource to protect members' well-being. This said, however, in contrast to these positive relations between group identification and wellbeing, others have noted that women low in gender identification experienced less depressed affect and higher self-esteem when given a negative evaluation due to sexism, compared to women high in gender identification who experienced increased depressed affect and low self-esteem (McCoy \& Major, 2003). It is possible that high group identification results in initial, temporary emotional vulnerability upon realization that one's ingroup is being attacked, but this vulnerability may eventually translate into 
emotional support and strength derived from high group identification (McCoy \& Major, 2003).

Responses to Discrimination: A Stress and Coping Framework

Perceiving and responding to prejudicial and discriminatory treatment may involve several processes. As already noted, discrimination must first be perceived and appraised. Once an event is identified as constituting discrimination, it might elicit an emotional response, which subsequently influences reactions to the event. As noted earlier, situational and individual difference factors might influence how individuals appraise a situation of discrimination. Perhaps for this reason, the appraisal outcome may be a stronger predictor of well-being than the objective events themselves (Lazarus \& Folkman, 1984). In particular, depending on how the event is appraised and the individual's ability to contend with it, the event might be experienced as stressful by one individual but not by another, even when the event itself is identical.

Lazarus and Folkman (1984) proposed a model that emphasizes the transactional nature of the event and the organism's responses (Figure 2). 
Occurrence of a

potentially stressful

event:

-major events

-minor events (hassles)
Primary Appraisal:

'Am I in trouble?'

-irrelevant

-benign (positive)

-stressful

*harm/loss

*threat

* challenge
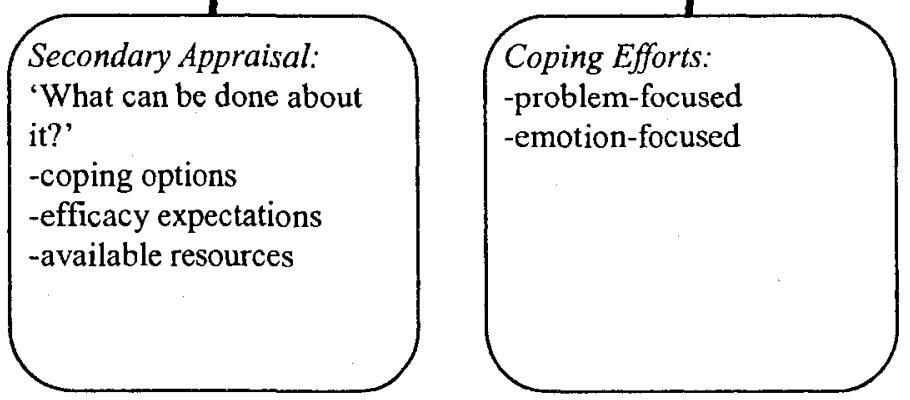

Adaptational Outcomes:

-social functioning

-morale

-somatic health

Figure 2. Model of the stress process (taken from Lazarus \& Folkman, 1984).

Lazarus and Folkman (1984) argue that stress is a two-way process: The

environment produces stressors and the individual interprets and finds ways to deal with

them, thereby changing the nature of the stressor. It is important to note that

characteristics of the stressor (e.g., severity, controllability, predictability, ambiguity,

chronicity, and intermittence) constitute factors that influence stressor reactivity. These

factors may work in conjunction with one another, such that an acute major event (e.g.,

divorce) may haye similar impacts on well-being in the long run as a series of chronic

minor hassles (e.g., the constant fighting in a dysfunctional relationship) (McEwen, 1998). According to the transactional model, reactions to a stressor consist of three core

elements that allow the individual to interpret and respond to the event: Primary appraisal (process of perceiving a threat to oneself), secondary appraisal (process of bringing to 
mind a potential response to the threat), and coping (process of executing that response). When individuals appraise their environment as endangering their well-being and as taxing/exceeding their resources, they experience stress (Lazarus \& Folkman, 1984).

During the primary appraisal process, the individual evaluates an event to determine whether or not it poses a threat. This process involves answering the question, 'Am I in trouble?', and the event may be appraised as (a) irrelevant, (b) benign/positive, or (c) stressful. Further appraisals are made with regard to the potential implications of the event: 1) harm-loss, which refers to the amount of damage that has already occurred, 2) threat, referring to the expectation of future harm (e.g., hear of losing one's job/income), and 3) challenge, referring to viewing stress in a positive manner, in that it may be difficult but possible to contend with. During the secondary appraisal process, an individual evaluates his/her resources, both internal (e.g., skill level) and external (e.g., social support), and his/her options for responding to the event. The individual asks the question 'What can be done about it?'. Secondary appraisals can co-occur with primary appraisals and are largely concerned with an individual's perceptions of their ability to cope with the situation.

Lazarus and Folkman (1984) identify two major categories of efforts a person may endorse to cope with a stressful event: Problem-focused and emotion-focused coping. Typically, problem-focused efforts are employed when the individual appraises the situation as controllable, whereas if the stressor is appraised as one that must be endured or it elicits particularly negative affect, emotion-focused coping might prevail (Lazarus \& Folkman, 1984; Lazarus, 1999; Stanton, Danoff-Burg, Cameron, Bishop, Collins, Kirk, \& Sworowski, 2000). Problem-focused coping strategies are active efforts 
to change the stressful circumstances in some way. These strategies encompass responses such as target reducing, modifying, or eliminating a source of stress (e.g., if grades are low, reduce work hours, change studying strategy). Problem-focused coping strategies consist of changing the situation, defining or redefining the problem, looking at alternative situations, evaluating the implications of the alternatives, and selecting the optimal strategy. Emotion-focused coping strategies include efforts to control one's emotional responses to the event (e.g., using relaxation techniques to decrease anxiety) and efforts to modify the meaning of the event (e.g., comparing one's problems to others' that are more serious). The goal is to minimize emotional distress, and such strategies are typically employed when the individual feels that nothing can be done about the situation itself. Reduction of emotional distress is achieved through cognitive reappraisal of the stressor, by directly focusing on feelings of distress through rumination and emotional expression or containment, self- or other-blame, or even passive acceptance of the circumstances.

Problem oriented coping strategies are typically related to adaptation and good health, whereas emotion oriented coping styles are negatively related to adaptation and good health (Compas, Malcarne, \& Fondacaro, 1988; Endler \& Park, 1994). However, although problem- vs. emotion-focused coping are often viewed as distinct efforts, similar coping strategies may serve different functions (Lazarus, 2000; Matheson \& Anisman, 2003). For example, social support seeking may be employed to receive information or tangible assistance (problem-focused), and/or to receive emotional support and affirmation (emotion-focused). Similarly, cognitive reappraisals may be directly applied to the problem at hand to identify alternative approaches for contending with a 
situation (problem-focused), or they may entail reappraising the emotional experience associated with the event in order to render it meaningful or manageable (emotionfocused). Finally, different coping strategies may be employed concurrently or sequentially to optimize adaptation to the stressor (Lazarus, 2000; Matheson \& Anisman, 2003), and their effectiveness may depend on the situation (Carver, Scheier, \& Weintraub, 1989; Cheng, 2001; Lazarus \& Folkman, 1984).

In applying the transactional model of stress and coping to discrimination, it is clear that the various situational factors that influence group members' appraisals of an event will likely influence their subsequent reactions. Moreover, a stigma related event may be experienced as more or less stressful depending on whether the individual has adaptive resources to cope with it. Supporting this contention, Noh and Kaspar (2003) noted that when group members who encountered discrimination adopted active, problem-focused coping strategies (e.g., spoke up against discrimination, reported discrimination to authorities), they were more effective in reducing the impacts of perceived discrimination on depressive affect, whereas those who chose to invoke passive, emotion-focused coping efforts (e.g., passive acceptance, pretended not to be offended by discrimination) demonstrated more debilitating mental health effects, namely depression. Similarly, in a response to an acute identity threat in a laboratory context, Matheson and Cole (2004) found that problem-focused coping strategies were related to increased appraisals of control, and reduced physiological stress reactivity (cortisol elevations) following the event, whereas group members who endorsed an emotionfocused style of coping were more likely to perceive the event as threatening, and such threat was associated with increased physiological reactivity. Thus, consistent with the 
transactional model of stress and coping, group members' appraisals of a discrimination event and their effects on well-being are likely influenced by their coping efforts, and conversely, such appraisals are likely to evoke particular strategies for contending with the event.

\section{Intergroup Emotion Theory}

In many respects, Social Identity Theory (Tajfel \& Turner, 1979) and Lazarus and Folkman's transactional model of stress and coping could be regarded as cognitive perspectives, as they focus primarily on individuals' perceptions, appraisals, and evaluations of their situation. In a growing recognition of the importance of emotional reactions, researchers in the area of intergroup relations developed the Intergroup Emotions Theory (IET) (Mackie et al., 2000; Smith, 1993; 1999), which builds upon and integrates Lazarus and Folkman's transactional model, as well as the Social Identity Theory. As posited by Social Identity Theory, when group membership is salient, people think of themselves as interchangeable members of the ingroup, rather than in terms of their individual identity (Tajfel \& Turner, 1979). As group membership becomes part of one's self and identity, it not only guides the self-concept, but also involves the regulation of emotional responses (Mackie et al., 2000; Smith, 1993, 1999). Essentially, IET asserts that when individuals identify with a group, they will appraise events in terms of their implications for the group and themselves as a member of that group and these appraisals will produce emotions. Indeed, Yzerbet et al. (2002) demonstrated that when social identity was salient and an event affected ingroup members as a whole, an emotional response (anger) was produced, even when the event did not affect members individually. It was argued that these emotions reflected perceptions of a threat to the collective aspect 
of the individual's self-concept. The more central this identity is to individuals' selfconception, the greater their emotional reaction is likely to be (Mackie \& Smith, 2002; Yzerbyt et al., 2002).

The nature of the emotions that are provoked by a collective threat depend on appraisals pertaining to the event (Frijda et al., 1989; Reisenzein \& Hofmann, 1990; Roseman, Spindel, \& Jose, 1990; Smith \& Lazarus, 1993; Tesser, 1990). For example, Mackie et al. (2000) observed that perceiving the ingroup to be strong was associated with more anger toward the outgroup, in comparison to those group members who perceived the ingroup to be weak. Moreover, the emotions group members experienced were associated with particular action tendencies (Mackie et al., 2000; van Zomeren et al., 2004; Yzerbyt et al., 2002). In particular, those individuals who experienced anger reported increased desires to take confrontational action against the outgroup, and this emotional reaction mediated the relations between appraisals and action, whereas fear was related to avoiding the outgroup (Mackie et al., 2000). This said, our own work has also demonstrated that anger, more than sadness, is likely to result in greater endorsements of collective action-taking, but anger (which was primed in advance of the event) appeared to influence appraisals of discrimination, and such appraisals either mediated, or were additive, in their influence on action endorsements (Gill \& Matheson, 2006). Yet another perspective on the relations among emotions and appraisals was presented by van Zomermen et al. (2004), who argued that collective action among disadvantaged groups may be a result of two pathways, emotion-focused and problemfocused coping. These authors argued that responses that were motivated by group-based anger that arise from appraisals of the event as unfair (threatening) reflect a form of 
emotion-focused coping, whereas appraisals of control (group efficacy) are likely to elicit problem-focused coping action efforts. van Zomermen et al. (2004) noted when these efforts worked in conjunction with one another, the likelihood of endorsing collective action strategies was greatest. Thus, it appears that appraisals may indeed elicit and be elicited by particular emotions, and thereby have both direct and indirect effects on individuals' behavioural responses to a discriminatory event.

The relations between emotions and appraisals are in fact dynamic and reciprocal, where both influence one another (Scherer, 2001; Smith \& Kessler, 2004). In other words, while appraisals of discrimination may influence emotional responses, tendencies to emotional states (i.e., perhaps emanating from past experiences with discrimination) may also influence appraisals (Bodenhausen, Mussweiler, Gabriel, \& Moreno, 2001; DeSteno, Dasgupta, Bartlett, \& Cajdric, 2004; Gill \& Matheson, 2006; Smith \& Kessler, 2004). Lambie and Marcel (2002) have found that emotional responses can occur even before individuals know why they feel the way that they do; therefore, subsequent appraisals may serve to explain the emotions experienced (DeSteno et al., 2004; Gilbert, 2004; Ochsner, Bunge, Gross, \& Gabrieli, 2002). Essentially, although different appraisals elicit anger, sadness, or fear, the emotional response produced might also influence subsequent interpretations of the event itself. Overview of the Present Investigations

The primary focus of the present investigations was to examine the effects of discrimination against women using a stress and coping framework. The stress and coping model of discrimination (Figure 1) that is being used as a general framework for this thesis was derived to reflect the experiences of members of multiple stigmatized 
groups. However, it was of particular interest to evaluate the role of emotions in determining strategies for contending with discrimination among women. In the present investigation, the role of women's emotions in predicting their appraisals and responses to a discrimination experience was examined. In order to avoid the confounds inherent to simply measuring perceptions of discrimination, these responses were evaluated in an experimental simulation that exposed women to an event that objectively constituted discrimination. In Study 1, the extent to which particular coping responses (situationally induced through normative expectations) moderated the effects of women's emotions on an array of appraisals and action endorsements was assessed. Following up on some of the unexpected findings of Study 1, Study 2 sought to evaluate the interactive effects of anger, ingroup strength, and identity on women's appraisals and actions to confront the discrimination. 


\section{Study 1}

It is not an uncommon belief that women are 'no longer at a disadvantage', even though objective indicators reveal that North American women continue to experience inequities in social, occupational, and educational settings (Baker \& Fortin, 2000;

Davison \& Burke, 2000; Everston, 2004; Roth, 2003; Statistics Canada, 2000). In 1997 nearly 25,000 charges of gender discrimination were filed with the Equal Employment Opportunity Commission (U.S. Equal Employment Opportunity Commission, 1997). In the federal government of Canada, a recent survey indicated that $38 \%$ of federal government employees felt discriminated against (Public Service Commission, 2005). Furthermore, within the academic community in Canada, eight female professors filed a complaint with the Canadian Human Rights Commission against Industry Canada's "Canada Research Chair" program where a survey of chair holders conducted by the Canadian Association of University Teachers in 2005 found that only $20 \%$ of Chairs had been awarded to women (Canadian Human Rights Commission, 2000). It may, therefore, not be surprising that numerous studies have found that women are more likely than men to exhibit stress-related symptoms, such as depression, anxiety, and posttraumatic stress disorder (Brown, Recupero \& Stout, 1995; McGrath, Strickland, Keita, \& Russo, 1990; Nolen-Hoksema, 1990; Russo \& Green, 1993). No single variable or theory has fully accounted for this gender difference; however, evidence suggests that gender differences in the life experiences of women may play an important role in the stress levels women experience (McGrath et al, 1990; Nolen-Hoksema, 1990; Russo \& Green, 1993).

Stressors specific to women that may contribute to this difference include rape, battery, physical and psychological abuse in intimate relationships, all of which have been shown 
to contribute significantly to psychological pathology (Arias \& Pape, 1999; Goodman, Koss, \& Russo, 1993; Koss, Koss, \& Woodruff, 1991). In the workplace, women also experience sexism or harassment in a variety of forms including jokes, comments demeaning women as a group, stereotyping, and exclusion from work teams and social networks (Gutek, 2001; Pogrebin \& Poole, 1997; Settles, Cortina, Malley, Stewart, 2006; Robson \& Wallace, 2001). This chronic pattern of everyday discrimination has also been linked to increased physical and psychological distress (e.g, high blood pressure, tension, anxiety, and depression) (Klonoff et al., 2000).

Clearly, however, not all women suffer from stress-related pathology; some of these variations are likely, in part, a reflection of differences in women's objective circumstances (Landrine et al., 1995); however, as noted earlier, cognitive and motivational factors may result in women denying that they have experienced discrimination (Crosby, 1982, 1984; Foster \& Matheson, 1998, 1999; Taylor et al., 1990, 1991), making it difficult to objectively ascertain the extent of discrimination in women's lives, and the factors that might influence the effects of such discrimination on their wellbeing. Thus, to identify such factors, the present investigation employed an experimental paradigm in which women were presented with an event that objectively constituted gender discrimination. The benefit of using a simulation paradigm is the control of confounds and external, superfluous variables (e.g. presence of others, offhand comments when discrimination occurs), ensuring that all participants experience the same event of discrimination. The goal of Study 1 was to examine the extent to which emotions (sadness, anger) and emotion-focused coping strategies, namely emotional regulation 
(suppression, expression, and control), affected women's appraisals of, and responses to, discrimination.

As argued by Gill and Matheson (2006), the effects of women's emotions on their appraisals of discrimination and actions may depend on salient social expectations concerning the appropriateness of expressing or acting on their emotions. For instance, there are gender-based societal pressures and expectations wherein women are encouraged to express sadness and discouraged from expressing anger (Brody, 2000; Brody \& Hall, 1993; Hess, Senechal, Kirouac, Herrera, Philloppot, \& Kleck, 2000; Kelly \& Hutson-Comeaux, 1999). Gill and Matheson (2006) examined the extent to which such societal pressures affected women's perceptions of and responses to discrimination. Women who were angered and for whom expectations regarding the regulation of their emotions were salient (either to suppress or express) were more likely to appraise a situation as constituting discrimination, which in turn predicted lower acceptance and greater endorsement of collective actions to contend with discrimination. In contrast, women who were saddened and for whom expectations regarding the regulation of their emotions were salient, specifically to suppress these feelings, appraised less discrimination. However, women who felt sad and engaged in expression were more inclined to respond to the discriminatory treatment, primarily through the use of normative actions that would be deemed as socially acceptable. Taken together, these results suggest that societal expectations regarding the expression of emotions may exert an influence not only on appraisals of discrimination, but also on contending with the discrimination, depending on the qualitative nature of the emotion (sadness vs. anger) experienced. Thus, in examining the relations between emotions and responses to 
discrimination, it may be important to consider the salient social expectations that group members' coping responses might be shaped by. Consequently, the focus of Study 1 in the present investigation was again on emotion-focused coping because emotions are being induced (sad, anger), and as a result emotional coping efforts may be most relevant to the management of these emotions (Gill \& Matheson, 2006; Stanton et al., 2000).

Although Gill and Matheson (2006) demonstrated a link between anger, perceptions of discrimination, and women's willingness to endorse confrontational actions to contend with the situation, such endorsements were not ubiquitous. Not only do appraisals of the discrimination include whether or not the event constitutes discrimination, but in addition, according to stress and coping perspectives, entail an appraisal of the extent of perceived control over the event. Perceived control can be defined as the 'belief that one can determine one's own internal states and behaviour, influence one's environment, and/or bring about desired outcomes' (Wallston, Wallston, Smith, \& Dobbins, 1987, p. 5). Ruggiero and Taylor (1997) ${ }^{1}$ suggest that by minimizing discrimination, minority group members may maintain a perception of control over personal outcomes in their lives. In effect, minority group members may be hesitant to blame their performance on discrimination because they would be placing control for their outcomes in the hands of others. Indeed, Foster, Amt, and Honkola (2004) found that among women and men who experienced gender discrimination, women endorsed taking less action against discrimination than did men, and argued that because members of groups who are typically advantaged perceive greater self-efficacy and control than members of

${ }^{1}$ Given that this article was withdrawn for falsified data, the present thesis does not cite findings from the study but only cites a suggestion made by Ruggiero regarding the potential association between discrimination and perceived control, which is not based on data from their study. 
disadvantaged groups (e.g. ethnic minorities, women, lower socioeconomic status) (Aruffo, Coverdale, Pavlik \& Vallbona, 1993; Hillman, Wood, \& Sawilowsky, 1992; Lachman \& Weaver, 1998), women may have felt disempowered in contending discriminatory treatment, in comparison to men. Thus, it is possible that perceptions of control and efficacy may be differentially related to group members' perceptions of, and responses to, discrimination, where perceptions of discrimination are associated with diminished appraisals of control and efficacy, hence attenuating the endorsement of actions to contend with the discrimination. Thus, Study 1 examined the extent to which appraisals of control and efficacy mediated the relations between perceived discrimination and actions.

In a similar vein, given that anger is found to be an empowering and activating emotion in recognizing and responding to unjust treatment (Gill \& Matheson, 2006; Mackie et al., 2000; van Zomeren et al., 2004; Yzerbyt et al., 2003), feelings of anger may foster a sense of perceived control over a situation of gender discrimination, whereas feelings of sadness, which are more likely to be associated with feelings of helplessness, are likely to be associated with a lack of perceived control. However, these relations might depend on the strategies women employ to regulate their emotions; for example, Gill and Matheson (2006) found that women who were primed to experience anger and engage in emotional expression were more inclined to endorse collective confrontational actions to address the discriminatory treatment compared to women who experienced anger and engaged in emotional suppression. Potentially, the experience and expression of anger may be related to greater perceived control, which facilitates the endorsement of collective confrontational actions. Thus, Study 1 assessed the extent to which emotions 
(sad, anger) and emotion-focused coping (expression, suppression, control) affected perceived control.

Paradoxically, although appraisals of control might be diminished when discrimination is perceived, they might also be related to perceptions of the efficacy of actions to contend with a discrimination event. In other words, a higher sense of control over the experience of discrimination may facilitate perceptions that one has the capacity to contend with negative treatment, hence facilitating the endorsement of such actions (van Zomeren et al., 2004). Conversely, a perceived loss of control over the event or its resolution may foster a sense of helplessness and reduced perception of efficacy in contending with the discrimination, resulting in greater acceptance of the situation. Thus, it is argued that perceptions of efficacy might mediate the relation between women's appraisals of control over the discrimination and their subsequent action endorsements. In sum, in Study 1, the effects of women's emotions and expectations regarding the regulation of their emotions in response to a situation of discrimination were examined in terms of their effects on women's appraisals of discrimination, including whether such discrimination has occurred, and perceived control. In addition, it was of interest to examine whether these appraisals were associated with women's perceptions of efficacy and desire to engage in actions to contend with the situation, depending on the emotions they were primed to experience (Figure 3). 


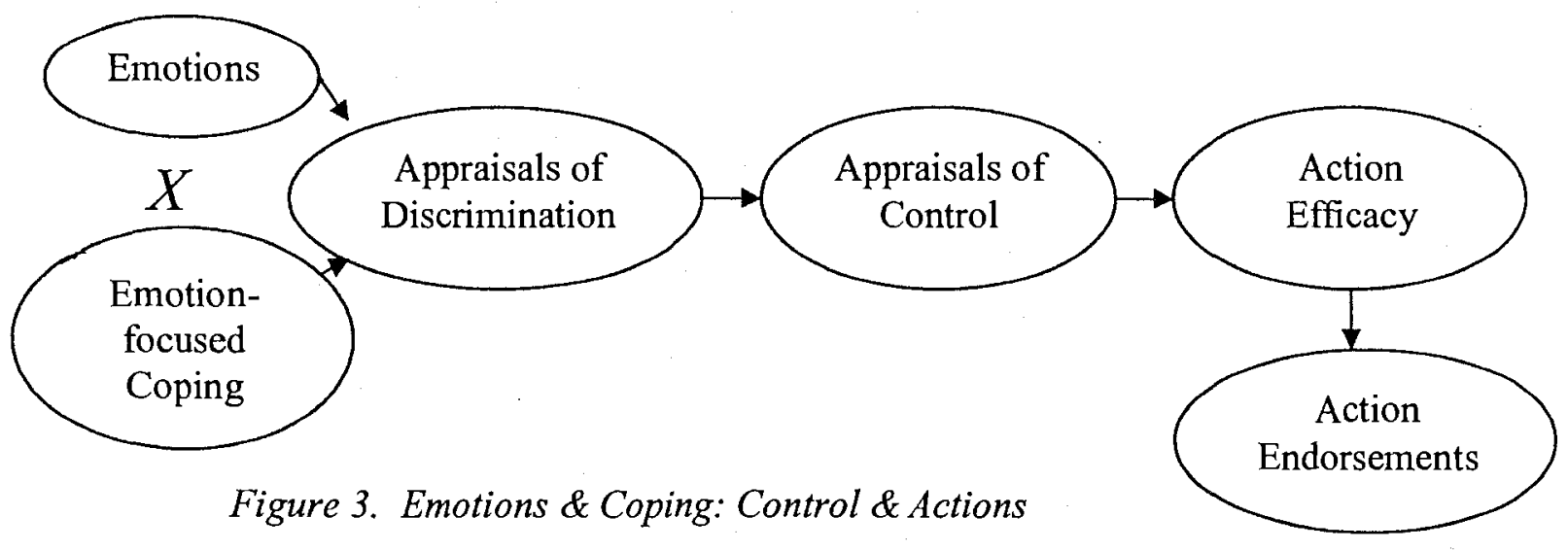

It was hypothesized that:

1. Women primed to experience anger would be more likely to recognize their experience as constituting discrimination than women primed to experience sadness. It was also expected that anger, compared to sadness, would result in appraisals of greater control, greater endorsements of collective actions to contend with discrimination, and perceptions that such actions would be more effective.

2. Women primed to experience anger and engage in emotional expression (or the control) would perceived greater discrimination, control, collective actions as being more effective, and therefore endorse these actions compared to women who experience anger but engage in suppression.

3. Women who experience sadness and engage in expression would perceive collective actions as being more effective and thus endorse these actions compared to women who experience sadness but engage in suppression (or the control). Perceptions of discrimination and control were not expected to vary according to sadness or the coping manipulation.

4. Perceived control and efficacy of actions to respond to discrimination were expected to mediate the relations between perceived discrimination and actions endorsed. 
5. Perceived efficacy of actions to respond to discrimination was expected to mediate the relations between perceived control and actions endorsed. 


\section{Method}

\section{Participants}

Women were recruited $(N=86 ; M$ age $=21.0$ years, $S D=4.2)$ to take part in a study examining storytelling abilities, for which they received experimental credit and eligibility to participate in a $\$ 100$ lottery. The majority of women were Caucasian $(n=68$, $81.0 \%)$, with the remainder of the sample comprising women of African $(n=4,4.8 \%)$, Asian or Middle-Eastern $(n=10,11.9 \%)$, or Native descent $(n=2,2.4 \%)$.

Procedure

Following the paradigm of Gill and Matheson (2006), upon arrival, participants were informed that the researchers were examining either creative or analytic abilities through storytelling (see verbal instructions Appendix A). The purpose of this cover story was to minimize possible demand characteristics, and to provide a meaningful context in which to introduce the manipulations of interest. The purpose of telling participants that the researchers were examining either creative or analytic abilities was to enhance the generalizability of the results across tasks. Several participants were run at once, but in separate adjoining rooms to ensure independence of responses (particularly in the expressive conditions). Participants were given a brief overview of the study, and completed an informed consent form.

After completing the informed consent form (Appendix B), participants were then asked to complete a story-writing task. The real purpose of this task was twofold: 1) to prime a particular emotion, and 2) to induce a situation of discrimination. A female experimenter told participants that if their stories passed a predetermined score they would be included in a high status group, and if their stories did not meet this criterion 
they would be categorized in a low status group. Women were told that those who qualified for the high status group would be eligible to participate in a $\$ 100$ lottery, while those in the low status group lottery would participate in a $\$ 10$ lottery. In reality, all participants participated in the $\$ 100$ lottery. Furthermore, they were informed that if they were placed in the low status group they would only receive half of an experimental credit, as they were not perceived as competent in possessing creative/analytic abilities, whereas as those in the high status group will receive the full credit (in actuality, all participants received full credit). The experimenter further explained to participants that once assigned to their group, in the remainder of the study their tasks were differentially interesting or mundane, and reflected differential respect for skill levels. The role of the high status group was to improve the stories created by the less creative/analytical participants; those in the low status group were required to complete a second writing task as well as a number of tedious tasks (e.g. alphabetizing, sentence completion) in order for the experimenters to assess the relation between lack of creativity/analytical ability and other skills. The manipulation of these incentives and task expectations was consistent with past research (Foster, Matheson, \& Poole, et al., 1994; Gill \& Matheson, 2006; Lalonde \& Silverman, 1994; Wright, Taylor, \& Moghaddam, 1990), and the intent was to provide sufficient incentive to make the two groups differentially desirable to belong to.

The writing task consisted of reading and imagining events of a story as though they were happening to them (Appendix C). While the task was presented as the basis for determining their success in being assigned to the high status group or not, it also served to prime emotion. Participants read a story describing an achievement failure 
situation in which a student received a poor grade in an important course and visits the professor, who has agreed to take a second look at the paper. The professor discusses the many and varied problems with the paper, and concludes that he will not change the grade (Robins, 1988). Participants were asked to form a mental picture of the events and experience how they would feel if they were the student in the story. After reading the story they were asked to write about the same event with themselves as the protagonist using a list of twelve target words. Participant were randomly assigned to one of two wordlist conditions (Appendix C); (1) Five of the words in the list varied in order to prime sadness (sad, hopeless, discouraged, helpless, despair), or (2) five of the words reflected anger (angry, hostile, infuriated, irritated, resentful). The remaining words were constant across the two conditions (grade point average, essay, course, future, office, university, classroom).

Women were then exposed to the discriminatory event. The female experimenter collected the stories, and informed participants that she had to give the papers to the alleged male student judges from the engineering department who were participating in this experiment to learn more about psychological research methods. The judges were male to reinforce the manipulation of gender-based discrimination. Before the experimenter left to deliver the stories, all participants were asked to complete a secondary task that was included to ensure the reality of the situation regarding time needed to grade the papers and to maintain emotional state (Appendix D). Participants in the sad condition were asked to write about something that occurred in their life, or to someone they know, that made them feel very sad or depressed. Those in the anger condition were given the same instructions but told to remember something that made 
them feel angry. Upon completion of this task, an emotional state manipulation check measure was administered (Appendix E).

A male confederate then entered the room and informed the participant that she had been assigned to the low status group. Specifically, he said, 'These guys never pass any of the women', after which he left the room. He then marks a tally under a 'fail' column on a blackboard that shows the number of participants who had failed or passed the task so far. The tally board provides a breakdown by sex, showing that all of the women had failed the task so far, thereby emphasizing that only men were being passed into the high status group. The female experimenter then returned and reminded the participant of what the low status group entailed. Women in each of the emotion prime conditions were randomly assigned to one of three emotional regulation instructions given at this time. Participants in the emotional suppression condition were asked to inhibit their behavior for the remainder of the study. Specifically they were told: "If you have any feelings during the remainder of the study, do not let those feelings show. Try to act in such a way that people watching you would not know you were feeling anything. This is important as it assures that you maintain your composure and act in a professional manner regardless of what group you are placed in". Participants in the emotional expression condition were encouraged to freely express any thoughts, feelings, or questions that may arise during the course of the experiment. For example, if they were displeased or pleased with a particular aspect of the experiment, then they should feel free to openly express and share their views. They were told, "This is important as it assures that you show a commitment to your professional status regardless of what group you are placed in." Those in the control condition were not given any instructions. 
All participants then completed a final questionnaire assessing perceptions of personal and group discrimination, perceived control, perceived efficacy of actions to respond to their treatment in the study, and action endorsements (Appendix F). Participants then completed a suspicion questionnaire ${ }^{2}$ to assess the extent to which they believed the manipulations (Appendix G). Participants were then given an oral debriefing (Appendix H). To alleviate feelings of sadness and anger, a second emotion induction procedure was included that was intended to provide humor.

Participants were then asked to read a monolugue by comedian Dennis Miller and respond to how entertaining/amusing they found it to be (Appendix I). Given that participants were deceived about the purposes of the study at the beginning, once they were informed of the true purpose of the study following debriefing, they completed a second informed consent delineating the true intent of the experiment that allowed the use of their data (Appendix J).

\section{Measures}

Emotion manipulation check. Women rated how they were currently feeling along 19 mood adjectives (taken from Diener \& Emmons, 1984) on 7-point scales, ranging from not at all (1) to extremely (7). A principal components analysis with a varimax rotation was performed and four factors were retained on the basis of having eigenvalues greater than 1 , which accounted for $62.5 \%$ of the variance.

2 Responses to the suspicion questionnaire revealed that, aside from $6 / 7$ participants, the majority of participants believed the study to be assessing creativity. 
Based on factor loadings greater than .50 , the first factor appeared to be a 'sad mood' factor, including the items hopelessness, sad, unhappy, depressed, helpless, and desolate (Cronbach's $\alpha=.85$ ). The second factor was labeled 'positive affect', containing the items pleased, relaxed, indifferent, calm, and happy (Cronbach's $\alpha=.80$ ). The third factor reflected 'anger' including the items angry, hostile, infuriated, and frustrated (Cronbach's $\alpha=.80)$.

The fourth factor was labeled the 'anxiety containing three items worried, anxious, and confused (Cronbach's $\alpha=.69$ ). Self-reported anger was positively correlated to sadness $(r=.32, p<.01)$, and anxiety $(r=.36, p<.01)$, and negatively correlated with positive feelings $(r=-.28, p<.05)$. Levels of sadness reported were positively correlated levels of anxiety $(r=.64 . p<.01)$ and negatively correlated with positive feelings $(r=-.34$, $p<.01$ ). Positive feelings was also negatively correlated with levels of anxiety reported $(r=-.34, p<.01)$. Even though the anxiety factor was highly positively correlated with levels of sadness, these two factors were not combined as the focus was on effects of sadness on perceptions and responses to discrimination.

Perceived discrimination. The extent to which women perceived personal and group discrimination was based on two items from Taylor et al. (1991), including "To what extent were you personally discriminated against because you are a women in the context of this experiment", and "To what extent do you feel that women as a group were discriminated against in the context of this experiment". These items were embedded among six filler items (Taylor et al., 1991). Women rated the items along 8-point rating scales, ranging from not at all (0) to very much (7). These two dimensions of perceived discrimination were highly correlated $(r=.61, p<.01)$. 
Perceived control. Two domains of perceived control were assessed, including performance control, that is, the extent to which participants felt competent about their performance (e.g., How much do you think you would improve on this creative task with practice?), and social control, which reflected the extent to which participants perceived control over social aspects of the experiment (e.g., Would it be better to meet the primary experimenter before he reads your story?) (Ruggiero et al., 1997). Each dimension consisted of four items rated on 8-point scales ranging from not at all $(0)$ to very much or very likely (7). The item-total reliabilities of these subscales were low (performance Cronbach's $\alpha=.52$; social Cronbach's $\alpha=.63$ ). Thus, a more reliable total score for perceived control was calculated, so that higher scores represented higher perceived control (Cronbach's $\alpha=.66$ ).

Action endorsements and perceived efficacy. Women indicated the extent to which they would be willing to participate in each of five actions if they had the opportunity to respond to their treatment (Wright et al., 1990). These actions included accept the situation, requests for individual or collective retests (normative actions), or confronting the male judges to demand an explanation, either as an individual or collectively (non-normative actions). Endorsements were indicated on a scale ranging from not at all likely to participate (0) to extremely likely to participate (7). As indices of efficacy, women also rated the extent to which the endorsed response would be difficult to request, would be effective for changing their personal status, and would be effective for improving selection procedures for other women, on scales ranging from not at all (0) to extremely (7).

In addition to this broad action measure, women also indicated the extent to which 
they would be willing to participate in eight more specific actions if they had the opportunity to respond to the discriminatory treatment. These actions were designed to be more ecologically valid in terms of reflecting the concrete strategies university women might adopt to deal with poor treatment in an experimental study.. They included dropping out of the study for no credit or lottery; staying in study for .5 credit and lottery; doing nothing even if another individual initiates a response; doing nothing however if another individual initiates a response would participate; taking a retest in a second attempt to become a member of the high status group; asking volunteers to sign a petition against the study being continued; going to the chair to make a complaint about the procedures of this study; and, soliciting the support of other low status group members in the form of a petition that I will organize. Endorsements of each of these actions were indicated on a scale ranging from not at all likely to participate $(0)$ to extremely likely to participate (7). To assess patterns of response, a principal components analysis with a varimax rotation was performed on these eight items. Two factors were retained on the basis of having eigenvalues greater than 1 , which accounted for $58.8 \%$ of the variance. Based on factor loadings greater than .50 , the first factor appeared to be a 'withdrawal' factor, comprising four items, including dropping out of study, doing nothing even if another individual initiates a response, and staying in for .5 credit or lottery, or doing nothing unless another individual initiates a response (negative loading) (Cronbach's $\alpha=.69$ ). The second factor was labeled the 'action' factor containing the remaining four items (Cronbach's $\alpha=.77$ ). 
Results

An assessment of the assumptions underlying the use of parametric statistics, including tests of normality based on Kolmogorov-Smirnov, kurtosis and skewness statistics, and homogeneity of variance, indicated that these assumptions were not violated. To minimize Type I errors, Bonferroni adjustment was applied to all multiple comparison analyses to maintain a family-wise error rate of $\alpha=.05$.

Manipulation Check for Perceived Discrimination

A one sample t-test was performed on women's perceptions of discrimination. This test was significant, $t(85)=-3.42, p<.001$, indicating that women minimized discrimination in the study $(M=3.25, S D=2.03)$.

\section{Manipulation Check for Emotion Primed}

To evaluate the extent to which the emotional priming manipulation was successful, a 4 (Self-reported emotion dimensions: sad, positive, anger, anxiety; within subjects) by 2 (Emotion primed: sad, angry; between subjects) mixed measures analysis of variance (ANOVA) was conducted. A significant main effect was observed for the self-reported emotional dimensions $F(3,252)=119.07, p<.001, \eta^{2}=.590$. Follow-up comparisons indicated that higher levels of negative emotions (sad, angry, anxious) were reported compared to positive emotion states $(p s<.05)$ (Table 1). In addition, irrespective of emotion prime, women rated their levels of anxiety higher than they rated feeling either sadness or anger $(p s<.05)$, and there was no difference in their ratings of these latter emotions. Although the interaction was not significant, $F(3,252)=1.65, p=.18$, based on a priori hypotheses, the relative levels of sadness, anger, and anxiety experienced for each of the emotion conditions were examined. The differences in self- 
reported levels of sadness and anger in the two emotion priming conditions were not significant, although women primed to feel sad reported marginally greater anxiety than those primed to feel angry, $F(1,84)=2.92, p=.09$. Thus, in contrast to Gill and Matheson (2006), the emotion priming manipulation did not appear to directly affect selfreported sadness and anger. Indeed, the differential, but nonetheless high levels of anxiety may have superseded the effects of sadness and anger in the respective conditions. Clearly this will have implications for interpreting the effects of this manipulation in subsequent analyses.

\section{TABLE 1}

Means and Standard Deviations of Self-reported Emotions following the Sad and Angry Emotion Prime Manipulations

\section{$\underline{\text { Sad Emotion Prime }}$}

Angry Emotion Prime

\begin{tabular}{lcccc} 
Self-reported Emotion & Mean & $(S D)$ & Mean & $(S D)$ \\
Sad & $4.42^{\mathrm{a}}$ & $(1.30)$ & $4.08^{\mathrm{a}}$ & $(1.30)$ \\
Angry & $4.17^{\mathrm{a}}$ & $(1.27)$ & $4.28^{\mathrm{a}}$ & $(1.34)$ \\
Positive & $1.72^{\mathrm{b}}$ & $(0.82)$ & $1.86^{\mathrm{b}}$ & $(0.90)$ \\
Anxiety & $4.94^{\mathrm{c}}$ & $(1.13)$ & $4.47^{\mathrm{c}}$ & $(1.38)$ \\
\hline
\end{tabular}

Note: the first superscripts denote significant differences at $p<.05$.

Appraisals

Perceptions of discrimination. A 2 (Level of discrimination: personal, group; within subjects) $\times 2$ (Emotion primed: sad, anger) $\times 3$ (Emotional regulation: suppression, expression, control) mixed model ANOVA was conducted on ratings of discrimination. 
The main effect for level of discrimination was significant, $F(1,80)=41.41, p<.001$, $\eta^{2}=.341$. Follow-up pairwise comparisons indicated that in contrast to previous research, women perceived higher personal $(M=3.95, S D=2.34)$ than group discrimination within the context of the experiment $(M=2.53, S D=2.18)$. In effect, women perceived the failure feedback due to the gender to be targeted at them personally.

A significant interaction was observed between emotion primed and emotional regulation, $F(2,80)=3.25, p<.05, \eta^{2}=.075$. Follow-up simple effects analyses were conducted to assess the effects of emotional regulation differed for women primed to feel angry or sad, respectively. Among women who were angered, emotional regulation expectations influenced perceptions, $F(2,42)=3.06, p<.05, \eta^{2}=.131$, in that discrimination was more likely to be perceived when women were instructed to monitor their emotional reactions, irrespective of whether the goal was to suppress or express their emotions (which did not differ), in comparison to the control condition (Table 2). No significant differences as a function of expectations were observed among women in the sad prime condition, $F<1$.

TABLE 2

Means and Standard Deviation) of Personal and Group Discrimination for Emotion Primed and Emotional Regulation

Regulation

\begin{tabular}{ccc}
\multicolumn{3}{c}{ Regulation } \\
Express & Suppress & Control \\
\hline Mean (SD) & Mean (SD) & Mean (SD)
\end{tabular}

Personal Discrimination

Sad prime

$3.62 \quad(2.10)$

4.07 

Angry prime
$3.92(2.55)$
$5.00 \quad(1.79)$
$3.13(2.67)$

Group Discrimination: Study

\begin{tabular}{|c|c|c|c|c|c|}
\hline Sad prime & 2.50 & (2.07) & 1.84 & (2.11) & 3.29 \\
\hline Angry prime & 2.86 & (2.38) & 3.13 & $(1.85)$ & 1.53 \\
\hline
\end{tabular}

Total Perceived Discrimination

\begin{tabular}{|c|c|c|c|c|c|}
\hline Sad prime & 3.21 & $(1.98)$ & 2.73 & (1.73) & 3.67 \\
\hline Angry Prime & 3.39 & (2.17) & 4.06 & (1.61) & 2.33 \\
\hline
\end{tabular}

Perceived control. To examine the extent to which women felt they maintained control over aspects of the experiment, a 2 (Emotion primed) $\times 3$ (Emotional regulation) between subjects ANOVA was conducted. No significant main or interaction effects were observed. On average, women reported relatively low levels of control $(M=3.18$, $S D=1.16)$.

Behavioral Responses

Perceived effectiveness of actions. Three mixed model ANOVAs were conducted for each set of efficacy ratings (e.g., difficulty in endorsing actions, extent to which the action would change their personal status, and whether the action would make the procedures fairer for others) using a 4 (Action: individual retest, individual confrontation, collective retest, collective confrontation; within subjects) $\mathrm{x} 2$ (Emotion primed) x 3 (Emotional regulation).

A main effect of action was observed on ratings of the difficulty in implementing the actions, $F(3,240)=9.32, p<.05, \eta^{2}=.102$. Follow up comparisons (indicated that 
women perceived that the most difficult actions to carry out were asking for either individual $(M=3.80, S D=1.94)$ or collective retests $(M=4.35, S D=2.42)$; these normative actions were both rated as more difficult than individual confrontation $(M=3.50$, $S D=2.31$ ). There were no further differences. Significant effects were not observed for emotion primed or emotional regulation (Table 3).

\section{TABLE 3}

Means and standard deviations of perceived efficacy of action endorsements in terms of difficulty in endorsing action, change status, and procedural fairness.

Difficulty

Individual retest

Individual confrontation

Collective retest

Collective confrontation

Change of status

Individual retest

Individual confrontation

Collective retest

Collective confrontation

Procedural fairness

Individual retest

Individual confrontation

Collective retest

Collective confrontation
Mean

3.92

3.17

4.32

3.46

2.31

2.32

1.98

2.61

2.19

2.68

2.63

3.53

2.29

1.71

1.80

1.89

1.84
2.71

3.09

3.29
2.43

2.68

2.48
1.83

1.60

$1.87 \quad 1.85$

$2.47 \quad 2.13$
$S D$

2.00 
A main effect of action was also found on perceptions of whether the various actions would change women's personal status, $F(3,240)=3.79, p<.05, \eta^{2}=.054$. Follow up comparisons indicated that women perceived the greatest change in personal status would be accomplished by asking for a collective retest $(M=2.23, S D=2.26)$ and collective confrontation $(M=2.26 . S D=2.11)$, in comparison to individual confrontation $(M=2.17, S D=2.08)$. Significant differences were not observed for emotion induced and emotional expectations. Finally, no significant effects were found for perceived action efficacy of making procedures fairer for others.

Action endorsements. A 5 (Action: accept, individual retest, individual confrontation, collective retest, collective confrontation; within subjects) x 2 (Emotion primed) $\times 3$ (Emotional regulation) mixed model ANOVA was performed on endorsement ratings. There was a main effect for action, $F(4,320)=9.04, p<.001$, $\eta^{2}=.103$. Consistent with past research, follow-up comparisons indicated that, overall, women were more likely to accept their status compared to any of the other action options (Table 4). It was also found that women were more likely to endorse confronting the experimenter individually $(M=2.99, S D=2.41)$ or collectively $(M=2.76, S D=2.62)$ than to endorse an individual retest $(M=2.02, S D=2.08)$.

However, the effect of action was qualified by a significant interaction with the emotions primed, $F(4,320)=2.93, p<.001, \eta^{2}=.035$. Simple effects analyses indicated that among women primed to feel sad, there were no significant differences in their ratings of the various actions, $F(4,176)=1.62$, ns (Table 3). However, women primed to feel angry differentially rated the actions, $F(4,176)=11.37, p<.001, \eta^{2}=.215$, such that, 
contrary to expectations, women induced to experience anger were more likely to accept their situation than to endorse any of the remaining actions. There were no further significant effects.

TABLE 4

Means and standard deviations of action endorsements and emotion prime

Sad Emotion Prime Angry Emotion Prime

$\begin{array}{lcllll}\text { Actions } & \text { Mean } & (S D) & \text { Mean } & (S D) \\ \text { Accept } & 3.51 & (2.12) & 4.22^{\mathrm{a}} & (1.95) \\ \text { Individual retest } & 2.48 & (2.33) & 1.60^{\mathrm{b}} & (1.75) \\ \text { Individual confrontation } & 3.34 & (2.43) & 2.67^{\mathrm{b}} & (2.36) \\ \text { Collective retest } & 2.92 & (2.66) & 2.04^{\mathrm{b}} & (2.26) \\ \text { Collective confrontation } & 3.41 & (2.72) & 2.16^{\mathrm{b}} & (2.40)\end{array}$

Note: different superscripts denote significant differences at $p<.05$.

Specific action endorsement. A 2 (Specific action: action factor, withdrawal factor; within subjects) $\times 2$ (Emotion primed) $\times 3$ (Emotional regulation) mixed model ANOVA was performed on participants' specific action endorsements. Only a main effect was observed for specific action $F(1,80)=7.23, p<.01, \eta^{2}=.084$, in that women endorsed greater withdrawal $(M=1.87, S D=1.46)$ than action in the study $(M=1.27$, $S D=1.47)$. 
Correlations among Self-reported Emotions, Perceptions, Perceived Control and Action

Given that the emotion priming manipulation was weak at best, to further evaluate the association among emotions, appraisals, and action variables, Pearson zero-order correlations among these variables were examined. As seen in Table 5 (see Appendix $\mathrm{K}$ for complete correlations table), self-reported sadness and anger were not related to perceptions of discrimination (collapsed across the two indices), perceptions of control, or endorsing actions to contend the discrimination. However, higher levels of anger (as well as sadness) were associated with greater perceptions of the difficulty in carrying out confrontational responses. Interestingly, when women perceived the situation as entailing discrimination, they were also more likely to rate the actions as more difficult; in contrast, when they perceived control, they were less likely to appraise such actions as difficult. Thus, on the whole, in the present study, feelings of anger did not appear to motivate action endorsements, but rather, perceived discrimination and emotional reactions were linked to perceiving actions to contend with the situation as especially difficult to carry out. None of the variables were related to women's perceptions of whether or not the actions would change their own personal status, or whether they would make the procedures fairer for others, and hence these correlations were not included. 


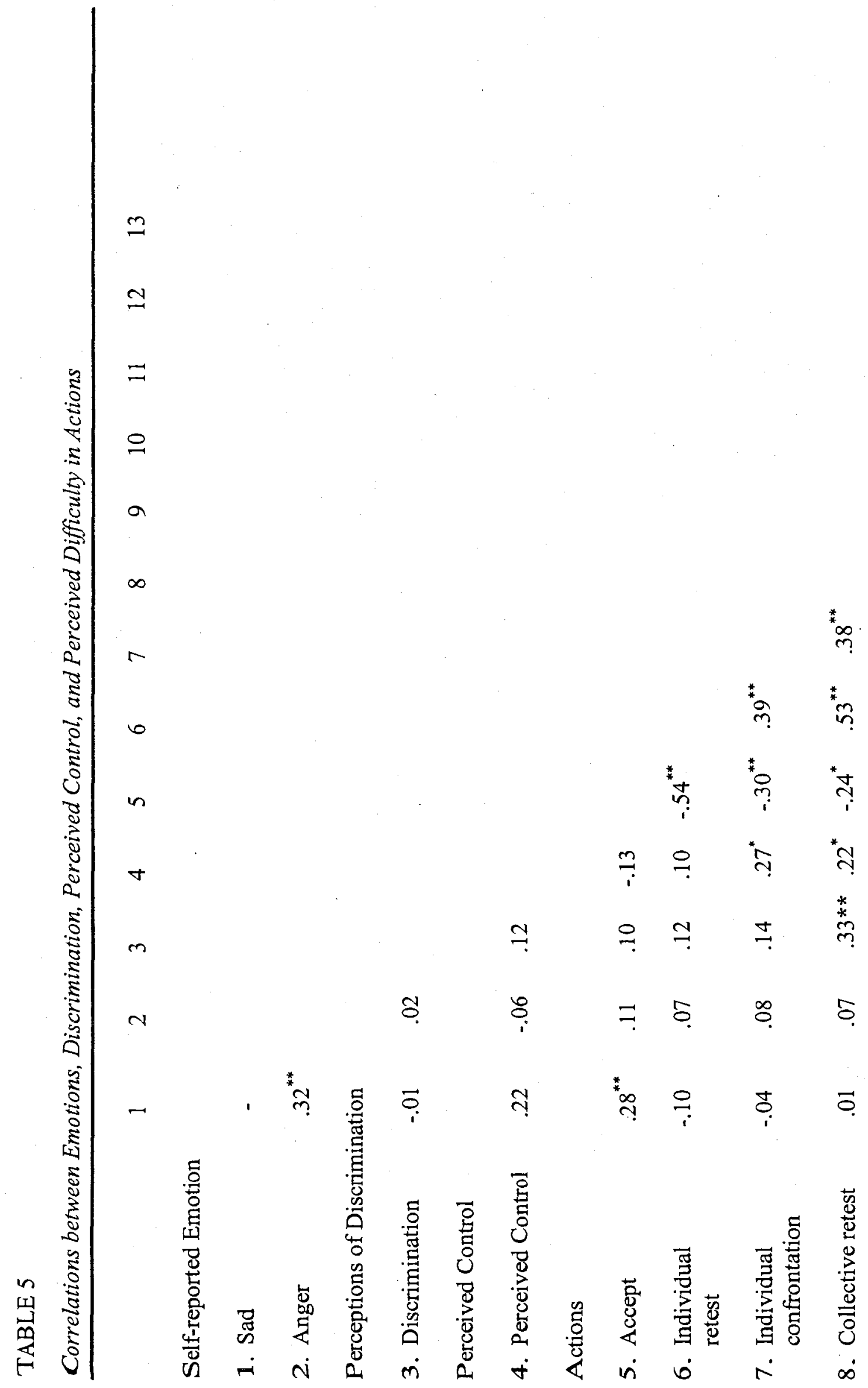




$$
\begin{aligned}
& \text { *8 } \\
& \text { * * ? }
\end{aligned}
$$

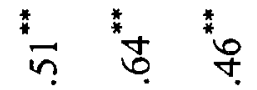

$$
\begin{aligned}
& \because \text { กับ } \\
& \text { *n } \\
& \stackrel{*}{*} \text { กิ } \\
& \text { in } \\
& \text { ㅎ. 의 } \\
& \text { * } \\
& \text { ㅎ. 으 후 } \\
& \stackrel{*}{7} \\
& \because \%=0
\end{aligned}
$$

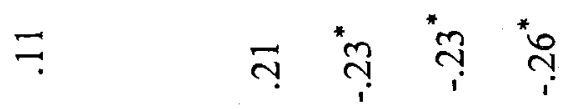

$$
\begin{aligned}
& \text { 華 }
\end{aligned}
$$

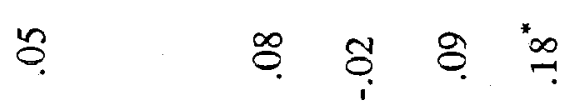

$$
\begin{aligned}
& \text { ㅎ. 훌 }
\end{aligned}
$$

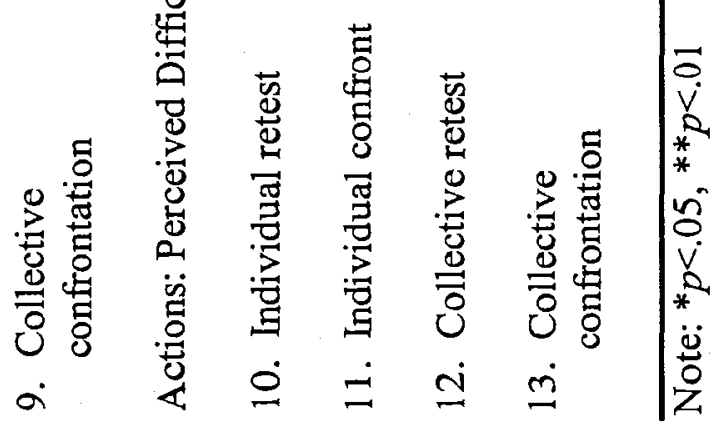




\section{Mediated Analyses}

It was hypothesized that women's perceptions of control and efficacy would mediate the relations between perceived discrimination and action endorsements, and that perceptions of efficacy, in turn, would mediate the relations between control appraisals and action endorsements. In order to assess this possibility, Preacher and Hayes (2004) bootstrapping approach to testing simple and multiple mediator models was employed. ${ }^{3}$ In order to assess the mediating role of perceptions of control and efficacy in the relation between perceived discrimination and actions endorsed several requirements for this model had to be met.

1) Perceived discrimination (predictor) must be significantly related to actions endorsed (outcomes). As seen in Table 5, perceived discrimination was significantly related to the extent to which women endorsed collective retest $(r=.33, p<.01)$, and collective confrontation $(r=.26, p<.05)$. Thus, only the mediating role of perceived control and efficacy with regard to these actions was examined further.

2) Perceived discrimination (predictor) would be related to perceived control (mediators) and perceived efficacy of the relevant actions (mediator). Perceived discrimination (predictor) was not related to perceived control (mediator) $(r=.12, n s)$, thus appraisals of control could not be a mediator of the relation between perceived discrimination and action endorsements.

${ }^{3}$ Preacher \& Hayes (2004) formal test of the indirect effect of X on Y using bootstrapping, is a more powerful method for assessing simple and multiple mediators compared to other parametric techniques (Preacher \& Hayes, 2004). The bootstrap method emphasizes "the direction and size of indirect effects, as they are most directly relevant to how much of the total effect is mediated and by what variable" (Hayes \& Preacher, 2003, p.16). Refer to Hayes and Preacher (2003) for a review of the advantages of the bootstrap method over the Sobel's test for multiple mediator models. 
Perceived discrimination was not correlated with efficacy perceptions in terms of the difficulty in implementing a collective retest $(r=.15, n s)$, perceptions that a collective retest would change their personal status $(r=-.02, n s)$, or that this action would make the procedures fairer for all women $(r=-.06, n s)$. Thus, these mediated paths were not viable. However, perceived discrimination was associated with the perceived difficulty of carrying out a collective confrontation $(r=32, p<.05)$, but not with perceptions that it would change one's personal status $(r=.15, n s)$, or achieving procedural fairness $(r=.07$, $n s)$. Thus, perceived discrimination was related to one aspect of perceptions of efficacy, namely the perceived difficulty of collective confrontation actions, and hence these perceptions might mediate the likelihood of women endorsing such an action.

3) Perceived efficacy of the actions (mediators) must be related to action endorsements (outcome variables). Perceptions of difficulty of carrying out a collective confrontation was not correlated with its endorsement $(r=.07, n s)$.

Thus, it appears that, on the basis of these analyses, although perceived discrimination was related to endorsing collective actions, this relation was not mediated by women's appraisals of control or efficacy. Nonetheless, control appraisals might serve an independent pathway influencing action endorsements, and hence the mediating role of efficacy perceptions in the relations between appraisals of control and actions were examined.

1) Perceived control (predictor) must be significantly related to actions endorsed (outcomes). As seen in Table 5, perceived control was related to the extent to which women endorsed individual confrontation (demanded an explanation for her own outcomes) $(r=.27, p<.05)$ or collective retest (ask that all women be given an opportunity 
to be retested) $(r=.22 . p<.05)$. Thus, only the mediating role of perceived efficacy with regard to these actions was examined.

2) Perceived control (predictor) would be related to perceived efficacy of the relevant actions (mediators). Indeed, perceived control was correlated with the perceived difficulty of taking individual confrontation actions $(r=-.23, p<.05)$, perceptions that such an action would change their personal status $(r=.22, p<.05)$, and that this action would make the procedures fairer for all women $(r=.23, p<.05)$. Similarly, perceived control was associated with the perceived difficulty of asking for a collective retest $(r=-.23$, $p<.05$ ), and with perceptions that such an action would make the procedures fairer for all women $(r=.24, p<.05)$, although control was not linked to perceiving that this action would change their own personal status $(r=14, n s)$. Thus, with the exception of this latter aspect of efficacy, perceived control was related to the indices assessing perceived efficacy of individual confrontation and collective retest actions.

3) Perceived efficacy of the actions (mediators) must be related to action endorsements (outcome variables). The perceived difficulty in taking individual confrontational actions was not related to the endorsement of this action endorsement $(r=.05, n s)$, but perceptions that such action would change their personal status $(r=.22, p<.05)$ and make the procedures fairer $(r=.45, p<.01)$ were both related to endorsing this action. The perceived difficulty in taking collective normative actions was not related to its action endorsement $(r=.06, n s)$, although perceptions that such action would make the procedures fairer $(r=.45, p<.01)$ was positively related to endorsing this action. 
Given this pattern of relations, it is evident that the relations between perceived control and the endorsement of individual confrontational and collective retest actions might be mediated by specific aspects of perceived efficacy. To assess these mediated models, two mediation analyses were conducted: a simple mediation model assessing collective normative actions as making procedures fairer as the mediator with this collective action as the outcome, and a multiple mediation model assessing whether perceptions of individual confrontation action as improving personal status and making procedures fairer as the mediators of the relation between control and endorsing this action. A simple mediation analysis (Preacher \& Hayes, 2004) assessing whether the relation between perceived control and the collective retest action was mediated mediation was not supported $\left(\mathrm{BC}_{\mathrm{ci}}=-.02\right.$ to .11$)$.

As shown in Table 6, a multiple mediation analyses (Preacher \& Hayes, 2004) assessing whether the relation between perceived control and endorsement of the individual confrontation action was mediated by whether this action was perceived as effective for changing women's personal status or the procedures fairer indicated that taken as a set, these mediators did not mediate the effect of perceived control on the individual confrontation action. Furthermore, when the specific indirect effects are examined, neither mediator significantly mediated the association between perceived control and individual confrontation. 
TABLE 6

Mediation of the effect of perceived control on individual confrontation through

perceptions of individual confrontation improving personal status and making

procedures fairer.

\begin{tabular}{|c|c|c|c|c|c|c|c|c|}
\hline & \multicolumn{4}{|c|}{ Product of Coefficients } & \multicolumn{4}{|c|}{ Bootstrapping } \\
\hline & \multirow[t]{2}{*}{ Point Estimate } & \multirow[t]{2}{*}{$S E$} & \multirow[t]{2}{*}{$\mathrm{Z}$} & \multirow[t]{2}{*}{$p$} & \multicolumn{2}{|c|}{ Percentile $95 \% \mathrm{Cl}$} & \multicolumn{2}{|c|}{$\mathrm{BC} 95 \% \mathrm{CI}$} \\
\hline & & & & & Lower & Upper & Lower & Upper \\
\hline \multicolumn{9}{|l|}{ Indirect Effects } \\
\hline Improve status & .02 & .02 & 1.16 & .24 & -.01 & .17 & -.01 & .08 \\
\hline Make proc fair & .01 & .03 & .24 & .81 & -.05 & .09 & -.05 & .09 \\
\hline Total & .03 & .03 & .87 & .39 & -.03 & .12 & -.04 & .12 \\
\hline
\end{tabular}

Note: $\mathrm{BC}=$ bias corrected; 1,000 bootstrap samples; Absence of zero in confidence interval suggests a significant indirect mediating effect. 


\section{Discussion}

The primary goal of Study 1 was to assess the effects of women's emotions and the regulation of these emotions on appraisals of a discriminatory event and their responses to it, with a particular focus on appraisals of control and efficacy. However, several factors complicate interpretations of the results of the present study. Firstly, despite using the same manipulation as that employed by Gill and Matheson (2006), the priming manipulation of anger versus sadness was not especially effective. This inconsistency may be due to the time limit placed on writing the story that was used to prime emotion, a limit that was not imposed by Gill and Matheson (2006). This time limit may have increased women's anxiety, while diminishing the differential impact of the sad versus angry word primes. In any event, the minimal significant effects associated with this manipulation may be because women were not sufficiently angry or sad to respond differently.

Secondly, contrary to previous research (Gill \& Matheson, 2006; Taylor, et al., 1991; Taylor, et al., 1991; Taylor, et al., 1990), in the present study women perceived greater personal discrimination than group discrimination against other women in the study. Certainly it is more common for women to recognize that their group is discriminated against, even if they do not typically see this happening to themselves personally (Crosby, 1982, 1984; Foster \& Matheson, 1998, 1999; Taylor et al., 1990, Taylor et al., 1991). The higher level of personal discrimination reported may be attributed to the use of a strong and blatant manipulation of gender-based discrimination that also provided the aggregate information (i.e., indicated the number of women relative to men who failed on a tally board) that is typically absent in real world instances of discrimination, as well as the male confederate directly conveying gender 
discrimination.

Despite these caveats, women's perceptions of discrimination were influenced by the emotion primed and the expectations conveyed regarding the regulation of their emotions through expression or suppression. Notably, while the emotion prime was weak, significant effects were still observed. Potentially, given anxiety superseded anger, it may have contributed to the significant effects. Specifically, women primed to experience anger (but not sadness) and for whom expectations to regulate their emotions were made salient (through expression or suppression), perceived greater discrimination than did angered women who were not provided with such emotional regulation instructions. Although it was expected that women who were induced to express anger would perceive greater discrimination, this finding in relation to the suppression of anger was surprising. Unfortunately, one limitation of the present investigation concerned the lack of a manipulation check for these expectations. Although women verbally reported that they understood the instructions prior to proceeding with the remainder of the experimental protocol, the common effect of the expression versus suppression of emotions raises the possibility that these instructions may have had multiple effects. For example, both sets of instructions (e.g., expression, suppression) may have served to enhance the extent to which women's emotions were salient to them, and so both may have facilitated a more emotion-focused approach. Although these strategies appear to be conceptually bipolar, in fact, the use of emotional expression and containment as coping strategies are often positively conflated (Matheson \& Anisman, 2003). Hence, rather than representing opposing strategies, they may share commonalities, with different aspects coming into play, depending on the nature of the response being 
assessed.

Contrary to expectations, the emotion primed did not directly influence women's perceived control. Moreover, contrary to our previous research using this same paradigm, women who were primed to feel angry were not more likely to endorse confrontational actions, but rather, were most likely to endorse accepting their failed status. Indeed, even the zeroorder correlations between self-reported anger and actions did not replicate past research demonstrating that anger resulted in greater endorsement of actions to contend discriminatory treatment (Gill \& Matheson, 2006; Mackie et al., 2000; Matheson \& Cole, 2004; Mikula, Scherer \& Athenstaedt, 1998; Swim, Hyers, Cohen, Fitzgerald, \& Bylsma, 2003; van Zomeren et al., 2004; Yzerbyt et al., 2003). It might simply be that women in the present study were not sufficiently outraged by their experience to feel considerable anger, or to act upon it. Alternatively, there is other research suggesting that there may indeed be circumstances under which group members who become angry do very little (Folger, 1997; Klandermans, 1997). For instance, the blatant nature of discrimination experience itself may have overridden the effects of women's emotions (particularly given that women's emotions were assessed prior to the discrimination event). Alternatively, it had originally been anticipated that women would be less likely to take actions if they perceived low control or efficacy to act; indeed, it is possible that by making salient issues of efficacy merely by asking about them, women were disinclined to endorse actions, even when angered.

Overall, women in the present study did not, for the most part, demonstrate support for actions to contend with their situation, even those women who self-reported greater levels of anger. It is unclear whether or not the findings of the present study are due to ineffective experimental procedures or whether effects were diminished due to an 
artifact of asking women to evaluate the efficacy of the various actions while concurrently being asked whether they would endorse such actions. 
Study 2

Although Study 1 found that priming anger evoked greater perceptions of discrimination when women were focused on their emotions (i.e., expected to regulated their emotions), these feelings of anger did not translate in to greater action endorsements. As already noted, the minimal effect of emotion states on women's behavioral responses to discrimination was unanticipated, and was contrary to prior research (e.g., Gill \& Matheson, 2006; Mackie et al., 2000). It was argued that the absence of such a relation may have been due to the contextualization of the questions regarding action endorsements among the items making salient the likely efficacy of the actions, which was perceived as minimal. In other words, by asking women to first evaluate the efficacy of potential actions and then endorse those actions, we may have inadvertently highlighted the ineffectiveness of the actions.

The perceived efficacy of particular action strategies might emanate from any number of factors, including women's past experience in taking action against unjust treatment, as well as the possibility that the ingroup as a whole was perceived as ineffective because it lacks the power, resources, or strength to rectify the injustice (Mackie et al., 2000). This latter possibility would be consistent with findings demonstrating that low perceived group efficacy or strength has been associated with non-action despite feelings of anger (Folger, 1987; Mummedy, et al., 1999). Conversely, anger combined with appraisals of high group efficacy or strength were related to greater endorsements of collective actions and moving against the outgroup, where ingroup strength is defined as perceiving the ingroup to have the power, support, or resources to address an injustice (Mackie et al., 2000; van Zomeren et al., 2004). Mackie et al. (2000) noted that appraisals of greater ingroup strength was related to higher levels of anger, and increased likelihood of endorsing confrontational actions against the 
outgroup (e.g., arguing, confronting, attacking). In effect, appraisals of ingroup strength may be necessary to evoke or allow individuals to acknowledge or appropriately channel feelings of anger. Without appraisals of the ingroup as strong, the anger evoked by a perceived injustice may be routed to other outlets that allow women to reduce their distress (e.g., seeking social support, distraction) (Matheson \& Anisman, 2006).

Although emotions are often regarded as the outcomes of particular patterns of appraisals (Frijda et al., 1989), as was noted earlier, emotions may also affect subsequent appraisals and perceptions, and may interact with the resources available in the situation to influence subsequent actions. In this regard, when individuals are angered and they perceive that they have the resources to contend with the situation (the ingroup is perceived as strong), perceptions of control and efficacy may be enhanced, which then might facilitate actions to confront the situation. In addition, being supported by a strong ingroup may provide a sense of empowerment that facilitates the ability to acknowledge discrimination, which further promotes the endorsement of actions to effectively address the situation. Thus, Study 2 assessed the extent to which ingroup strength interacted with anger to promote appraisals of discrimination and control, and whether in this instance, perceptions of discrimination, control, and efficacy mediated the effects of anger and ingroup strength on endorsements of collective actions.

Related to perceiving one's ingroup as strong is the extent to which the individual feels a strong connection to their group. Strength of group identification may also be a factor in perceptions of discrimination and endorsement of actions, where the stronger the group identity the more likely one is to recognize and respond to discriminatory treatment (Branscombe et al, 1999; Mendoza-Denton et al, 2002; Operario \& Fiske, 2001; Pinel, 
1999; Shelton and Sellers, 2000). Furthermore, group identification may also provide a basis for responding to discrimination; for instance, strongly identified women demonstrated a greater degree of involvement on behalf of women and women's issues (Crosby et al, 1996; Liss et al, 2004). Thus, in addition to situationally varying the extent to which the ingroup could be perceived as strong (vs. weak vs. control), Study 2 also measured the extent to which women identified with their group, and whether group identification influenced perceptions of and responses to discrimination.

In sum, Study 2 sought to evaluate the effects of anger priming, making salient the strength of the ingroup, and group identification on women's appraisals of discrimination and actions to confront discrimination, and whether these outcomes were mediated by perceived control and efficacy of actions (Figure 4).

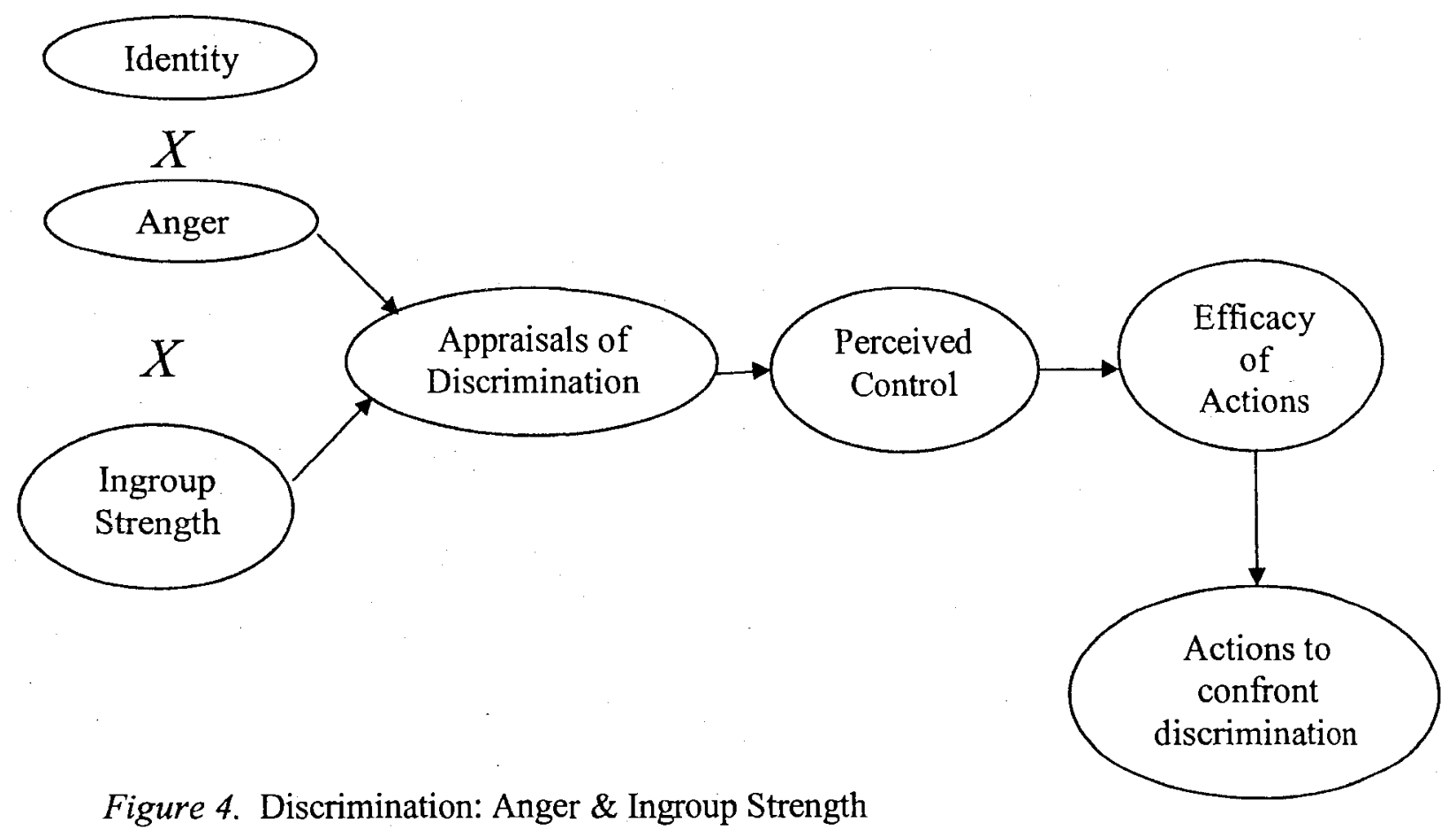

Figure 4. Discrimination: Anger \& Ingroup Strength 
It was hypothesized that:

1. Women who had high gender identification would perceive greater discrimination, control, collective actions as being more effective, and thus endorse these actions.

2. Primed anger (anger vs. control) and the group's strength (strong vs. weak vs. control) would have interactive effects on appraisals of discrimination, control, efficacy of actions, and action endorsements, and these effects would be further moderated by the strength of women's gender identity (high vs. low).

Specifically, among highly identified women, level of anger and the group's strength would interact: Among women who were angered, when the ingroup was perceived as strong, they would perceive greater discrimination and control, perceive collective actions to be more effective, and hence would be more likely to endorse collective actions compared to women who perceived the ingroup to be weak (which would not differ from controls), and compared to women who were not primed to experience anger, who would not vary as a function of the group's strengths on these outcome measures. Among women who were low in their gender identification, perceptions of discrimination and control were not expected to vary as a function of anger or ingroup strength, and would generally be lower than among women who were highly identified. Similarly, these low identified women would not perceive collective or confrontational actions to be effective, and hence would not endorse these actions.

3. Perceived discrimination, control, and efficacy of action would mediate the relations between the hypothesized interaction of the manipulations of anger and ingroup strength and women's gender identification on women's action endorsements. 
4. The mediational hypotheses from Study 1 assessing the mediating role of perceived control and efficacy between perceived discrimination and action endorsements, as well as the mediating role of perceived efficacy between control appraisals and action endorsements, were re-examined. 
Method

\section{Participants}

Female participants $(N=151 ; M$ age $=21$ years, $S D=5.95)$ were recruited to take part in a study examining storytelling abilities, for which they received grade increases in their first year psychology course and eligibility to participate in a $\$ 100$ lottery. The majority of participants were Caucasian $(n=113,74.8 \%)$, with the remainder of the sample comprising women of Chinese $(n=10,6.6 \%)$, South Asian $(n=8,4.6 \%)$, Middle Eastern $(n=6,4 \%)$, and

Black ( $n=4,2.6 \%$ ) descent, and the remainder comprised of Aboriginal, Hispanic, Korean, and Vietnamese origin $(n=10,6.7 \%)$. Only women who completed a mass testing session, in which the gender identity scale was administered as a pre-measure, were invited to participate in the study (Appendix R).

\section{Procedure}

Participants were exposed to the same paradigm as Study 1, wherein women completed the story-writing task and were told that those who qualify for the high status group would be eligible to participate in a $\$ 100$ lottery, while those in the low status group lottery would participate in a $\$ 10$ lottery. Furthermore, they were informed that if they are placed in the low status group they will only receive $.5 \%$, rather than the full $1.5 \%$ toward their first year psychology final grades if placed in the high status group. In reality all participants were fully compensated and eligible for the $\$ 100$ lottery. The experimenter further explained to participants that once assigned to their group, in the remainder of the study their tasks are differentially interesting or mundane, and reflect different skill levels. 
Participants first completed the informed consent form and demographic questionnaire (Appendix L) (verbal instructions see Appendix M). They then read a story and wrote about the same event with themselves as the protagonist in the story. In creating their story, participants used a list of twelve target words; if they were in the anger condition five of the twelve words consisted of anger adjectives (angry, hostile, infuriated, irritated, resentful), and if they were in the emotion control condition, five of the emotional words were replaced by five adjectives with no affective content (grade point average, essay, course, future, office) (Appendix C). Based on limitations noted in Study 1 regarding length of time to write the story, participants were given an additional 10-15 minutes (total time $25 \mathrm{~min}$ ) to complete their story. As in Study 1, the stories were collected by the female experimenter, and while allegedly being graded by a group of male engineering students, participants were asked to complete a secondary task (writing about an event that made them angry vs. creative, in the anger prime and control conditions, respectively) to ensure the reality of the situation regarding time needed to grade the papers and to maintain emotional state (see Appendix D). Participants had 5-6 minutes to complete this task; upon completion of this task, an emotion manipulation check measure was administered (Appendix N).

Another modification in procedure from Study 1 was that a male confederate entered the experimental room and handed the story to the female experimenter. While passing the graded story to the experimenter he simply said, 'Here is the story that we graded', and then left. The female experimenter then informed the participant that she had been assigned to the low status group and reminded the participant of what the low status group entailed (i.e., being placed in a lottery with a smaller monetary payout and 
only receiving .5 credits for participation instead of 1.5 credits). The female experimenter then marked a tally under a 'fail' column on a blackboard that showed the number of participants who had failed or passed the task so far. The tally board provided a breakdown by sex, which showed that all of women who had participated in the study failed, thereby emphasizing that only men were being passed into the high status group. The tally board provided a visual stimulus for the gender discrimination manipulation. In order to provide a cover story for the manipulation of ingroup strength, the female experimenter then closed the door and told the participant in a confidential manner that something was amiss with the study; specifically, she informed the participant that the male judges did not seem to be doing a fair job of evaluating the stories. The participant was then directed to the tally board as evidence of the experimenter's claim. Due to the unfair evaluations that were being made, the participant was told that she (the experimenter) was attempting to gather data to present to her thesis advisor so the advisor would be aware of the unfair evaluations. It was then explained to the participant that previous participants had responded to her request for assistance by writing a short paragraph about how they felt about the unfair treatment they received from the male judges.

Following from the ingroup strength manipulation employed by Mackie et al., (2000), those in the strong ingroup condition were presented with 19 hand written statements from previous female participants, 16 of which supported the ingroup (women) (e.g., If the girls in this study were to share our experience in this study with other people I think they would listen to us and take us seriously; I would get together with other women and talk about my experience in this study. I think we would all be 
supportive of each other; If we want, women in this study have the ability to improve the study by voicing our concern) and only 3 did not support the ingroup (e.g., Most women in this study don't care enough to do anything; I wouldn't be willing to get together with other girls in this study, and I don't think the other girls would want to do anything anyway; It's unlikely that the women in this study will even be listened to if they say anything) (Appendix O). In the weak ingroup condition, 16 statements did not support ingroup actions, whereas 3 were supportive (Appendix P). To reinforce the manipulation, and as a manipulation check, participants indicated whether each statement reflected women's support for one another to take action, because the experimenter wanted to get their opinions of these statements before drawing conclusions from them. In the control group, participants did not read and rate any statements (Mackie et al., 2000).

All participants were then asked to complete a final questionnaire, the results of which would also be summarized and presented to the female experimenter's thesis advisor for consideration. The participant was assured that the thesis advisor would only see an aggregate of responses and that individual participant's responses would not be identifiable. The questionnaire contained measures to assess emotions, perceptions of personal and group discrimination, perceived control, perceived efficacy of actions to respond to their treatment in the study, and actions endorsed (Appendix Q). In addition, a measure of group entativity was included as a potential confound with the manipulation of ingroup strength. Participants then completed a suspicion questionnaire to determine the extent to which they believed the manipulations (Appendix G), followed by an oral debriefing (Appendix T). To alleviate any feelings of anger, a second emotion induction 
procedure was included to provide humor. Participants were shown a 'Mr. Bean' video clip approximately 2-5 minutes in length and asked how entertaining they found it.

Given that participants were deceived about the purpose of the study at the beginning, once they were informed of the true purpose of the study following debriefing, they completed a second informed consent delineating the true intent of the experiment to allow the use of their data (Appendix U).

\section{Measures}

Group identification. In a pre-testing session, women completed Cameron's ingroup identification scale (Cameron, 2004). This 12 -item scale assessed three components of identity: cognitive centrality (i.e., the amount of time spent thinking about being a group member), ingroup affect (i.e., the positive feelings associated with membership in the group), and ingroup ties (i.e., perceptions of similarity, bond, and belongingness with other group members). Responses ranged from strongly disagree (1) to strongly agree (7). Analyses of this scale can involve either the three subscales, or a total gender identification score, wherein higher scores indicate greater importance of the identity (Cronbach's $\alpha=.78$ ). Because the three subscales were correlated (range of $r^{\prime} s=.17$ to $.46, p^{\prime} s<.05$ ), and the inter-item reliability for the total score was satisfactory, this latter index formed the basis of the present analyses. In order to assess gender identity as moderating variable using analyses of variance, a median split (Median=5.0) was performed on group identification with participants divided into high $(\mathrm{N}=79)$ or low $(\mathrm{N}=72)$ gender identity categories ${ }^{4}$.

\footnotetext{
${ }^{4}$ A median split into high vs. low was conducted as it commonly used in this literature (Doosje et al., 1995; Ethier \& Deaux, 1994), and it facilitated the description of possible higher order interactions, particularly given that gender identification was the variable expected to moderate the effects of the manipulated variables.
} 
Emotion manipulation check. Women rated 21 emotion adjectives on 7-point scales, ranging from not at all (1) to extremely (7). To assess the extent to which the emotion manipulation was effective and women reported anger, the emotion adjectives assessing anger (angry, annoyed, enraged, frustrated, hostile, infuriated, and irritable) were combined to provide a self-report index of anger (Cronbach's $\alpha=.90$ ).

The emotion measure was also administered after the discrimination event to assess how women felt at that moment to determine whether differential levels of anger were sustained (Cronbach's $\alpha=.91$ ).

Ingroup strength manipulation check. Women rated each of the 19 statements on three questions evaluating perceived collective support, including a) does this statement indicate women's support for doing something together to try to change the procedures of the study, b) is this statement indicating women's support of each other in this study, and c) does this statement suggest that women in this study are supportive of each other and are willing to help each other out by getting together, addressing the situation, and/or having their voices heard. These items were rated along 7-point rating scales ranging from not at all (1) to very much (7). The mean ratings across the 19 statements for each of the three questions were found to be highly positively correlated ( $r$ 's $>.95)$, and so the mean values across the three questions were calculated, with higher scores indicating greater perceived ingroup strength.

To ensure that this manipulation did not simultaneously vary with another related concept, namely entativity, which refers to one's sense of group cohesiveness, this variable was also measured (Hamilton, Sherman, \& Rodgers, 2004). This measure consisted of three items including 'I consider women to be a cohesive group', 'I think of 
women as being a singular unit', ' all women are interconnected'. These items were rated along a 7-point rating scales, ranging from not at all (1) to very much (7). Responses to these statements were averaged to yield one total score, with higher scores indicating greater perceived entativity (Cronbach's $\alpha=.53$ ).

Perceived discrimination. The two items used in Study 1 to assess perceived personal and group discrimination were embedded among six filler items and were rated along 7-point rating scales, ranging from not at all (1) to very much (7). A paired sample t-test indicated that women perceived greater group $(M=5.59 ; S D=1.64)$ versus personal discrimination $(M=5.35 ; S D=1.83), t(150)=-2.35, p<.05$. These two items were significantly positively correlated $(r=.76, p<.01)$, and so in this instance, were combined to produce a single score, with higher scores indicating greater perceptions of discrimination.

Perceived control. Given the poor reliabilities demonstrated for the measure of perceived control used in Study 1, in Study 2, perceived control was assessed using Lachman and Weaver's (1998) questionnaire consisting of 12 items, such as "I have little control over the things that happen to me", "what happens to me in the future mostly depends on me". Items were modified to be appropriate for responding to the situation in the laboratory. Perceived control was operationalized along two dimensions: personal mastery and perceived constraints. The former refers to one's sense of efficacy or effectiveness in carrying out goals, while the latter indicates the extent to which one believes there are obstacles beyond one's control that interfere with reaching goals. Participants indicated the extent to which they agreed with the statements using a rating scale ranging from strongly disagree (1) to strongly agree (7). Cronbach's alpha was .58 
for personal mastery, and .71 for perceived constraints; these subscales were not significantly correlated $(r=-.01)$. Higher scores reflected greater personal mastery, or greater perceived constraints (Lachman \& Weaver, 1998).

Perceived efficacy and action endorsements. As indices of perceived efficacy, women again rated the extent to which the endorsed response would be difficult to fulfill, effective for changing their personal status, and for improving the selection procedures for other women, on scales ranging from not at all (1) to extremely (7).

Women completed the same action endorsement survey as Study 1. They indicated the extent to which they would be willing to participate in each of five actions if they had the opportunity to respond to their treatment in the study (Wright et al., 1990). These actions included accept the situation, request for individual or collective retests (normative actions), or confronting the male judges to demand an explanation, either as an individual or collectively (non-normative actions). Endorsements were indicated on a scale ranging from not at all (1) to extremely (7). 


\section{Results}

An assessment of the assumptions underlying the use of parametric statistics, including tests of normality based on Kolmogorov-Smirnov, kurtosis and skewness statistics, and homogeneity of variance, indicated that these assumptions were not violated. To minimize Type I errors, Bonferroni adjustment was applied to all multiple comparison analyses to maintain a family-wise error rate of $\alpha=.05$.

\section{Manipulation Check for Perceived Discrimination}

A one sample t-test was performed on women's perceptions of discrimination. This test was significant, $t(150)=-11.11, p<.001$, indicating that women perceived discrimination in the study $(M=5.47, S D=1.63)$. Manipulation Check for Emotion Primed (Pre-Discrimination and Post-Discrimination)

To evaluate whether the emotion induction manipulation was successful, a 2 (Emotional priming: anger, control) by 2 (Gender identity: high, low) univariate ANOVA was conducted on the anger subscale. A significant main effect, $F(1,147)=29.43, p<.05$, $\eta^{2}=.167$, was found for emotional priming, in that, consistent with expectations, women in the anger prime condition reported greater anger $(M=4.34, S D=1.27)$ than did women in the emotional priming control condition $(M=3.24, S D=1.29)$, suggesting that the emotional priming manipulation was effective. This said, a significant interaction was observed between the emotional priming and gender identity, $F(1,147)=6.17, p<.05$, $\eta^{2}=.040$. Simple effects analyses indicated that among women who had a strong gender identity, those who were primed to feel angry reported greater anger than women in the emotional priming control condition, $F(1,147)=32.79, p<.001, \eta^{2}=.338$ (see Table 7), but no significant effects of emotional priming were observed among women with a weak 
gender identity $(F=3.49, p=.06)$, although the mean levels of anger were in the expected direction.

To assess any change of anger following the discrimination event (and the manipulation of ingroup strength), a 2 (Time of measure: pre- vs. post-discrimination; within subjects) by 2 (Emotional priming: anger, control) by 3 (Ingroup strength: strong, weak, control) by 2 (Gender identity: high, low) mixed measures ANOVA was conducted. A significant interaction was observed between time of measure and the emotional priming, $F(1,139)=12.21, p<.001, \eta^{2}=.081$. Simple effects analyses indicated that women primed to feel anger, $F(1,139)=10.94, p<.001, \eta^{2}=.135$, reported greater anger prior to the discrimination experience than after (see Table 8), indicating that anger slightly dissipated over time. There were no significant differences over time observed for the emotional priming control group. Notably, self-reported anger pre and postdiscrimination were significantly positively correlated $(r=.25, p<.01)$, suggesting that although anger following discrimination had subsided, it was still greater among those participants most angered prior to the event, albeit at a lower level. This effect was also observed by Matheson and Anisman (2006) who suggested that once an emotion is induced, it might continue to operate to influence the processes initially evoked to respond to a situation. 


\section{TABLE 7}

Means and standard deviations of self-reported anger as a function of gender identity and the emotional priming manipulation.

Anger Prime

Gender Identity

High

Low
Mean (SD)

$4.82^{\mathrm{a}}(1.06)$

$3.90 \quad(1.31)$
Control Prime

Mean (SD)

$3.19^{\mathrm{b}}(1.20)$

$3.30 \quad(1.41)$

Note: Different superscripts denote differences in a given row were significant at $p<.05$

\section{TABLE 8}

Means and standard deviations of self-reported anger pre and post-discrimination experience within the emotional priming conditions.

$\begin{array}{lc}\text { Anger Prime } & \text { Control Prime } \\ \text { Mean (SD) } & \text { Mean (SD) }\end{array}$

Anger

$\begin{array}{lllll}\text { Pre-discrimination } & 4.34^{\mathrm{a}} & (1.28) & 3.24 & (1.29) \\ \text { Post-discrimination } & 3.65^{\mathrm{b}} & (1.69) & 3.51 & (1.57)\end{array}$

Note: Superscripts denote differences in a given column at $\mathrm{p}<.05$

Manipulation Check for Ingroup Strength

To evaluate the extent to which the ingroup strength manipulation was effective, a 2 (Emotional priming: anger, control) $x 2$ (Ingroup strength: strong, weak) by 2 (Gender 
identity: high, low) univariate ANOVA was conducted on mean ratings of ingroup strength. Note that the third level of ingroup strength (control condition) was not included in this analysis, as this group did not complete the manipulation check for ingroup strength as relevant materials to rate were not presented to these participants. A significant main effect was observed for ingroup strength, $F(1,93)=473.77$, $p<.001, \eta^{2}=.836$. Women who were in the strong ingroup condition reported greater perceptions of collective support for women in the study $(M=5.47, S D=.50)$ compared to women in the weak ingroup condition $(M=2.32, S D=.84)$, indicating that the ingroup strength manipulation was effective.

In order to assess the possibility that the ingroup manipulation may have been influencing other related concepts such as entativity a 2 (Emotional priming: anger, control) by 3 (Ingroup Strength: strong, weak, control) by 2 (Gender identity: high, low) univariate ANOVA was conducted on mean ratings of entativity. No significant main effects or interactions were observed $(F \mathbf{S}<1)$, indicating that entativity was not influenced by the ingroup strength manipulation.

Perceptions of discrimination. A 2 (Emotional priming: anger, control) by 3 (Ingroup strength: strong, weak, control) by 2 (Gender identity: high, low) univariate ANOVA was conducted on women's ratings of perceived discrimination. There was a significant 2-way interaction between emotional priming and gender identity, $F(1,139)=6.29, p<.05, \eta^{2}=.043$. The simple effects of emotional priming for women with high or low group identification indicated a significant main effect for emotional priming, $F(1,77)=6.56, p<.05, \eta^{2}=.078$, among women who were highly identified. When these women were primed to experience anger greater discrimination was perceived than 
among women in the emotional priming control condition (see Table 9). No significant differences were observed for women with low gender identification.

\section{TABLE 9}

Means and standard deviations of perceived discrimination as a function of gender identity and emotional priming.

$\begin{array}{ll}\text { Anger Prime } & \text { Control Prime } \\ \text { Mean (SD) } & \text { Mean (SD) }\end{array}$

Gender Identity
High
$6.13^{\mathrm{a}}(1.00)$
$5.25^{\mathrm{b}}$
Low
$5.03(1.85)$
5.56

Note: Superscripts denote differences in a given row at $\mathrm{p}<.05$

Perceived control. A 2 (Emotional priming: anger, control) by 3 (Ingroup strength: strong, weak, control) by 2 (Gender identity: high, low) MANOVA was conducted on women's ratings of perceived control (mastery, constraints). A significant multivariate main effect was observed for ingroup strength, Pillais $=100, F(4,278)=3.66$, $p<.05, \eta^{2}=.050$. Univariate analyses indicated that when the ingroup was strong, women perceived the lowest levels of mastery, $F(2,139)=3.35, p<.05, \eta^{2}=.046$, compared to the control condition for ingroup strength (see Table 11). Furthermore, when the ingroup was strong, women perceived the greatest constraints, $F(2,139)=4.01, p<.05, \eta^{2}=.055$, compared to when the ingroup was weak (see Table 10). No further significant main effects or interaction were observed $\left(F_{\mathrm{S}}<1\right)$. 
TABLE 10

Means and standard deviations of personal mastery and perceived constraints as a function ingroup strength

Perceived Control

$\begin{array}{ll}\text { Personal Mastery } & \text { Constraints } \\ \text { Mean (SD) } & \text { Mean (SD) }\end{array}$

Ingroup Strength

$\begin{array}{lllll}\text { Strong } & 1.47^{\mathrm{a}} & (0.58) & 4.10^{\mathrm{a}} & (1.06) \\ \text { Weak } & 1.56^{\mathrm{a}, \mathrm{b}} & (0.65) & 3.66^{\mathrm{b}} & (1.09) \\ \text { Control } & 1.80^{\mathrm{b}} & (0.83) & 3.68^{\mathrm{a}, \mathrm{b}} & (0.95)\end{array}$

Note: Superscripts denote differences in a given column at $p<.05$

Behavioral Responses.

Perceived effectiveness of actions. Three mixed model ANOVAs were conducted, one for each set of efficacy ratings (e.g., difficulty of fulfilling the action, extent to which the action would improve personal status, and procedural fairness achieved by the action) using a 4 (Action: individual retest, individual confrontation, collective retest, collective confrontation; within subjects) by 2 (Emotional priming: anger, control) by 3 (Ingroup strength: strong, weak, control) by 2 (Gender identity: high, low). A significant main effect for action was observed on ratings of the difficulty of fulfilling the action, $F(3,417)=10.31, \mathrm{p}<.05, \eta^{2}=.070$, which was qualified by a significant interaction with emotion primed $F(3,417)=5.10, \mathrm{p}<.05, \eta^{2}=.040$. Among women primed to feel anger, the simple effect of action type was not significant, $F<1$. In 
contrast, among women in the emotional priming control condition, $F(3,417)=15.98$, $p<.001, \eta^{2}=.191$, follow-up simple comparisons indicated that women perceived the most difficult action to carry out was collective confrontation, particularly in comparison to the individualistic actions (see Table 11).

\section{TABLE 11}

Means and standard deviations of perceived difficulty, improving personal status, and procedural fairness of actions and emotional priming.

\section{Emotional Priming}

\begin{tabular}{lll} 
Angry & Control & Total Sample \\
Mean (SD) & Mean (SD) & Mean (SD) \\
\hline
\end{tabular}

Actions: Perceived Difficulty

\begin{tabular}{|c|c|c|c|c|c|}
\hline Individual retest & 3.98 & $(2.06)$ & $3.89^{\mathrm{b}}$ & $(1.92)$ & $3.94^{\mathrm{b}}(1.98)$ \\
\hline Individual confrontation & 4.05 & $(2.03)$ & $3.43^{\mathrm{b}}$ & $(1.87)$ & $3.74^{\mathrm{b}}(1.97)$ \\
\hline Collective retest & 4.12 & $(1.97)$ & $4.53^{\mathrm{a}, \mathrm{b}}$ & $(2.16)$ & $4.33(2.07)$ \\
\hline Collective confrontation & 4.28 & $(1.93)$ & $4.84^{\mathrm{a}}$ & (2.04) & $4.55^{\mathrm{a}}(2.01)$ \\
\hline
\end{tabular}

Improve Personal Status

$\begin{array}{lcccccc}\text { Individual retest } & 4.35 & (1.73) & 4.30 & (1.77) & 4.32^{\mathrm{a}} & (1.74) \\ \text { Individual confrontation } & 3.74 & (1.71) & 3.90 & (1.88) & 3.82^{\mathrm{b}} & (1.79) \\ \text { Collective retest } & 4.36 & (1.67) & 4.03 & (1.81) & 4.19 & (1.79) \\ \text { Collective Confrontation } & 4.07 & (1.66) & 3.97 & (1.80) & 4.01 & (2.01)\end{array}$

Improve Procedural Fairness

\begin{tabular}{lllllll} 
Individual retest & 5.01 & $(1.71)$ & 4.56 & $(1.97)$ & 4.79 & $(1.85)$ \\
Individual confrontation & 4.52 & $(1.82)$ & 4.46 & $(1.88)$ & $4.49^{\mathrm{a}}(1.85)$ \\
\hline
\end{tabular}




$\begin{array}{lllllll}\text { Collective retest } & 5.41 & (1.50) & 5.17 & (1.75) & 5.29^{\mathrm{b}} & (1.63) \\ \text { Collective confrontation } & 5.09 & (1.66) & 5.27 & (1.70) & 5.18^{\mathrm{b}} & (1.68)\end{array}$

Note: Superscripts denote differences in a given column at $\mathrm{p}<.05$

In examining whether various actions would improve women's personal status, a main effect of action type was again observed, $F(3,417)=6.04, \mathrm{p}<.001, \eta^{2}=.04$. Followup comparisons indicated that women perceived the greatest change in their personal status would be accomplished by the individual retest relative to the individual confrontation action (see Table 11). No further significant effects were observed.

In examining whether various actions would improve procedural fairness for other women in future, a main effect for action type was observed, $F(3$, $417)=13.51, p<.001, \eta^{2}=.089$. Not surprisingly, follow-up comparisons indicated that women perceived collective actions to be more likely to result in fairer procedures for women in the study compared to the individual retest (see Table 11). No further significant effects were observed.

Action endorsements. A 5 (Actions: accept, individual retest, individual confrontation, collective retest, collective confrontation; within subjects) by 2 (Emotional priming: anger, control) by 3 (Ingroup strength: strong, weak, control) by 2 (Gender identity: high, low) mixed measures ANOVA was conducted on women's ratings of endorsement. A significant main effect was observed for action, $F(4,556)=7.78, p<.001$, $\eta^{2}=.053$. Follow-up comparisons indicated that, overall, women were more likely to endorse the collective retest strategy than any other response (see Table 12). No further significant main effects or interactions were observed. 


\section{TABLE 12}

Means and standard deviations of action endorsements.

\section{Mean (SD)}

Action Endorsements

$\begin{array}{lcc}\text { Accept } & 4.05 & (1.78) \\ \text { Individual retest } & 4.09^{\mathrm{b}} & (2.05) \\ \text { Individual confrontation } & 3.74^{\mathrm{b}} & (2.04) \\ \text { Collective retest } & 5.15^{\mathrm{a}} & (3.74) \\ \text { Collective confrontation } & 4.01^{\mathrm{b}} & (2.11)\end{array}$

Note: Superscripts denote differences at $\mathrm{p}<.05$

Correlations among Self-reported Anger Pre-Post Discrimination, Perceived Ingroup Strength, Discrimination, Control, and Action Endorsements.

Given that anger post-discrimination slightly dissipated, as well as the limited significant results between emotional priming and the dependent variables, it was of interest to examine the pattern of Pearson zero-order correlations between self-reported anger pre- and post-discrimination and the dependent variables (see Appendix S for all correlations). As indicated in Table 13, whereas anger prior to the discrimination event was largely unrelated to women's responses, greater anger post-discrimination was associated with greater perceptions of discrimination, and fewer perceived constraints. As well, anger following the discrimination event was related to lower acceptance of women's treatment in the study, and greater endorsement of individual normative and 
non-normative actions, as well as the collective non-normative action.

Interestingly, the more women perceived the situation as constituting discrimination, the greater they perceived the ingroup to be strong, and the more likely they were to endorse individual and collective normative and non-normative actions. In addition, such perceptions were associated with lower perceptions of constraints to their control over the situation.

Suspicion Questionnaire

A frequency distribution indicated that only $7.9 \%$ of the participants figured out that the study was about discrimination. The cover story appeared to be believable, in that $79.5 \%$ believed the study was about creativity, $6 \%$ believed it was on sex differences in creativity, or 5.3\% indicated other related possibilities (e.g., creative differences between academic disciplines). 
$\infty$

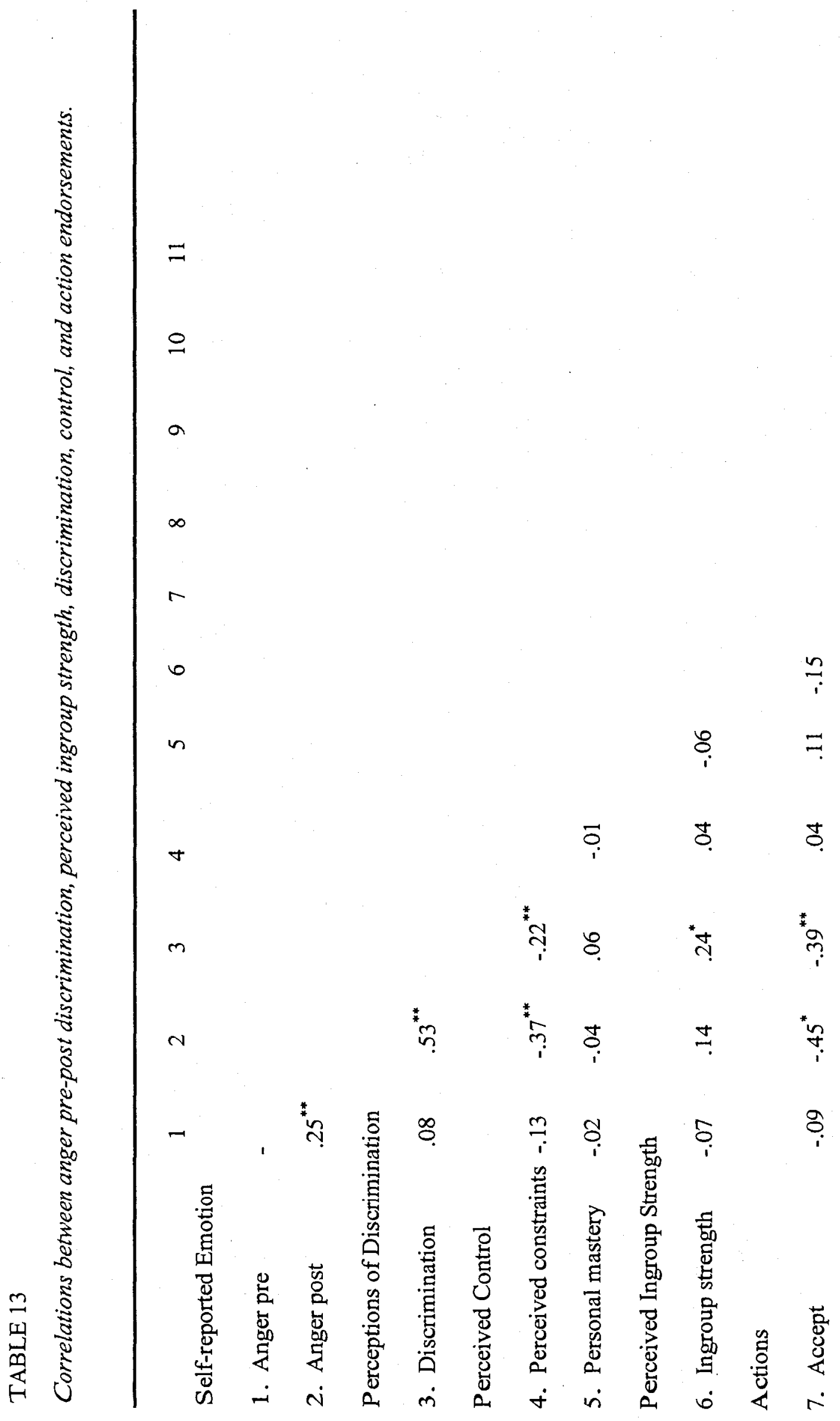




$$
\begin{aligned}
& \text { ? } \\
& \text { * }
\end{aligned}
$$

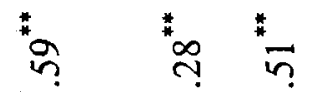

$$
\begin{aligned}
& \text { * } \\
& \text { ช } \\
& \text { ० } \\
& \text { * ก } \\
& \text { * * } \quad \stackrel{m}{*} \stackrel{*}{*} \stackrel{*}{*} \\
& \text { * } \\
& \text { ำ }
\end{aligned}
$$

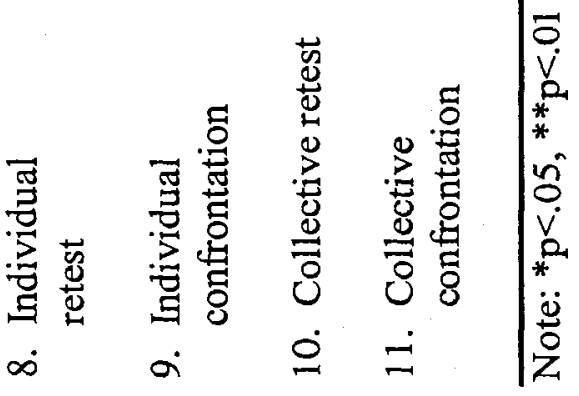




\section{Mediational Analyses}

It was hypothesized that the effects of anger priming, making salient the strength of the ingroup, and group identification on women's actions to confront discrimination would be mediated by perceived discrimination, control, and efficacy of actions. However, this interaction effect on women's actions was not supported. Moreover, these variables appeared to have differential effects across the various outcomes measures. Specifically, as expected, the strength of women's gender identification moderated the effects of the anger they were primed to feel on their perceptions of discrimination, in that women who had a strong gender identity and were primed to experience anger perceived greater discrimination than when they were not primed to be angry; this effect of anger priming was not evident among low identified women. However, irrespective of their gender identification unlike women who were primed to be angry, those who were not primed to experience anger (control) perceived the collective confrontational actions to be most difficult. Finally, the manipulation of the strength of the ingroup impacted perceived control, in that contrary to expectations, when the ingroup was strong, women reported lower personal mastery and greater constraints (e.g., lower perceived control). Thus, although anger priming and ingroup strength appeared to influence aspects of control and efficacy, they did not appear to do so by common routes. Thus, the moderated-mediation model was not viable, and so was not pursued.

Although Study 2 did not expand upon the hypothesized mediated relations from Study 1 , namely that women's perceptions of control and efficacy would mediate the relations between perceived discrimination and action endorsements, and that perceptions of efficacy, in turn, would mediate the relations between control appraisals and action 
endorsements, given the pattern of correlations, as well as the alternative measure of perceived control measure used in Study 2, this mediated model was again considered. In order to assess the mediating role of perceptions of control and efficacy in the relation between perceived discrimination and actions endorsed several requirements for this model had to be met.

1) Perceived discrimination (predictor) must be significantly related to actions endorsed (outcomes). As seen in Table 13, perceived discrimination was significantly related to all action endorsements including the extent to which women endorsed individual retest $(r=.41, p<.01)$, individual confrontation $(r=.33, p<.01)$, collective retest $(r=.18, p<.01)$, and collective confrontation $(r=.42, p<.01)$.

2) Perceived discrimination (predictor) must be related to perceived control (mediators) and perceived efficacy of the relevant actions (mediators) (see Appendix S). Perceived discrimination (predictor) was not related to personal mastery (mediator) $(r=.06, n s)$, but was significantly related to constraints (mediator) $(r=-.22, p<.05)$. Thus, appraisals of constraints was a potential mediator of the relation between perceived discrimination and action endorsements. Perceived discrimination was correlated with all three efficacy perceptions in relation to an individual retest, including perceived difficulty in $(r=.21, p<.05)$, perceptions that the individual retest would change their personal status $(r=.34, p<.05)$, and that this action would make the procedures fairer for all women $(r=.27, p<.01)$. Perceived discrimination was also correlated with efficacy perceptions in terms of the difficulty in implementing an individual confrontation $(r=-.20, p<.05)$, perceptions that the individual confrontation would change their personal status $(r=.26$, $p<.05)$, and that this action would make the procedures fairer for all women $(r=.41$, 
$p<.01)$. With respect to endorsements of a collective retest, perceived discrimination was not correlated with perceptions of the difficulty in implementing a collective retest $(r=-$ $.09, n s)$, but it was correlated with perceptions that the collective retest would change their personal status $(r=.28, p<.05)$, and that this action would make the procedures fairer for all women $(r=.25, p<.01)$. Finally, perceived discrimination was correlated with efficacy perceptions in terms of the difficulty in implementing a collective confrontation $(r=-.20, p<.05)$, and so this index of efficacy may serve a mediating role. However, perceived discrimination was not correlated with perceptions that the collective confrontation would change their personal status $(r=.01, n s)$, or that this action would make the procedures fairer for all women $(r=.14, p>.05)$, thus these mediated relations were not considered further.

3) Constraints (mediator) and perceived efficacy of the actions (mediators) must be related to action endorsements (outcome variables). Perceived constraints was correlated only with the individualistic actions, namely an individual retest $(r=-.17$, $p<.05)$ and individual confrontation $(r=-.22, p<.05)$. Thus, constraints might serve as a mediating variable between perceptions of discrimination and the individualistic action endorsements

However, the perceived difficulty in taking the individual retest action was not related to the endorsement of this action endorsement $(r=-.11, n s)$. However, perceptions that such actions would change their personal status $(r=.38, p<.01)$ and make the procedures fairer $(r=.27, p<.01)$ were both related to endorsing this action. Likewise, the perceived difficulty in taking the individual confrontation action was not related to its action endorsement $(r=-.05, n s)$, but perceptions that such action would change their 
personal status $(r=.54, p<.01)$ and make the procedures fairer $(r=.41, p<.01)$ were both related to endorsing this action.

The perceived difficulty in taking the collective retest action was not related to the endorsement of this action endorsement $(r=-.01, n s)$. However, perceptions that such actions would change their personal status $(r=.30, p<.01)$ and make the procedures fairer $(r=.25, p<.01)$ were both related to endorsing this action. Likewise, the perceived difficulty in taking the collective confrontation action was related to its action endorsement $(r=-.29,01)$, perceptions that such action would change their personal status $(r=.43, p<.01)$, and make the procedures fairer $(r=.34, p<.01)$ were both related to endorsing this action.

Given this pattern of relations, it is evident that the relations between perceived discrimination and the endorsement of individual retest and confrontational actions might be mediated by constraints and specific aspects of perceived efficacy, namely improving women's personal status, and making the procedures fairs. To assess these mediated models, two separate multiple mediation analyses were conducted, one for each of the action outcome variables.

As shown in Table 14 (and Figure 5), a multiple mediational analysis (Preacher \& Hayes, 2004) assessing whether the relation between perceived discrimination and the individual retest action was mediated by control and efficacy was supported. Furthermore, only the specific indirect effect of perceiving the individual retest action as improving personal status was significant indicating that the association between perceived discrimination and endorsing the individual retest action was mediated by perceiving this action as effective in improving personal status (Table 14). 


\section{TABLE 14}

Mediation of the effect of perceived discrimination on individual retest through perceptions of constraints, individual retest improving personal status and making procedures fairer.

\begin{tabular}{lcccc}
\hline & \multicolumn{2}{c}{ Product of Coefficients } & \multicolumn{2}{c}{ Bootstrapping } \\
& Point Estimate & $S E$ & \multicolumn{2}{c}{$\begin{array}{c}\text { BC 95\% CI } \\
\text { Lower Upper }\end{array}$} \\
\hline Indirect Effects & .09 & .04 & & \\
Improve status & .02 & .02 & .03 & .22 \\
Make proc fair & .01 & .02 & -.01 & .09 \\
Constraints & .12 & .05 & -.03 & .07 \\
Total & & & .04 & .24 \\
\hline
\end{tabular}

Note: $\mathrm{BC}=$ bias corrected; 1,000 bootstrap samples; Absence of zero in confidence interval suggests a significant indirect mediating effect. 


\section{FIGURE 5}

Mediation of the effect of perceived discrimination on individual retest through

perceptions of constraints, individual retest improving personal status and making

procedures fairer.

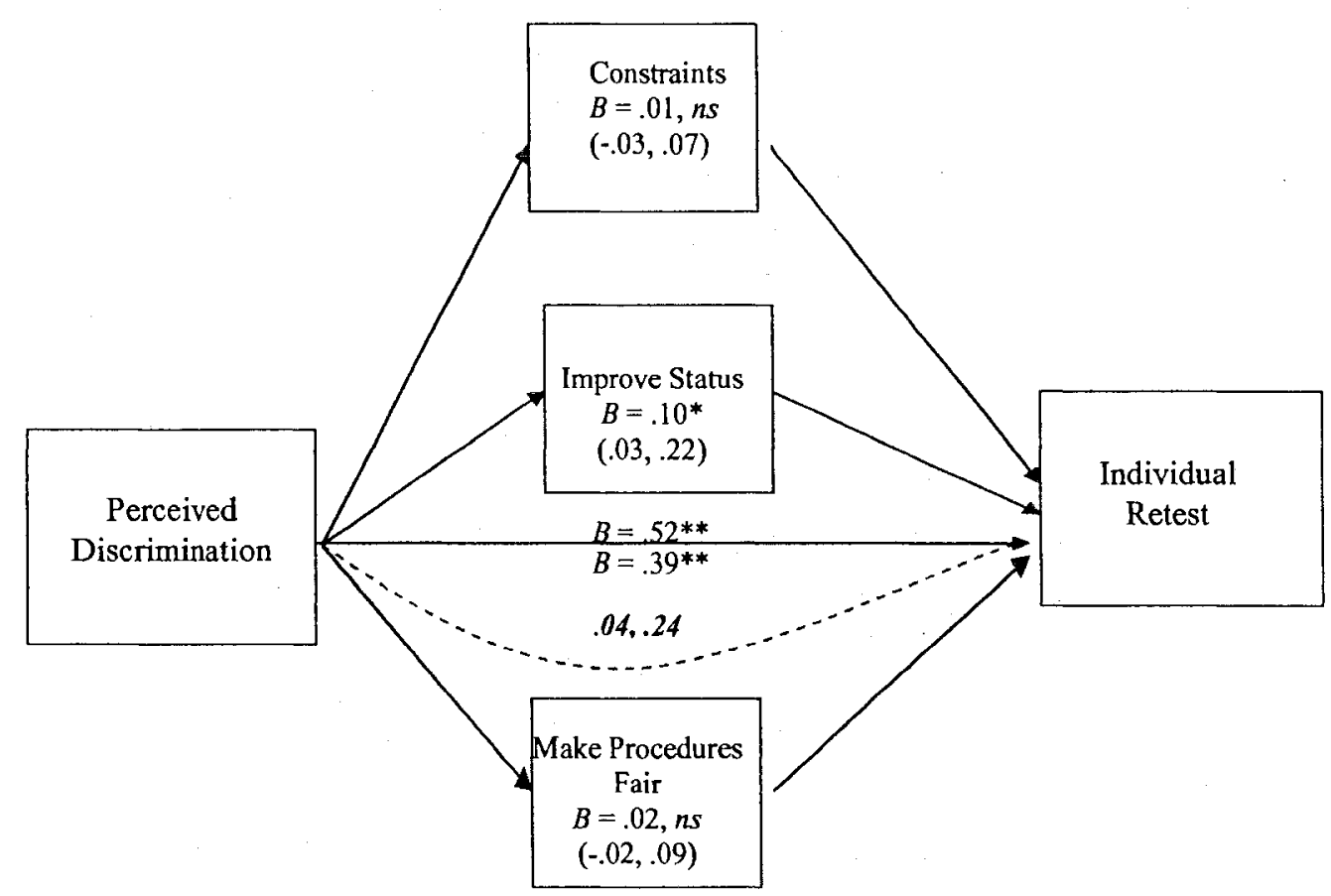

Note. The unstandardized coefficients for the total effects (c paths) of perceived discrimination on individual retest are presented above the horizontal arrow-line; the unstandardized coefficients for the direct effects (c' paths) of perceived discrimination on individual retest (controlling for mediators) are presented below the horizontal arrow-line. The unstandardized coefficients for the specific indirect effects ( $a b$ paths) of the mediators and the bootstrapped $95 \%$ bias corrected confidence intervals are presented inside the boxes. The bias corrected confidence intervals for the total indirect effect is presented in the black dashed line. ${ }^{*} p<.05 ;{ }^{* *} p<.01 ;{ }^{* * *} p<.001$ 
In addition, as shown in Table 15 and Figure 6 , the mediated relation between perceived discrimination and the individual confrontation action was also supported. As seen in Table 6, the $95 \%$ bias corrected confidence interval for the total indirect effect of constraints, perceiving the individual confrontation action as improving personal status and making procedures fairer was significant. Furthermore, the specific indirect effects of perceiving the individual confrontation action as improving personal status was significant, along with constraints; both of these pathways accounted for unique variance in the association between perceived discrimination and endorsing individual confrontation (Table 15).

\section{TABLE 15}

Mediation of the effect of perceived discrimination on individual confrontation through perceptions of constraints, individual confrontation improving personal status and making procedures fairer.

\begin{tabular}{lcccc}
\hline & \multicolumn{2}{c}{ Product of Coefficients } & \multicolumn{2}{c}{ Bootstrapping } \\
& Point Estimate & $S E$ & \multicolumn{2}{c}{ BC 95\% CI } \\
& & & & \\
& & & & \\
Lower & Upper \\
\hline Imdirect Effects & .12 & .05 & .04 & .26 \\
Makrove status & .01 & .02 & -.02 & .06 \\
Constraints & .05 & .02 & .01 & .13 \\
Total & .18 & .06 & .06 & .34 \\
\hline
\end{tabular}

Note: $\mathrm{BC}=$ bias corrected; 1,000 bootstrap samples; Absence of zero in confidence interval suggests a significant indirect mediating effect. 
FIGURE 6

Mediation of the effect of perceived discrimination on individual confrontation through perceptions of constraints, individual confrontation improving personal status and making procedures fairer.

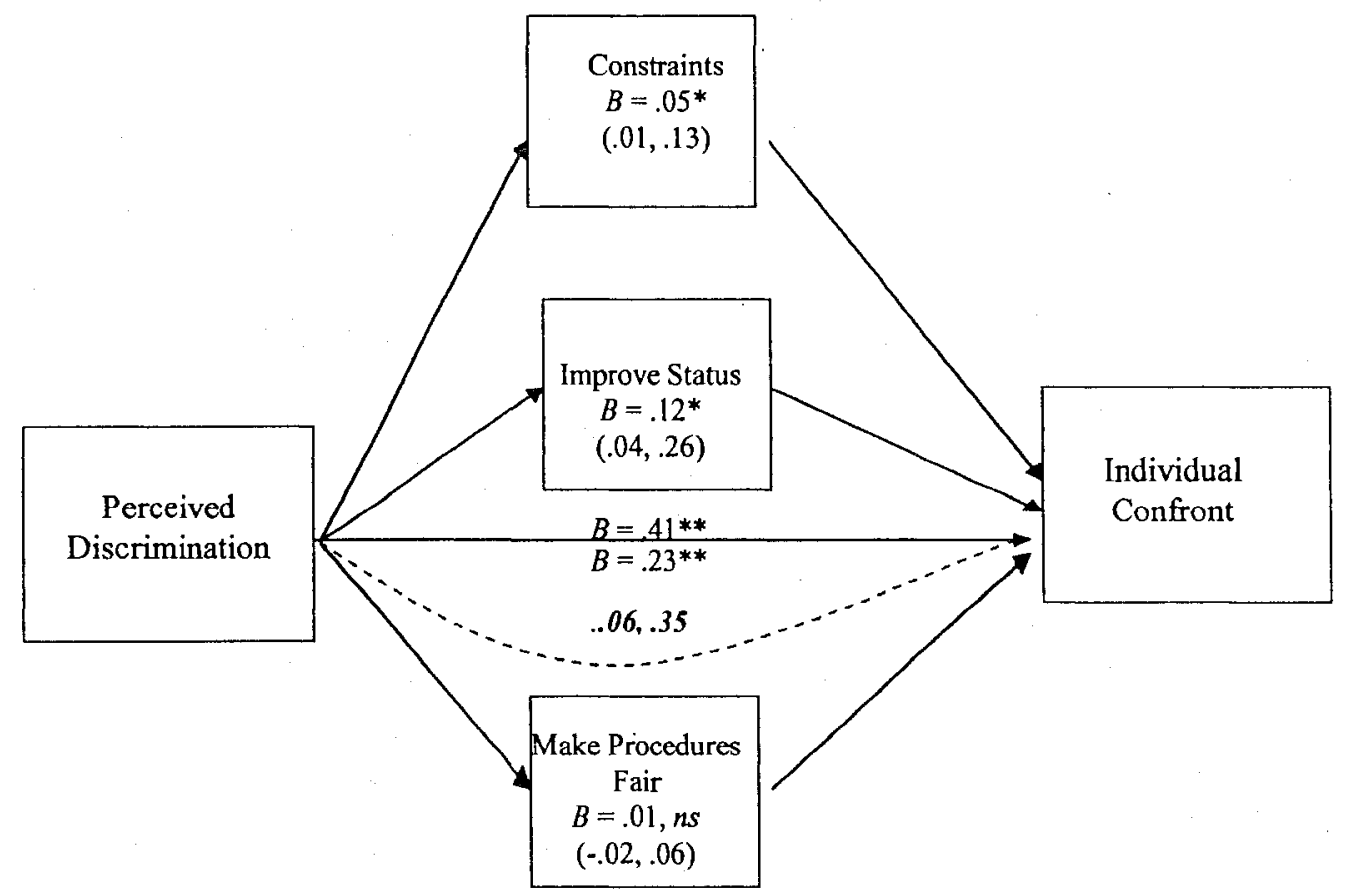

Note. The unstandardized coefficients for the total effects (c paths) of perceived discrimination on individual confront are presented above the horizontal arrowline; the unstandardized coefficients for the direct effects (c' paths) of perceived discrimination on individual confront (controlling for mediators) are presented below the horizontal arrow-line. The unstandardized coefficients for the specific indirect effects ( $a b$ paths) of the mediators and the bootstrapped $95 \%$ bias corrected confidence intervals are presented inside the boxes. The bias corrected confidence intervals for the total indirect effect is presented in the dashed black line. ${ }^{\dagger} p<.10 ;{ }^{*} p<.05 ;{ }^{* *} p<.01 ;{ }^{* * *} p<.001$ 
Finally, although control perceptions (constraints) were not linked to collective action endorsements, perceived efficacy of collective actions might nonetheless serve as a potential mediator between appraisals of discrimination and these action endorsements. To assess these mediated models, two separate multiple mediation analyses were conducted, one for each of the collective action outcome variables (collective retest and collective confrontation).

As shown in Table 16 and Figure 7, a multiple mediational analysis (Preacher \& Hayes, 2004) assessing whether the relation between perceived discrimination and the collective retest action was mediated by this action being perceived as improving personal status and procedural fairness was supported. As seen in Table 17 and Figure 7 , the total indirect effect was significant, as was the specific indirect effect of perceiving the collective retest action as improving personal status. Thus, the association between perceived discrimination and endorsing the collective retest action was mediated by perceiving this action as effective in improving personal status (Table 16). 
TABLE 16

Mediation of the effect of perceived discrimination on collective retest through

perceptions of collective retest improving personal status and making procedures fairer.

\begin{tabular}{lcccc}
\hline & \multicolumn{2}{c}{ Product of Coefficients } & \multicolumn{2}{c}{ Bootstrapping } \\
& Point Estimate & $S E$ & \multicolumn{2}{c}{ BC 95\% CI } \\
Lower Upper
\end{tabular}

Note: $\mathrm{BC}=$ bias corrected; 1,000 bootstrap samples; Absence of zero in confidence interval suggests a significant indirect mediating effect. 


\section{FIGURE 7}

Mediation of the effect of perceived discrimination on collective retest through

perceptions of collective retest improving personal status and making procedures fairer.

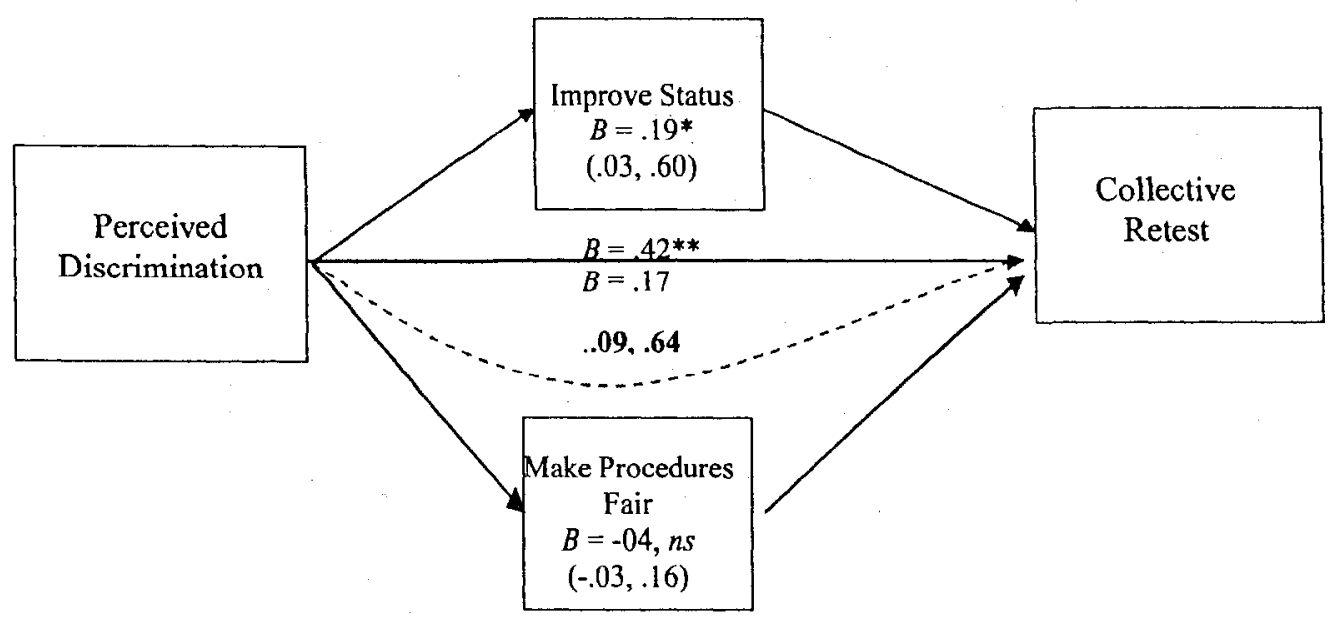

Note. The unstandardized coefficients for the total effects (c paths) of perceived discrimination on collective retest are presented above the horizontal arrow-line; the unstandardized coefficients for the direct effects (c' paths) of perceived discrimination on collective retest (controlling for mediators) are presented below the horizontal arrow-line. The unstandardized coefficients for the specific indirect effects ( $a b$ paths) of the mediators and the bootstrapped $95 \%$ bias corrected confidence intervals are presented inside the boxes. The bias corrected confidence intervals for the total indirect effect is presented in the dashed black line. ${ }^{\dagger} p<.10$; ${ }^{*} p<.05 ;{ }^{* *} p<.01 ;{ }^{* * *} p<.001$ 
As shown in Table 17 and Figure 8, a multiple mediational analysis assessing whether the relation between perceived discrimination and the collective confrontation action was mediated by this action being less difficult to endorse, improving personal status and procedural fairness was supported. The specific indirect effects suggest that the association between perceived discrimination and endorsing the collective confrontation action was mediated by perceiving this action as less difficult to implement, and more effective in improving personal status (Table 17).

\section{TABLE 17}

Mediation of the effect of perceived discrimination on collective confrontation through perceptions of collective confrontation being less difficult, improving personal status, and making procedures fairer.

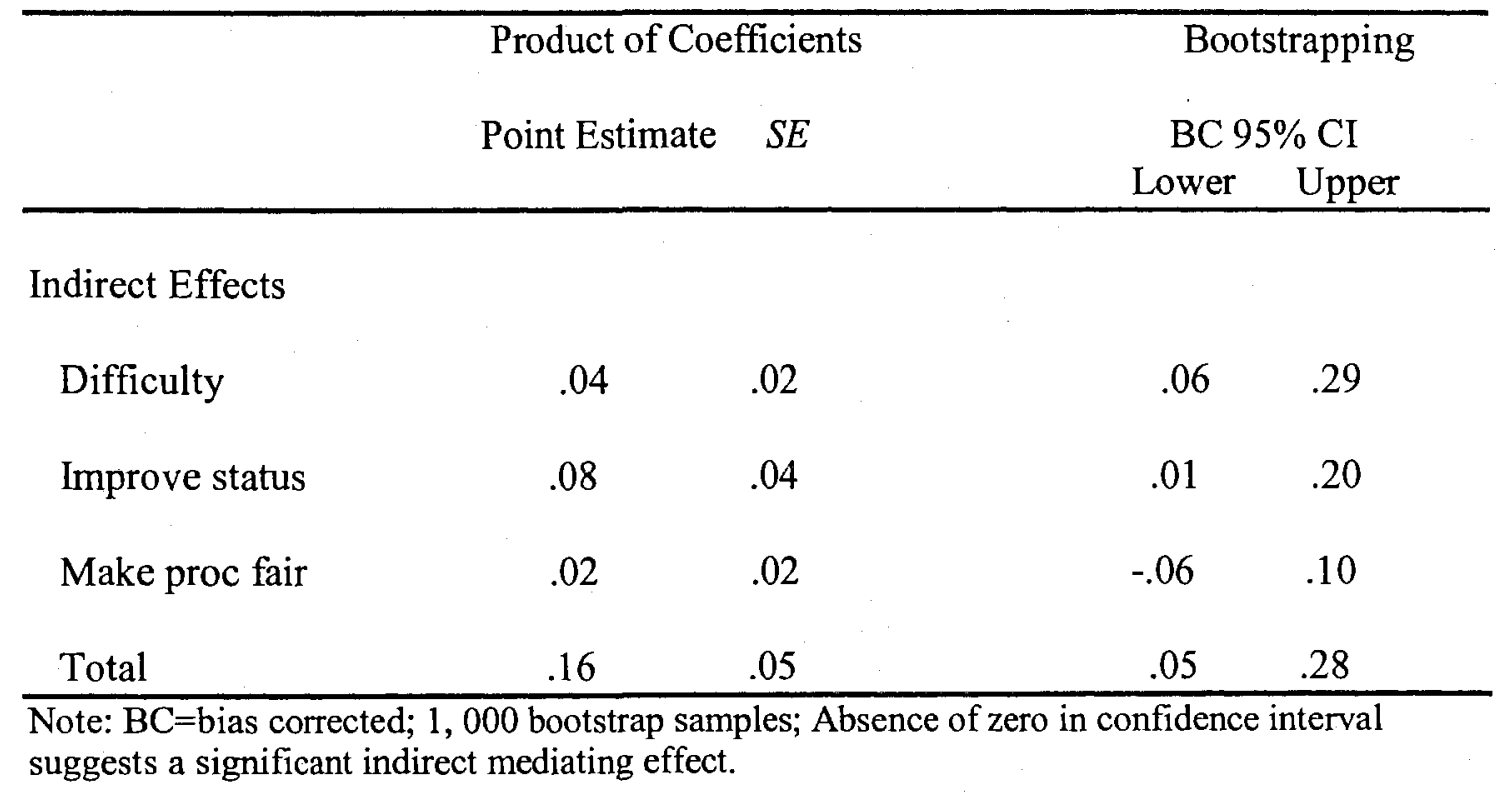




\section{FIGURE 8}

Mediation of the effect of perceived discrimination on collective confrontation through perceptions of collective confrontation being less difficult to endorse, improving personal status, and making procedures fairer.

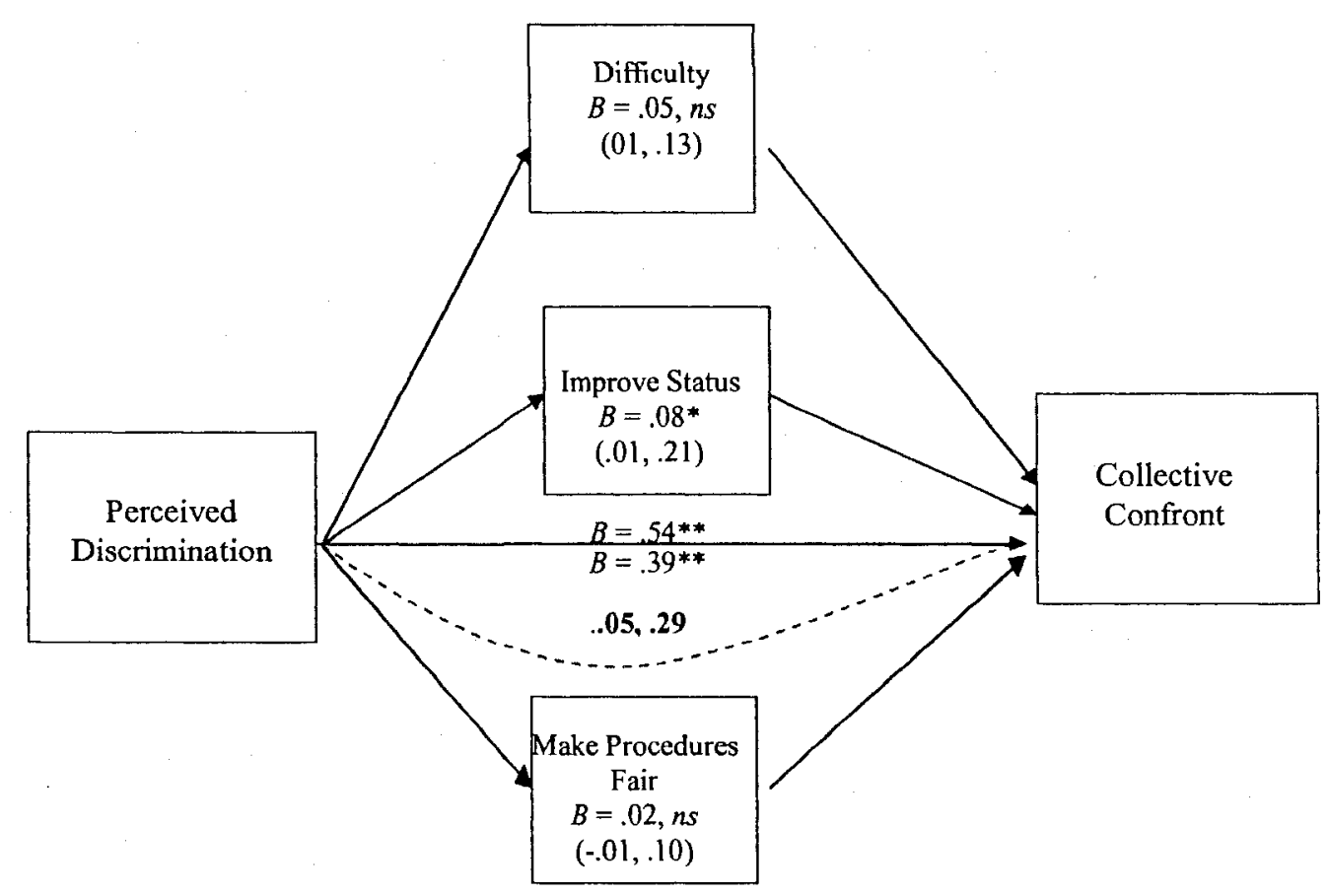

Note. The unstandardized coefficients for the total effects (c paths) of perceived discrimination on individual confront are presented above the horizontal arrowline; the unstandardized coefficients for the direct effects (c' paths) of perceived discrimination on individual confront (controlling for mediators) are presented below the horizontal arrow-line. The unstandardized coefficients for the specific indirect effects ( $a b$ paths) of the mediators and the bootstrapped $95 \%$ bias corrected confidence intervals are presented inside the boxes. The bias corrected confidence intervals for the total indirect effect is presented in the dash black lie. ${ }^{\dagger} p<.10 ;{ }^{*} p<.05 ;{ }^{* *} p<.01 ;{ }^{* * *} p<.001$ 
As indicated earlier, perceived control appraisals might also serve as an independent pathway influencing action endorsements, and hence the mediating role of efficacy perceptions in the relations between appraisals of control and actions were examined. Recall that, perceived constraints were correlated with endorsements of the individualistic actions. Likewise, control was associated with perceptions that an individual retest would change their personal status $(r=-.23, p<.01)$, and that this action would make the procedures fairer for all women $(r=-.21, p<.01)$. With respect to the individual confrontation action, constraints were not associated with perceptions that this action would improve personal status $(r=-.02, n s)$, or with perceptions that such an action would make the procedures fairer for all women $(r=.08, n s)$. Thus, the relation between perceived constraints and this latter action was independent of perceived efficacy of this action. And indeed, it might be recalled that these variables independently mediated the relation between perceived discrimination and endorsements of this action.

Given this pattern of relations, it is evident that the relations between constraints and the endorsement of the individual retest action might be mediated by the extent to which the individual retest action may improve personal status and make procedures fairer. However, as shown in Table 18, a multiple mediational analysis indicated that this model was not supported. 


\section{TABLE 18}

Mediation of the effect of constraints on individual retest through perceptions of individual retest improving personal status and making procedures fairer.

\begin{tabular}{lcccc}
\hline & \multicolumn{2}{c}{ Product of Coefficients } & \multicolumn{2}{c}{ Bootstrapping } \\
& Point Estimate & $S E$ & \multicolumn{2}{c}{$\begin{array}{c}\text { BC 95\% CI } \\
\text { Lower Upper }\end{array}$} \\
\hline Indirect Effects & .01 & .02 & & \\
Make proc fair & -.01 & .06 & -.02 & .14 \\
Improve Status & -.01 & .06 & -.15 & .11 \\
Total & & & -.15 & .14 \\
\hline
\end{tabular}

Note: $\mathrm{BC}=$ bias corrected; 1,000 bootstrap samples; Absence of zero in confidence interval suggests a significant indirect mediating effect. 


\section{Discussion}

The primary goal of Study 2 was to assess the effects of group identification, anger, and ingroup strength on women's appraisals and actions to confront discrimination. Although the anger priming manipulation was effective in Study 2, anger appeared to dissipate once the discrimination feedback (and ingroup strength manipulation) was given. However, given the positive correlation between pre and post self-reported anger, it appears that although anger subsided following the intervening tasks, it was still greater among women who were initially more angry. Indeed, this trend of anger dissipating following discrimination feedback was also noted by Matheson and Anisman (2006), who found that emotions shifted over the course of events, and became an amalgamation of emotions. For instance, although they successfully induced anger, they found anger shifted following failure feedback to include feelings of shame. Likewise, it was possible in Study 2, that the shift in anger may have reflected the elicitation of other emotions. Nonetheless, the priming of anger continued to have limited effects on women's appraisals of discrimination and perceived efficacy of actiontaking.

Alternatively, as noted, not only were women exposed to the discrimination feedback, but they had also completed the ingroup strength manipulation task prior to assessing their post-discrimination emotions. Potentially, the ingroup strength manipulation may have altered feelings of anger, whereby focusing on the responses of other women in the study may have served as a distraction from the discriminatory feedback. Indeed, the ingroup strength manipulation itself may have provided conflicting emotional cues that may have potentially provided relief for those who perceived other 
women were ready to act and were supportive, or shame/embarrassment when other women were refusing to act and were unsupportive.

Not surprisingly, given women's shift of emotions, the anger priming had limited effects on women's appraisal and action responses in Study 2. Nonetheless, consistent with previous research (Gill \& Matheson, 2006; Mackie et al., 2000; van Zomeren et al., 2004; Yzerbyt et al., 2003), the greater anger women reported post-discrimination, the more likely they were to perceive discrimination, and the less likely they were to perceive constraints within the study. In addition, greater anger was related to women's lower acceptance of discriminatory treatment in the study and greater likelihood of endorsing action-taking. In effect, as in other correlational studies, anger appeared to be an emotional component involved in women's responses to discrimination, but it remains unclear as to the causal processes involved.

It was also expected that identity, anger, and ingroup strength would interact to affect women's appraisals and actions. However, the data did not support this expectation. Although the manipulation of ingroup strength was clearly effective, its impact was limited to women's perceptions of control. In this case, however, contrary to expectations, when the ingroup was conveyed as being strong, they reported greater obstacles beyond their control within the study (constraints), as well as a lower sense of efficacy in carrying out their goals related to the study (mastery), compared to women for whom the ingroup was conveyed to be weak or who were in the control condition for ingroup strength. Although speculative, it is possible that when the ingroup was strong, women may have concluded that they did not derive a sense of personal control because they trusted that their group members would take control. In this regard, it would have 
been interesting to include a measure of collective trust, which refers to the level of trust in one's group or organization (Kramer, Brewer, Hanna, 1996). The concept of collective trust has largely been studied in the context of organizational psychology (Bigley \& Pearce, 1998; Kramer et al., 1996) but may also extend to the intergroup context. In this instance, it was possible that the manipulation of ingroup strength simultaneously enhanced women's trust in their group, which may potentially account for the reduced perceptions of control. In line with this, the perceived control questionnaire assessed women's perceived control as individuals (e.g., I have little control over the things that happen to me), rather than as a group (e.g., the women in this study have little control over the things that happen to them). Had a more collective index of control been employed, ingroup strength might very well have been associated with greater perceived control.

Although the ingroup strength manipulation did not directly affect other variables of interest, the pattern of correlations revealed that greater self-reported perceptions of ingroup support were associated with greater the perceived discrimination, and higher endorsements of the collective confrontational actions. Indeed, these results are consistent with Mackie et al. (2000) who had found strong ingroup support to be related to the endorsement of collective actions.

Based on the findings of previous research (Mackie et al., 2000), it was expected that the extent to which women identified with their gender would moderate the effects of the anger priming and ingroup strength. Indeed, among women who were highly identified, the priming of anger elicited greater perceptions of discrimination, relative to the no-prime control group; this effect of anger was not evident among low identified 
women, who overall tended to be less likely to perceive their experience as constituting discrimination. ${ }^{5}$ Thus, as found by others (Branscombe et al., 1999; Major et al., 2003; Mendoza-Denton et al., 2002; Operario \& Fiske, 2001; Pinel, 1999; Shelton \& Sellers, 2000), highly identified group members may very well be more astute in recognizing discrimination, and this is especially likely to be the case if they are primed to be angry.

It was further expected that identity, emotion, and ingroup strength would interact to influence appraisals of the efficacy of actions and their endorsements. Contrary to expectations, and to previous research (Foster \& Matheson, 1999; Gill \& Matheson, 2006; Matheson \& Anisman, 2003), irrespective of these variables, women were most likely to overall endorse the collective normative action of requesting a retest of all women. As past research has found acceptance to be the predominant overall response (in the absence of moderating variables such as anger) (Gill \& Matheson, 2006; Matheson \& Anisman, 2006), there was clearly something unique about women's responses in the present study. Indeed, it is possible that features of the operational definitions of discrimination event may account for such variations. In particular, it is possible that when the discrimination is conveyed through the perpetrator himself, women are less inclined to take action potentially due to the directness of the threat (as observed in Study 1). In contrast, when the discrimination is conveyed through a third person or alternative source (e.g., a written scenario), women may potentially feel such a threat is more defensible, and hence may be more inclined to endorse action taking.

\footnotetext{
${ }^{5}$ Notably, when the association between identity and perceived discrimination was examined with identity as a continuous variable, identity and discrimination were significantly related ( $r=$ $.18, p<.05)$.
} 
Notably, one variable that is most likely to elicit collective action endorsements is a strong perception that the event does, indeed, constitute discrimination. Indeed, the ratings of discrimination in Study 2 were relatively high $(M=5.47, S D=1.62$, on a 1-7 scale). By contrast, the mean rating of the extent of discrimination against women in Study 1 was only $3.25(S D=2.03)$. Thus, for some reason, the discrimination intervention appeared to be especially effective in Study 2, perhaps resulting in the greater inclination to endorse a collective response. In line with this, collective normative (and nonnormative) actions were perceived as having the greatest potential to change the procedures of the study to be fairer for other women, although the greatest change in their personal status was perceived to be accomplished by the individual normative action. Furthermore, the leadership role of the experimenter in collecting statement and questionnaires from participants may have influenced women's endorsement of collective actions.

In Study 2, the mediational analyses supported the notion that the relations between perceived discrimination and individualistic actions were mediated by perceived control and efficacy, with these variables serving independent roles with regard to normative and confrontational individualistic actions. In contrast, perceived control was not associated with collective action endorsements, but efficacy perceptions were significant mediators in the relations between discrimination perceptions and the endorsement of these actions. The significance of these mediations observed in Study 2 and not Study 1 may be attributed to a change in the perceived control measure which allowed for a more sensitive analyses of the mediation models, as well as the a change in 
the discrimination manipulation which apparently led to greater perceptions of discrimination compared to Study 1 .

Notably, in examining the role of perceived control, it appears that it was a mediator for individualistic actions but not collective actions. As highlighted earlier, the perceived control measure consisted of items that assessed how the individual felt as opposed to assessing a more collective index of control. The nature of the individualistic perceptions of control may explain why control was a mediator for individualistic actions but not collective actions. 


\section{General Discussion}

Experiences of prejudice and discrimination have been documented as constituting a source of acute and chronic stress for members of stigmatized groups, with a positive association between discrimination and stress-related pathologies being consistently observed (Baumeister \& Tice, 1990; Branscombe et al., 1999; Finch et al., 2000; Kessler et al., 1999; Krieger, 1999; Ren et al., 1999). Based on prior research, in the present investigation it was posited that factors emanating from the combination of social identity theory and a stress and coping model may account for the association between discrimination and well-being, including strength of group identity, appraisals, emotions, and actions endorsed to respond to discrimination (Branscombe et al., 1999; Crosby et al., 1989; Operario \& Fiske, 2001; Mossakowski, 2003). Notably, much of the past research examining the negative impact of discrimination on stress-related outcomes has assessed discrimination as a self-report retrospective event or scenario (Branscombe et al., 1999; Clark, 2006; Eccleston \& Major, 2006; Foster, 2000; Lightsey \& Barnes, 2007; Kaiser \& Miller, 2004; Peters, 2006; Schmitt et al., 2002; Scott \& House, 2005). The limitation of such an approach includes recalling events, appraisals, and emotions based on one's memory of the situation, which may be underreported due to the passage of time or the uncertainty of how to interpret the event in the first place, as is reflected in the greater perceptions of group-based (as opposed to personal) discrimination (Crosby, 1982; 1984; Foster \& Matheson, 1998; 1999; Gill \& Matheson, 2006; Taylor et al., 1990; Taylor et al., 1991). However, in the present investigation, discrimination was examined as an event occurring in the present moment, allowing for the assessment of appraisals and emotions in relation to an objective situation of discrimination. Indeed, the situation 
of discrimination employed in the present investigation was interpreted as such by the participants, especially those in Study 2. Consequently, conclusions drawn from the objective experience of gender discrimination in the present investigation may indeed be relevant to understanding the processes evoked by discriminatory encounters.

\section{Group Identification \& Intergroup Emotion Theory}

In line with social identity theory, it was argued that the strength of the individual's identification with their group would act as a buffer between discrimination experiences and well-being. Previous research has found strong group identifiers were more likely to perceive discrimination (Branscombe et al., 1999; Crocker \& Major, 1989; Mossakowski, 2003; Operario \& Fiske, 2001; Petta \& Walker, 1992; Major et al., 2003; Mendoza et al., 2002; Shelton \& Sellers, 2000). Indeed, in the present investigation, there was a tendency for women who were highly identified to perceive greater discrimination. However, the primary role served by women's identification with their gender was to moderate the impacts of a predisposition (priming) of anger on appraisals of discrimination; specifically, women who strongly identified with their group and were angered were most likely to recognize their situation as constituting discrimination. Such a finding is consistent with the Intergroup Emotion Theory (IET) (Mackie et al., 2000; Smith, 1993; 1999). For instance, Mackie et al. (2000) found that when ingroup identity was made salient, and group members encountered an injustice against their group, specific emotions were evoked, namely anger, which in turn facilitated actions against the outgroup.

The present investigation further contributes to our understanding of the role of emotions in relation to how group members respond to discrimination by demonstrating 
that the association between emotions and appraisals appears to be dynamic and reciprocal (Scherer, 2001; Smith \& Kessler, 2004). In the present investigation, emotions were primed, reflecting the possibility that in real life group members may come to a situation with a predisposition to particular emotional states. In this regard, some individuals are especially sensitive to group-based rejection (Mendoza-Denton, Downey, Purdie, Davis, \& Pietrzak, 2002; Pinel, 1991; Stangor et al., 2003), and this sensitivity may be due to prior experiences that elicit rapid emotional responses to salient cues. Emotional predispositions might similarly evolve as a function of prior experiences. As in previous research (Bodenhausen et al., 2001; DeStano et al., 2004; Gill \& Matheson, 2006; Smith \& Kessler, 2004), a priori emotional states influenced appraisals, in that priming anger in particular, altered women's appraisals of discrimination, although these effects were moderated by situational cues (emotional regulation in Study 1) and individual differences (gender identification in Study 2). In addition, however, subsequent events (and perhaps appraisals) influenced emotions. Notably, self-reported anger following discrimination in Study 2 was diminished, but the levels expressed were related to appraisals of discrimination, control, and the perceived efficacy of actions. Indeed, prior studies examining the role of anger in collective action have typically varied aspects of the situation that would directly alter appraisals (e.g., ingroup strength), and assessed emotions as an outcome measure that mediated responses toward the outgroup (e.g., Mackie et al., 2000; van Zomeren et al., 2004). Thus, it appears that appraisals and emotions may very well shift over the course of the event, and have reciprocal relations on one another to culminate in a particular behavioural response. 
Just as different emotions may have differential effects on appraisals or action endorsements, different dimensions of appraisals might operate through varying pathways. For instance, in the theoretical model proposed at the outset of this thesis (Figure 1), appraisals of discrimination, perceived control, as well as perceptions of efficacy may all have implications for actions endorsed to respond to discriminatory treatment through varying pathways. The relations between discrimination (or threat) appraisals and particular actions were mediated by control and efficacy perceptions for Study 2. Specifically, greater perceptions of discrimination were associated with greater perceived control and efficacy (i.e., would improve women's personal status and make procedures fairer) in relation to the individualistic actions, which in turn, were related to the endorsement of these actions. This result suggests that the endorsement of individual actions (normative and confrontational) are a function of a dual pathway: perceived control and efficacy of actions, where the former assessed the extent to which women perceived limited obstacles in the study and the latter referring to how effective women perceived each action to be in terms of difficulty in implementing, improving personal status, and procedural fairness.

However, control perceptions were not implicated in the endorsement of collective actions. Rather, greater perceptions of discrimination were associated with greater perceived efficacy (i.e., action perceived as less difficult, likely to improve personal status, and procedural fairness) in relation to collective normative and confrontational actions, which in turn, predicted the endorsement of these actions. This latter result echoes van Zomeren et al. (2004) pathway of efficacy to collective action. Notably, van Zomeren et al. (2004) defined efficacy in terms of social support, whereas 
the present investigation defined efficacy as the perceived difficulty and effectiveness of carrying out the actions, suggesting that different notions of efficacy (both conceptually and operationally) should be explored in future research.

\section{Responses to Discrimination: A Stress \& Coping Framework}

According to a stress and coping perspective, the impact of a discrimination event is likely to be influenced not only by subjective appraisals of the situation, but also by the coping responses employed to contend with the situation. Problem-focused coping strategies are active efforts to change a stressful situation through modifying or eliminating the source of stress, whereas emotion-focused coping strategies include efforts to control one's emotional response to the event or by modifying the meaning of the event. Building on this, van Zomeren et al. (2003) argued and demonstrated that perceiving the ingroup to be treated unfairly and taking collective action was mediated by two pathways, namely, one involving anger (emotion-focused pathway), and the second involving appraisals of group efficacy (problem-focused pathway). Likewise, the mediated relations between discrimination, appraisals of efficacy, and collective action endorsements found the present investigation may reflect the problem-focused model proposed by van Zomeren et al. Although the present investigation did not directly assess problem-focused coping as it is typically defined (e.g, planning, information seeking), arguably, the actions endorsed in response to unjust treatment could be construed as various problem-focused strategies, in that they involve attempts to alter the situation that was created by the discriminatory behavior (Lazarus, 1991; 2001). These actions might well be harbingers of greater subsequent well-being, as other investigators have found that when group members' encountered discrimination and actions such as 
speaking up against the discrimination or reporting it to authorities were endorsed, they were less likely to report depressive affect (Noh \& Kaspar, 2003).

Notably, the present investigation did not find that encouraging particular emotion-focused responses (e.g., emotional expression vs. suppression) influenced women's actions in relation to discrimination, whereas encouraging results were reported in past research (Matheson \& Cole, 2004), who found that emotion-focused coping was associated with disidentification with a group when it was directly threatened, which in turn, was associated with reduced biological stress reactivity. As indicated earlier, this may be attributed to the ineffectiveness of the emotional coping manipulation in the present investigation, as well as the possibility that inducing particular coping responses is less telling than the impacts of the coping responses individuals themselves naturally use (e.g., due to individual differences in coping propensities). However, as noted earlier, although women understood the instructions with respect to emotional regulation, there was no manipulation check employed to evaluate the extent to which the emotion focused coping strategies were actually adopted by the women.

\section{Limitations}

Clearly a gap in the present investigation was the absence of indices of wellbeing. In order to effectively evaluate the stress and coping model, and the impacts of these processes on well-being, a measure of well-being would be needed. In acute situations, such as those that occur in a laboratory context, well-being is often assessed as a state of distress, which in the present studies, would have been confounded with mood. In assessing the implications of discrimination on well-being, it may be of greater 
relevance to assess the longer term implications (Foster, 2006), which is not always practical in association with laboratory paradigms.

Additionally, a limitation of the present studies was the use of a simulated experimental context; discrimination resulting in entrance into a low status group in an experimental context is not comparable to being passed over for employment as a result of discrimination. The latter involves grave consequences, namely lack of income to survive, whereas in the present studies the negative consequences of women being placed in the low status group were minimal and certainly did not extend beyond the laboratory. In addition, an inherent disadvantage of employing an experimental design is the possibility of demand characteristics. Women in these studies may have formed interpretations regarding how they should act in response to the discrimination or to the story writing task. This said, a primary advantage of studying discrimination in an experimental context is the manipulation of variables and examination of cause and effect associations.

Related to the use of such laboratory paradigm was the reliance on a sample of female university students, which constitutes a select group rather than a representative sample of the population. Consequently, results may be limited to a similar group rather than to a broader population than the sample warrants. This sample of female university students may have also been less cognizant of their options in responding to discrimination. Indeed, Beaton and Tougas (1997) note that the more women experienced discrimination, the more likely they were to acknowledge that women were discriminated against and support actions to counter the discrimination. 
Finally, although the theoretical model employed in the present thesis was intended to reflect the response of members of other stigmatized groups, it is acknowledged that similar results may not be observed across other groups, such as ethnic minorities who often report different forms, and more severe experiences of discrimination (Dion \& Kawakami, 1996). For instance, Black Canadians perceived higher levels of group and personal discrimination than most other ethnic groups, including Chinese and South Asians (Dion \& Kawakami, 1996). The more discrimination is perceived as pervasive, the more deleterious effects it has on well-being (although this association may be attenuated with increased group identification) (Branscombe et al., 1999). Pervasive rejection or discrimination, particularly by the dominant social group, is viewed as fostering feelings of a lack of value (Solomon, Greenberg, \& Pyszczynksi, 1992; Tajfel \& Turner, 1986).

Likewise, it is recognized that although anger is viewed as a fundamental emotion in discrimination research, its implications may be qualitatively different for women compared to men, as the former experience greater pressure to contain anger (Brody, 2000; Brody \& Hall, 1993; Hess et al., 2000; Kelly \& Huston-Comeaux, 1999). More specifically, women, and other minority group members, may experience greater pressure to regulate their negative emotions, especially in the presence of dominant group members who control their resources (Gross \& John, 2003; Keltner, Gruenfeld, \& Anderson, 2003). Furthermore, greater action endorsements tend to be observed by men who belong to the dominant group, as women are less likely to endorse confrontational actions in response to unjust treatment (Foster et al., 2004). Members of groups who are 
typically advantaged may perceive greater self-efficacy and control compared to members of disadvantaged groups, and hence are more likely to act.

\section{Conclusions}

Overall, the present investigation contributes to our understanding of the relations among appraisals and emotions in a discriminatory situation, as well as appraisal pathways to the endorsement of actions. Both appraisals and emotions appear to work in conjunction with one another; for instance, past experiences of discrimination may influence subsequent emotions associated with the event, as well as appraisals of discrimination. Furthermore, it has been previously demonstrated that emotions were predictive of appraisals of discrimination (Gill \& Matheson, 2006), and likewise appraisals of discrimination were associated with emotions (Branscombe et al., 1999). Clearly, appraisals and emotions are processes that may be regarded as co-occurring rather than simple cause-effect associations.

In addition, the present investigation contributes to our understanding of how different dimensions of appraisals facilitate the endorsement of different action strategies. Evidently, individualistic actions (e.g., ask for a retest, confrontation) were endorsed by a dual pathway when perceiving discrimination, namely perceived control and efficacy of individualistic actions, where the former refers to women perceiving limited obstacles within the study and the latter refers to how effective women perceive action to be. This contributes to our understanding of what factors compel women to feel empowered enough to respond to discrimination as opposed to engage in withdrawal or acquiescence. Indeed, appraisals of control and efficacy may reflect distinct sources of empowerment for women in contending with discrimination. Moreover, perceived efficacy of the 
collective actions was fundamental in mediating the link between perceiving discrimination and endorsing collective strategies to confront it. As indicated earlier, these processes may reflect real life coping processes where women might engage in primary and secondary appraisals of control/threat, which may then ultimately facilitate responses to fight the discrimination. Furthermore, the social implications of these findings suggest that active responses to discrimination may effectively challenge the existing social system that benefits members of privileged groups.

Finally, while the present investigation highlights the importance of perceived efficacy of actions in women's ability to actually collective endorse actions, other situational factors may affect a minority group member's perceptions of efficacy, and in turn his/her ability to challenge the discrimination. Future research may focus on examining situational factors that might contribute to efficacy perceptions such as past experiences (personal, observational) of endorsing actions to contend discrimination, nature of discrimination (e.g., subtle vs. blatant), or even the societal status of perpetrator as well as the resources the perpetrator controls. 


\section{References}

Anderson, N. B., Myers, H. F., Pickren, T., \& Jackson, J.S. 1989. Hypertension in blacks: Psychosocial and biological perspectives. Journal of Hypertension, 7, 161-172.

Arias, I., \& Pape, K. T. (1999). Psychological abuse: Implications for adjustment and commitment to leave violent partners. Violence and Victims, 14, 55-67.

Armstead, C. K., Lawler, A., Gordon, G., Cross, J. \& Gibbons, J. 1989. Relationship of racial stressors to blood pressure responses and anger expression in black college students. Health Psychology, 8, 541-556.

Aruffo, J. F., Coverdale, J. H., Pavlik, V. N., \& Vallbona, C. (1993). AIDS knowledge in minorities: Significance of locus of control. American Journal of Preventive Medicine, $9,15-20$.

Baker, M. \& Fortin, N. (2000). The gender composition and wages: Why is Canada different from the United States? Statistics Canada Catalogue no. 11F0019MIE00140.

Baron, R.M., \& Kenny, D.A. (1986). The moderator-mediator variable distinction in social psychological research: Conceptual, strategic, and statistical considerations. Journal of Personality and Social Psychology, 51, 1173-1182.

Baudenhausen, G. V., Mussweiler, T., Gabriel, S. \& Moreno, K. N. (2001). Affective influences on stereotyping and intergroup relations. In J. P. Forgas (Ed.). pp. 319-343. Handbook of affect and social cognition, Mahwah, NJ: Erlbaum.

Baumeister, R.F., \& Tice, D.M. (1990). Anxiety and social exclusion. Journal of Social and Clinical Psychology, 9, 165-195.

Bigley, G.A. \& Pearce, J.L. (1998). Straining for shared meaning in organization science: Problems of trust and distrust. The Academy of Management Review, 23(3), 
405-421.

Branscombe, N.R., Schmitt, M.T. \& Harvey, R.D. (1999). Perceiving pervasive discrimination among African Americans: Implications for group identification and well-being. Journal of Personality and Social Psychology, 77, 125-149.

Brody, L.R. (2000). The socialization of gender differences in emotional expression: Display rules, infant temperament, and differentiation. In A.H. Fischer (Ed.), Gender and emotion: Social psychological perspectives (pp. 24-47). New York: Cambridge University Press.

Brody, L.R., \& Hall, J.A. (1993). Gender and emotion. In M. Lewis \& J.M. Haviland (Eds.), Handbook of emotions (pp. 447-460). New York: Guilford Press.

Brown, P. J., Recupero, P. R., \& Stout, R. (1995). PTSD substance abuse comorbidity and treatment utilization. Addictive Behaviors, 20(2), 251-4.

Cameron, J. E. (2004). A three-factor model of social identity. Self and Identity, 3, 239262.

Canadian Human Rights Commission (2000). http://www. caut.ca/en/issues/women/ crccomplaint/pdf.

Carver, C.S., Scheier, M.F., \& Weintraub, J.K. (1989). Assessing coping strategies: A theoretically based approach. Journal of Personality and Social Psychology, 59, 7381.

Cheng, C. (2001). Assessing coping flexibility in real-life and laboratory settings: A multimethod approach. Journal of Personality and Social Psychology, 80, 814-833. Clark, R., Anderson, N.B., Clark, V.R., \& Williams, D.R. (1999). Racism as a stressor for African Americans: A biopsychosocial model. American Psychologist, 34, 805- 
816.

Clark, R. (2006). Interactive but not direct effects of perceived racism and trait anger predict resting systolic and diastolic blood pressure in Black adolescents. Health Psychology, 25, 580-585.

Cohen, J. (1983). The cost of dichotomization. Applied Psychological Measurement, 7, 249-253.

Cohen-Kettenis, P.T., Owen, A., Kaijser, V.G., Bradley, S.J., \& Zucker, K. J. (2003). Demographic characteristics, social competence, and behavior problems in children with gender identity disorder: A cross national, cross clinic comparative analysis. Journal of Abnormal Child Psychology, 31(1), 1573-2835.

Compas, B.E., Malcame, V. L., \& Fondacaro, K. M. (1988). Coping with stressful events in older children and young adolescents. Journal of Consulting and Clinical Psychology, 56, 405-411.

Crocker, J., \& Major, B. (1989). Social stigma and self-esteem: The self-protective properties of stigma. Psychological Review, 96, 608-630.

Crocker, J., Major, B., \& Steele, C. (1998). Social stigma. In S. Fiske, D. Gilbert, \& G. Lindzey (Eds.), Handbook of social psychology (pp.504-543). Boston: McGraw Hill.

Crosby, F. J. (1982). Relative deprivation and working women. NY: Oxford University Press.

Crosby, F. (1984). The denial of personal discrimination. American Behavioral Psychologist, 27, 371-386.

Crosby, F.J., Pufall, A., Snyder, R.C., O'Connell, M., \& Whalen, P. (1989). The denial of personal disadvantage among you, me, and all other ostriches. In M. Crawford \& $\mathrm{M}$. 
Gentry (Eds.), Gender and thought: Psychological perspectives. New York: SpringerVerlag.

Crosby, F., Todd, J., \& Worell, J. (1996). Have feminists abandoned social activism? Voices from the academy. In L. Montada \& M. Lerner (Eds.). Current societal concerns about justice: Critical issues in social justice. (pp. 85-102). New York: Plenum.

Davison, H. K., \& Burke, M. J. (2000). Sex discrimination in simulated employment contexts: A meta-analytic investigation. Journal of Vocational Behavior, 56, 225-248.

DeSteno, D. Dasgupta, N., Bartlett, M.Y., \& Cajdric, A. (2004). Prejudice from thin air: The effect of emotion on automatic intergroup attitudes. Psychological Science, 15, 319-324.

Diener, E., \& Emmons, R.A. (1984). The independence of positive and negative affect. Journal of Personality and Social Psychology, 47, 1105-1117.

Dion, K.L., Dion, K.K., \& Pak, W.P. (1992). Personality-based hardiness as a buffer for discrimination-related stress in members of Toronto's Chinese community. Canadian Journal of Behavioural Science, 24, 517-536.

Dion, K.L. \& Kawakami, K. (1996). Ethnicity and perceived discrimination in Toronto: Another look at the personal/group discrimination discrepancy. Canadian Journal of Behavioral Science, 28(3), 203-218.

Doosje, B., Ellemers, N., \& Spears, R. (1995). Perceived intragroup variability as a function of group status and identification. Journal of Experimental Social Psychology, 31, 410-436. 
Eccleston, C.P., \& Major, B. N. (2006). Attributions to discrimination and self-esteem: The role of group identification and appraisals. Group Processes and Intergroup Relations, 9, 147-162.

Ethier, K. A. \& Deaux, K. (1994). Negotiating Social Identity When Contexts Change: Maintaining Identification and Responding to Threat. Journal of Personality and Social Psychology, 67(2), 243-251.

Endler, N.S., \& Parker, J.D.A. (1994). Assessment of multidimensional coping: Task, emotion, and avoidance strategies. Psychological Assessment, 6, 50-60.

Everston, M. (2004). Formal on the job training: A gender-typed experience and wage related advantage. European Sociological Review, 20, 79-94.

Finch, K..F., Kolody, B., Vega, W.A. (2000). Perceived discrimination and depression among Mexican-origin adults in California. Journal of Health and Social Behavior 41:295-313, 2000.

Folger, R. (1987). Reformulating the conditions of resentment: A referent cognition model. In J.C. Masters \& W.P. Smith (Eds.), Social comparison, social justice, and relative deprivation (pp. 183-215). UK: Erlbaum.

Foster, M.D. (2001). The motivational quality of global attributions in hypothetical and experienced situations of gender discrimination. Psychology of Women Quarterly, 25, 242-253.

Foster, M. D. (2000). Positive and negative responses to personal discrimination: Does coping make a difference? Journal of Social Psychology, 140, 93-106.

Foster, M.D., Arnt, S., \& Honkola, J. (2004). When the advantaged become disadvantaged: Men's and women's actions against gender discrimination. Sex Roles, 
$50,27-36$.

Foster, M.D., \& Matheson, K. (1999). Perceiving and responding to the personal/group discrimination discrepancy. Personality and Social Psychology_Bulletin, 25, 13191329.

Foster, M.D., \& Matheson, K. (1998). Perceiving and feeling personal discrimination: Motivation or inhibition for collective action? Group Processes and Intergroup Relations, $1,165-174$.

Foster, M.D., Matheson, K., \& Poole, M. (1994). Responding to sexual discrimination: The effects of societal and self-blame. Journal of Social Psychology, 34, 743-754.

Frijda, N.H., Kuipers, P., \& ter Schure, E. (1989). Relations among emotion, appraisal, and emotional action readiness. Journal of Personality and Social Psychology, 57, 212-228.

Gill, R., \& Matheson, K. (2006). Responses to discrimination: The role of emotion and expectations for emotional regulation. Personality and Social Psychology Bulletin, $32,149-161$.

Goodman, L. A., Koss, M. P., Fitzgerald, L. F., Russo, N. F., \& Keita, G. P. (1993). Male violence against women: Current research and future directions. American Psychologist, 48, 1054-1058.

Grant, P.R., \& Brown, R. (1995). From ethnocentrism to collective protest: Responses to relative deprivation and threats to social identity. Social Psychology Quarterly, 58, 195-211.

Gross, J.J. \& John, O.P. (2003). Individual differences in two emotion regulation processes.: Implications for affect, relationships, and well-being. Journal of 
Personality and Social Psychology, 85, 348-362.

Gutek, B. A. (2001) Women and paid work. Psychology of Women Quarterly, 25(4), 379393.

Hamilton, D. L., Sherman, S. J., \& Rodgers, J. (in press). Perceiving the groupness of groups: Entativity, homogeneity, essentialism, and stereotypes. In V. Yzerbyt, C. M. Judd, \& O. Corneille (Eds.), The Psychology of Group Perception: Contributions to the Study of Homogeneity, Entativity and Essentialism. Philadelphia, PA: Psychology Press.

Herrald, M.M., \& Tomaka, J. (2002). Patterns of emotion-specific appraisal, coping, and cardiovascular reactivity during an ongoing emotional episode. Journal of Personality and Social Psychology, 83, 434-450.

Hess, U., Senechal, S., Kirouac, G., Herrera, P., Philloppot, P., \& Kleck, R. (2000). Emotional expressivity in men and women: Stereotypes and self-perceptions. Cognition and Emotion, 14, 609-642.

Hillman, S.B., Wood, P.C., \& Sawilowsky, S.S. (1992). Externalization as a selfprotective mechanism in a stigmatized group. Psychological Reports, 70, 641-642.

Hodson, G., \& Esses, V.M. (2002). Distancing oneself from negative attributes and the personal/group discrimination discrepancy. Journal of Experimental Social Psychology, 38, 500-507.

James, S., LaCroix, A. Z., Kleinbaum, D. G., \& Strogatz, D. S. (1984). John Henryism and blood pressure differences among black men II: The role of occupational stressors. Journal of Behavioral Medicine, 7, 259-275. 
Jones, D. R., Harrell, J.P., Morris-Prather, C.E., Thomas, J., \& Omowale, N. 1996. Affective and physiological responses to racism: the roles of afrocentrism and mode of presentation. Ethnicity and Disease, 6, 109-122.

Kaiser, C.R., \& Miller, C.T. (2004). A stress and coping perspective on confronting abstract sexism. Psychology of Women Quarterly, 28, 168-178.

Kawakami, K., \& Dion, K.L. (1993). The impact of salient self-identities on relative deprivation and action intentions. European Journal of Social Psychology, 23, 525540.

Kelly, J.R., \& Hutson-Comeaux, S.L. (1999). Gender-emotion stereotypes are context specific. Sex Roles, 40, 107-120.

Keltner, D., Gruenfeld, D. H., \& Anderson, C. (2003). Power, approach, and inhibition. Psychological Review, 110, 265-284.

Kessler, R. C., Mickelson, K. D., \& Williams, D. R. (1999). The prevalence, distribution, and mental health correlates of percieved discrimination in the United States. Journal of Health and Social Behavior, 40(3), 208-230.

Kirschbaum, C., Klauer, T., Filipp, S.H. \& Hellhammer, D.H. (1995). Sex-specific effects of social support on cortisol and subjective responses to acute psychological stress. Psychosomatic Medicine, 57, 23-31.

Klandermans, B. (1997). The social psychology of protest. UK: Basil Blackwell.

Kramer, R.M. \& Tyler, T. R. (1996). Trust in organizations. Frontiers of theory and research. Sage Publications: California.

Kobrynowicz, D., \& Branscombe, N.R. (1997). Who considers themselves victims of 
discrimination? Individual difference predictors of perceived gender discrimination in women and men. Psychology of Women Quarterly, 21, 347-363.

Koss, M.P., Koss, P., \& Woodruff, W. (1991). Deleterious effects of criminal victimization on women's health and medical utilization. Archives of Internal Medicine, 151, 342-357.

Krieger, N. (1999). Embodying inequality: a review of concepts, measures and methods for studying health consequences of discrimination. International Journal of Health Services, 29, 295-352.

Krieger, N., \& Sidney, S. (1996). Racial discrimination and blood pressure: The CARDIA study of young black and white adults. American Journal of Public Health, $86,1370-8$.

Lachman, M. E., \& Weaver, S. L. (1998). Sociodemographic variations in the sense of control by domain: Findings from the MacArthur studies of midlife. Psychology and Aging, 13, 553-562.

Lalonde, R.N., \& Silverman, R.A. (1994). Behavioral preferences in response to social injustice: The effects of group permeability and social identity salience. Journal of Personality and Social Psychology, 66, 78-85.

Lambie, J.A., \& Marcel, A.J. (2002) Consciousness and the varieties of emotion experience: A theoretical framework. Psychological Review, 109, 219-259.

Landrine, H., Klonoff, E.A., Gibbs, J., \& Manning, V. (1995). Physical and psychiatric correlates of gender discrimination: An application of the schedule of sexist events. Psychology of Women Quarterly, 19, 473-492.

Lazarus, R. S. (1999). Stress and emotion. A new synthesis. New York: Springer. 
Lazarus, R.S. (2000). Toward better research on stress and coping. American Psychologist, 55, 665-673.

Lazarus, R. S., \& Folkman, S. (1984). Stress appraisal, and coping. New York: Springer.

Lee, J.A.B., \& Rosenthal, S.J. (1983). Working with victims of violent assault. Journal of Contemporary Social Work, December, 593-601.

Lightsey, O. R. \& Barnes, P.W. (2007). Discrimination, attributional tendencies, generalized self-efficacy, and assertiveness as predictors of psychological distress among African Americans, Journal of Black Psychology, 33, 27-50.

Liss, M, Crawford, M., \& Popp, D. (2004). Predictors and Correlates of Collective Action. Sex Roles, 50(11/12), 771-779.

Louis, W.R., \& Taylor, D.M. (1999). From passive acceptance to social disruption: Towards an understanding of behavioural responses to discrimination. Canadian Journal of Behavioural Science, 31, 19-28.

Mackie, D.M., Devos, T., \& Smith, E.R. (2000). Intergroup emotions: Explaining offensive action tendencies in an intergroup context. Journal of Personality and Social Psychology, 79, 602-616.

Mackie, D.M. \& E.R. Smith (2002). Intergroup emotions and the social self: prejudice reconceptualized as differentiated reactions to out-groups. In J.P. Forgas \& K.D. Williams (Eds.) The social self: Cognitive, interpersonal, and intergroup perspectives. (pp. 309-326). Philadelphia, PA.: Psychology Press.

Major, B., Quinton, W.J., \& McCoy, S.K. (2002). Antecedents and consequences of attribution to discrimination: Theoretical and empirical advances. In M. Zanna (Ed.). Advances in experimental social psychology, Vol. 34 (pp. 251-330). San Diego, CA: 
Academic Press.

Major, B., Quinton, W.J., \& Schmaeder, T. (2003). Attributions to discrimination and self-esteem: Impact of group identification and situational ambiguity. Journal of Experimental Social Psychology, 39, 220-231.

Major, B., \& Schmader, T. (1998). Coping with stigma through psychological disengagement. In J.K. Swim \& C. Stangor (Eds.), Prejudice. The target's perspective (pp. 219-241). San Diego: Academic Press.

Matheson, K. \& Anisman, H. (2003). Systems of coping associated with dysphoria, anxiety, and depressive illness: A multivariate profile perspective. Stress, 6, 223-234.

Matheson, K., \& Anisman, H. (2006). Anger on the flip side: Shame elicited by discrimination in relation to coping and neuroendocrine responses. (under review).

Matheson, K. \& Cole, B. (2004). Coping with a threatened group identity: Psychological and neuroendocrine Responses. Journal of Experimental Social Psychology, 40, 777-786.

Matheson, K., Ofleh, I., Kelly, O. \& Anisman, H. (Feb., 2004). Discrimination as a traumatic event: Implications for psychological and neuroendocrine functioning. Paper presented at the Annual Convention of the Society for Personality and Social Psychology, Austin, TX.

McCallum, R.C., Zhang, S., Preacher, K.J., \& Rucker, D.D. (2002). On the practice of dichotomization of quantitative variables. Psychological Methods, 7(1), 19-40.

McCoy, S. K. \& Major, B. (2003). Group identification moderates emotional responses to perceived prejudice. Personality and Social Psychology Bulletin, 29, 1005-1017.

McGrath, E., Keita, G. P., Strickland, B. R., \& Russo, N. F. (1990). Women and depression: Risk factors and treatment issues. Washington, DC: American Psychological Association. 
McEwen, B.S. Protective and damaging effects of stress mediators. New England J. Med. $338,171-179(1998)$.

Mendoza-Denton, R., Purdie, V., Downey, G., \& Davis, A. (2002). Sensitivity to statusbased rejection: Implications for African-American students' college experience. Journal of Personality and Social Psychology, 83, 896-918.

Mikula, G., Scherer, K. R., \& Athenstaedt, U. (1998). The role of injustice in the elicitation of differential emotional reactions. Personality and Social Psychology Bulletin, 24, 769-783.

Miller, D. (under review). A dual pathway approach of collective action: The multiple routes of two classic correlates of collective action.

Morris-Prather, C. E., Harrell, J.P., Rakale, C., Leonard, K.L., Boss, M., \& Lee, J.W. 1996. Gender differences in mood and cardiovascular responses to socially stressful stimuli. Ethnicity and Disease, 6, 123-131.

Mossakowski, K. N. (2003). Coping with perceived discrimination: Does ethnic identity protect mental health? Journal of Health and Social Behavior, 44(3), 318-331.

Mummedy, A., Kessler, T., Klink., A., \& Mielke, R. (1999). Strategies to cope with negative social identity: Predictions by social identity theory and relative deprivation theory. Journal of Personality and Social Psychology, 76, 229-245.

Noh, S., \& Kaspar, V. (2003). Perceived discrimination and depressions: Moderating effects of coping, acculturation, and ethnic support. American Journal of Public Health, 93(2), 232-238.

Nolen-Hoksema, S. (1990). Sex differences in depression. Stanford, CA: Stanford 
University Press.

Operario, D., \& Fiske, S. T. (2001). Ethnic identity moderates perceptions of prejudice: Judgments of personal versus group discrimination and subtle versus blatant bias. Personality and Social Psychology Bulletin, 27(5), 550-561.

Ochsner, K.N., Bunge, S., Gross, J.J., \& Gabrieli, J. (2002). Rethinking feelings: An fMRI study of the cognitive regulation of emotion. Journal of Cognitive Neuroscience, 14, 1215-1229.

Pak, A., Dion, W.P., \& Dion, K.L., \& Dion, K.K. (1991). Social-psychological correlates of experienced discrimination: Test of the double jeopardy hypothesis. International Journal of Intercultural Relations, 15, 243-254.

Petta, G., \& Walker, I. (1992). Relative deprivation and ethnic identity. British Journal of Social Psychology, 31, 285-293.

Pinel, E.C. (1999). Stigma consciousness: The psychological legacy of social stereotypes. Journal of Personality and Social Psychology, 76, 114-128.

Pogrebin, M.R., \& Poole, E.D. (1997). The sexualized work environment: A look at women jail officers. The Prison Journal, 77, 41-57.

Power and Precision. (2000). http://www.power-analysis.com/

Public Service Employee Survey. (2005). http;//www. Psagencyfp.gc.ca/surveysondage/2005/results-resultants/04/result-e.htm.

Reisenzein, R., \& Hofmann, T. (1990). An investigation of dimensions of cognitive appraisal in emotion using the repertory grid technique. Motivation and Emotion, 14, 1-25. 
Ren, X.S., Amick, B.C., \& Williams, D.R. (1999). Racial/ethnic disparities in health: the interplay between discrimination and socioeconomic status. Ethnicity and Disease, $9(2), 151-165$.

Riggs, D.S., Dancu, C.V., Gershuny, B.S., Greenberg, D., \& Foa, E.B. (1992). Anger and post-traumatic stress disorder in female crime victims. Journal of Traumatic Stress, 5(4), 613-625.

Robins, C. (1988). Development of experimental mood induction procedures for testing person event interaction models of depression. Journal of Clinical Psychology, 44, 938-963.

Robson, K. \& Wallace, J.E. (2001). Gendered inequalities in earnings: A study of Canadian Lawyers. Canadian Review of Sociology and Anthropology, 38(1), $75-95$.

Roseman, I. J., Spindel, M. S., \& Jose, P. E. (1990). Appraisals of emotion-eliciting events: Testing a theory of discrete emotions. Journal of Personality and Social Psychology, 59, 899-915.

Roth, L.M. (2003). Selling women short: A research note on gender differences in compensation on Wall Street. Social Forces, 82, 783-802.

Ruggiero, K.M., \& Taylor, D.M. (1997). Why minority group members perceive or do not perceive the discrimination that confronts them: The role of self-esteem and perceived control. Journal of Personality and Social Psychology, 72, 373-398.

Rutte, C.G., Diekman, K., \& Polzer, J.T. (1994). Organization of information and the detection of gender discrimination. Psychological Science, 5, 226-231. 
Russo, N.F. \& Green, B.L. (1993). Women and mental health. In F.L. Denmark \& M.A. Paludi (Eds.), Psychology of Women: A Handbook of Issues and Theories. Westport, $\mathrm{CN}$ : Greenwood Press.

Scherer, K. R. (2001). Appraisal considered as a process of multilevel sequential checking. In K. R. Scherer, A. Schorr, \& T. Johnstone, (Eds.). Appraisal processes in emotion: Theory, methods, Research. (pp. 92-120). Oxford University Press.

Schmitt, M. T., Branscombe, N. R., Kobrynowicz, D., \& Owen, S. (2002). Perceiving discrimination against one's gender group has different implications for well-being in women and men. Personality and Social Psychology Bulletin, 28(2), 197-210.

Scott, L.D., \& House, L.E. (2005). Relationship of distress and perceived control to coping with perceived racial discrimination among Black youth. Journal of Black Psychology, 31, 254-272.

Settles, I.S., Cortina, L.M., Malley, J., Stewart, A.J. (2006). The climate for women in academic science: The good, the bad, and the changeable. Psychology of Women Quarterly, 30(1), 47-58.

Shelton, J. N., \& Sellers, R. M. (2000). Situational stability and variability in African American racial identity. Journal of Black Psychology, 26, 27-50.

Simon, B., Loewy, M., Stürmer, S., Weber, U., Freytag, P., Habig, C., Kampmeier, C., \& Spahlinger, P. (1998). Collective identification and social movement participation. Journal of Personality and Social Psychology, 74, 646-658.

Smith, C. A., \& Lazarus, R. S. (1993). Appraisal components, core relational themes, and the emotions. Cognition and Emotion, 7, 233-269.

Smith, E. R. (1993). Social identity and social emotions: Toward new conceptualizations 
of prejudice. In Mackie, D. M., D. L. Hamilton (Eds). Affect, cognition, and stereotyping: Interactive processes in group perception. (pp. 297-315). San Diego, CA, US: Academic Press, Inc.

Smith, E.R. (1999). Affective and cognitive implications of a group becoming a part of the self: New models of prejudice and of the self-concept.

Smith, E. R., \& Mackie, D. M. (2000). Social psychology (2nd ed.). New York, NY, US: Psychology Press.

Smith, H.J., \& Kessler, T. (2004). Group-based emotions and intergroup behavior: The case of relative deprivation. In L.Z. Tiedens \& C.W. Leach (Eds.) The social life of emotions (pp. 292-313). Cambridge, UK: Cambridge University Press.

Solomon, S., Greenberg, J., \& Pyszczynski, T. (1992). A terror management theory of self-esteem and its role in social behavior. In M.P. Zanna (Ed.), Advances in Experimental Social Psychology, 24, 93-159. New York: Academic Press.

Statistics Canada (2000). Women in Canada 2000: A gender-based statistical report. Statistics Canada Catalogue no. 89-503-XPE.

Stanton, A.L., Danoff-Burg, S., Cameron, C.L., Bishop, M., Collins, C.A., Kirk, S.B., \& Sworowski, L.A. (2000). Emotionally expressive coping predicts psychological and physical adjustment to breast cancer. Journal of Consulting and Clinical Psychology, $68(5), 875-882$.

Staub, E. (1996). Moral exclusion, personal goal theory, and extreme destructiveness. Journal of Social Issues, 46, 47-64.

Stryker, S., Owens, T. J., \& White, R. W. (2000). Self, Identity, and Social Movements. Minneapolis, MN: University of Minnesota Press. 
Sutherland, M. E., \& Harrell, J.P. 1986. Individual differences in physiological responses to fearful, racially noxious, and neutral imagery. Imagination, Cognition, and Personality, 6, 133-149.

Swim, J. K., Everyday Sexism: Evidence for Its Incidence, Nature, and Psychological Impact From Three Daily Diary Studies. Journal of Social Issues 57 (Spring 2001): $31-53$.

Swim, J.K., Hyers, L.L., Cohen, L.L., Fitzgerald, D.C., \& Bylsma, W.H. (2003). African American college students' experiences with everyday racism: Characteristics of and responses to these incidents. Journal of Black Psychology, 29, 38-67.

Tajfel, H., \& Turner, J. (1979). An integrative theory of intergroup conflict. In W. Austin \& S. Worchel (Eds.), The social psychology of intergroup relations (pp. 33-47). CA: Brooks/Cole.

Tajfel, H., \& Turner, J. (1986). The social identity theory of intergroup behavior.

In S. Worchel \& W. Austin (Eds.), Psychology of intergroup relations, pp. 33-48, Chicago: Nelson-Hall.

Tangney, J.P., Wagner, P., Fletcher, C., Gramzow, R. (1992). Shamed into anger? The relation of shame and guilt to anger and self-reported aggression. Journal of Personality and Social Psychology, 62, 669-675.

Taylor, D.M., Wright, S.C., Moghaddam, F.M., \& Lalonde, R.N. (1990). The personal/group discrimination discrepancy: Perceiving my group, but not myself to be a target of discrimination. Personality and Social Psychology Bulletin, 16, 254-262.

Taylor, D.M., Wright, S.C., \& Ruggiero, K.M. (1991). The personal/group discrimination discrepancy: Responses to experimentally induced personal and group 
discrimination. Journal of Social Psychology, 131, 847-858.

Tesser, A. (1990). Smith and Ellsworth's appraisal model of emotion: A replication, extension, and test. Personality and Social Psychology Bulletin, 16, 210-223.

Tracy, J.L., \& Robins, R.W. (2004). Putting the self into self-conscious emotions: A theoretical model. Psychological Inquiry, 15, 103-125.

Tougas, F., \& Veilleaux, F. (1988). The influence of identification, collective relative deprivation, and procedure of implementation of women's response to affirmative action: A casual modelling approach. Canadian Journal of Behavioral Science, 20, $15-28$.

Tropp, L. R., \& Wright, S. C. (1999). Ingroup identification and relative deprivation: An examination across multiple social comparisons. European Journal of Social Psychology, 29, 707-724.

Twiss, C., Tabb, S., \& Crosby, F. (1991). Affirmative action and aggregate data: The Importance of patterns in the perception of discrimination. Oxford University Press.

Ullah, P. (1987). Self-Definition and Psychological Group Formation in an Ethnic Minority. British Journal of Social Psychology 26, 17-23.

van Zomeren, M., Spear, R., Fischer, A.H., \& Leach, C.W. (2004). Put your money where your mouth is! Explaining collective action tendencies through group-based anger and group efficacy. Journal of Personality and Social Psychology, 87, 649-664.

Walker, I., \& Mann, L. (1987). Unemployment, relative deprivation, and social protest. Personality and Social Psychology Bulletin, 13, 275-283.

Wallston, K.A., Wallston, B.S., Smith, S., \& Dobbins, C.J. (1987). Perceived control and health. Current Psychological Research and Reviews, 6, 5-25. 
Wright, S.C., Taylor, D.M., \& Moghaddam, F.M. (1990). Responding to membership in a disadvantaged group from acceptance to collective protest. Journal of Personality and Social Psychology, 58, 994-1003.

Wright, S. C., \& Tropp, L. R. (2002). Collective action in response to disadvantage: Intergroup perceptions, social identification, and social change. In I. Walker \& H. Smith (Eds.), Relative deprivation: Specification, development, and integration. (pp. 200-236). Cambridge: Cambridge University Press.

Yassen, J., \& Glass, L. (1984). Sexual assault survivors groups: A feminist practice perspective. Social Work, May-June, 252-257.

Yzerbyt, V., Dumont, M., Wigboldus, D., \& Gordijn, E. (2003). I feel for us: The impact of categorization and identification on emotions and action tendencies. British Journal of Social Psychology, 42, 533-49.

Zanna, M.P., Crosby, F., \& Lowenstein, G. (1987). Male reference groups and discontent among female professionals. In B.A. Gutek \& L. Larwood (Eds.), Women's career development (pp. 28-41). Thousand Oaks, CA: Sage Publications. 


\section{Appendix A}

\section{Verbal Instructions: Study 1}

Hello, my name is and I am a graduate student working on a project concerned with creative abilities as they're expressed in writing and storytelling. We're attempting to determine what characteristics might be associated with people who are highly creative. Creative ability is essential to succeed in today's job market in which information is available quickly and easily and so people need to find creative ways to organize information and ideas to understand it. We've found that employers are interested in identifying the characteristics associated with these highly creative individuals so that they can hire the best people. We're also looking at creativity in terms of how it differs across academic background, for instance, psychology vs computer science vs English vs engineering etc.

The study will take approximately 1 hour. Before we begin I will ask you to complete these 2 items: an informed consent form, which states what the study is about, that we have your permission to use the results in research publications, you have the right to withdraw etc. If you excuse me for a moment, I have to explain this to other students participating in the rooms next door.

\section{Experimenter leaves and returns a few minutes later. Items are collected.}

Now you will be asked to read a short story. While reading this story I would like for you to pretend that you are the student in the story; in other words, whatever the student is thinking/feeling, you are also thinking/feeling. After reading the story, we'll ask you to write/respond to the short story using 12 words we give you as though you are the student in the story. We will want you to be as creative in your response and your ability to work with the 12 words as you can. After completing this task, your story will be scored by one of five male students from engineering that we currently have working in this lab, as we're collaborating on some parts of this research, as you will find out later on in the study. Based on the score given by this engineering student you'll be placed in the high creativity group if you achieve a passing grade, or if your score is low, we'll be putting you in the low creativity group. Those who qualify for the high creativity group are viewed as possessing superior, more advanced creative abilities. You will have to obtain a minimum cut-off mark of $80 \%$ on the creativity task, in order to be considered for as a highly creative individual. If you fail to meet this score then you will be placed in the low status creativity group. Those who make it to the high creativity group will work with the engineering student to try to improve the stories written by those in the low creativity group. However, those in the low creativity group will be working with myself and I will ask them to complete a basic skills task which includes sentence completion and alphabetizing. The purpose of the low creativity group completing these tasks is to allow us to assess the relation between poor language and writing skills and lack of creativity. Clearly though their work isn't as important here or in real life, those in the high creativity group will qualify for the $\$ 100$ lottery, while those who are in the low creativity group are only eligible for the $\$ 10$. Also, considering that those placed in the 
low status group are not viewed as competent, they will only receive half of a credit as opposed to 1 full credit as the task was not successfully completed.

Participants are given 15 minutes to complete the task.

Before the experimenter exits the room, in front of the participant she writes the name of the participant on the front of the story. After 15 minutes the experimenter returns and collect the story.

Now we're moving on to the second creativity task. This part of the creativity task will be used for those in the high creative group. (For those in the sad condition): Take a few minutes to think of something that happened in your life, or you have known to happen to someone else that made you feel very sad or depressed. Once you remember what made you feel this way, take a few minutes to write about it on this blank piece of paper. (For those in the anger condition): Take a few minutes to think of something that happened in your life, or you have known to happen to someone else that made you feel very angry. Once you remember what made you feel this way, take a few minutes to write about it on this blank piece of paper. (For those in the control condition): Take a few minutes to think of something that happened in your life, or you have known to happen to someone else that inspired a creative moment within you; it could be reading a short story, watching a movie or play. Once you remember what made you feel this way, take a few minutes to write about it on this blank piece of paper. While you are completing this task I'll hand your story to one of the judges to grade.

Following the completion of this task, subjects will be asked to complete an emotion rating scale.

After 3-5 minutes a male experimenter enters the room and returns with the graded story. He hands it back to the participant, he mumbles to himself: 'These guys never pass any of the women". The story is handed back to the participant with a 'LOW' in red lettering marked on the front of the paper. He also indicates on the blackboard the number of women who have failed the task, and the number of men to emphasize that only men are being passed into the high status group and exits the room.

Female experimenter: So this means that you are in the low creativity group and will qualify for the $\$ 5$ lottery. You also will not receive the credit. We still have some questionnaires that we need you to complete to see how well we can differentiate between high and low creative people.

The female experimenter then addresses those in the suppression condition and gives them the following instructions: 
Despite your group assignment, it is important to your performance in the rest of this study that you try to be logical and reasonable, and not emotional. If you have any feelings during the remainder of the study, do not let those feelings show. Try to act in such a way that a person watching you would not know you were feeling anything. This is important as it assures that you maintain your composure and act in a professional manner regardless of what group you were placed in.

Those in the expression condition:

Despite your group assignment, it is important to your performance in the rest of this study that you make sure that you try to express your emotions and feelings as much as possible. As we continue on in the experiment, I would like for you to feel free to express any thoughts, feelings, questions, or concerns you have. Feel free to openly express your views and share them in any of the questions we ask you, and in your responses to the task that we'll be asking you to. This is important as it assures that your responses reflect a sense of commitment and professional concern regardless of what group you were placed in.

Those in control condition given no instructions.

Before you begin the low status task, you will need to complete these questionnaires.

After the questionnaire packages have been finished and collected, participants will be debriefed and informed of the true nature of the experiment. They will be given 1 experimental credit and contact numbers. Participants will then be given the positive task to ensure that they leave the experiment in a neutral/happy mood.

Now I will ask you to read this short monologue by Dennis Miller and then respond to it. 


\section{Appendix B}

\section{Informed Consent Form: Study 1}

The purpose of an informed consent form is to ensure that you understand the purpose of the study and the nature of your involvement. The informed consent must provide sufficient information such that you will have the opportunity to determine whether or not you wish to participate in the study.

Research Title: Examining Creative Abilities through Storytelling

Research Personnel: The following people are involved in this research project and may be contacted at any time. Ritu Gill (Principal investigator, 520-2600 ext.2683), Dr. Kim Matheson (Faculty Investigator and Chair, Department of Psychology, 520-2648). Should you have any ethical concerns then please contact Dr. Gick (Chair, Carleton University Research Ethics Committee for Psychological Research, 520-2600 ext.1155).

Purpose and Task Requirements: The purpose of this study is to examine the relation between high and low creative abilities and story writing. You will be asked to complete two creativity tasks, consisting of reading and writing a short story. You will also be asked to complete several questionnaires, some of which may ask for sensitive information, such as emotions, mood, health and medication use. The study will take approximately 1 hour.

Potential Risk/Discomfort: There are no potential physical or psychological risks, or potential for embarrassment in this study. There may be some stress associated with personal expectations of performance.

Anonymity/Confidentiality: The data collected in this study will remain anonymous and confidential. All data will be coded such that your name is not associated with the data. In addition the coded data are made available only to researchers associated with this project.

Right to withdraw: Your participation in this study is entirely voluntary. At any point during the study you have the right to not complete certain questions or to withdraw with no penalty whatsoever.

Signatures: I have read the above description of the study concerning creativity abilities and story writing. The data in this study will be used in research publications or for teaching purposes. My signature indicates I agree to participate in the study, and this in no way constitutes a waiver of my rights.

\section{Participant's Name: \\ Participant's Signature: \\ Researcher's Name: \\ Researcher's Signature: \\ Date:}




\section{Appendix C}

\section{Story}

Please read and imagine the events of the following story with yourself acting as the protagonist (e.g., the student). To do this, try to imagine yourself in the shoes of the student. Pay attention to your reactions and how you would feel as the events occurred to you. You have 15 minutes to read and write the short story. Try to be as clear as possible when using the 12 words to write the story.

You have been at the university for only a short time and you have found it a difficult transition in some ways. In particular, you have found that it is much more difficult academically than high school was. You have always been a good student and it is very important to you to continue to do well. Aside from what it means for your future after graduation, good grades are important for you to feel good about yourself.

This semester, although you have been working hard, you find the material for some of your classes difficult to understand and remember. In one course that was very important to your future plans, your final grade was much lower than you expected considering the amount of work you put in. You asked the professor who graded the final paper to take another look at it and have set an appointment with him to discuss it.

Imagine now that you have arrived for the appointment and are now in the professor's office. This is what he has to say: 'Well I took another look at your paper as you asked me to and it's not really a bad paper, but there are definitely some holes in it. Places where you forgot something or didn't mention something important, or you mention something and just do not develop it at all. I don't have time to go into all the problems with you now, but I spent a lot of time re-examining you paper and I've made plenty of comments in the margins so you can see where the problems are. In general, I wonder whether you really understood the question properly. A lot of what you wrote here leads me to think that you misinterpreted it, and as a result went off in left field a few times. Also, your style here is very abstract and wordy. You need to learn to be more concrete and to the point. Now, I'm really sorry that you're disappointed with the grade. I would've gladly helped you with any problems if you had come to me earlier in the semester, but it's too late now. There's really nothing I can do to help you at this point. Your paper looks pretty much the same to me on the second reading, and if you want to stay and try to show me that I've overlooked something or misinterpreted something, but I don't anticipate changing the grade at all. If you really have to have a better grade you'll just have to take the course again'.

You leave the professor's office feeling that he had done all he reasonably could and wondering if perhaps you didn't have the ability to perform at the required level. As you know, you did work hard on the paper. You are particularly concerned because you had intended to take several other courses in that area. Now you wonder if you should or could. You can't stop thinking about your situation at school, the hard work you put in, the poor grade, the professor won't change his opinion, and what this means for your future plans. 
Sad Word List

Now that you have read the story and imagined yourself in the student's shoes, we would like to know how you feel about what occurred and your reactions. To do so, we would like you to rewrite the story. When you rewrite the story, we want you to be as imaginative as possible and to convey as accurately as possible how you are feeling in the scenario. We also want you to include the following 12 words in your story. It is important to our ability to assess your creativity that you use all 12 words in your story. They may be used in any order.

1. sad

2. student

3. classmates

4. career

5. hopeless

6. grade

7. discouraged

8. professor

9. helpless

10. classroom

11. despair

12. university 


\section{Angry Word List}

Now that you have read the story and imagined yourself in the student's shoes, we would like to know how you feel about what occurred and your reactions. To do so, we would like you to rewrite the story. When you rewrite the story, we want you to be as imaginative as possible and to convey as accurately as possible how you are feeling in the scenario. We also want you to include the following 12 words in your story. It is important to our ability to assess your creativity that you use all 12 words in your story. They may be used in any order.

1. angry

2. student

3. classmates

4. career

5. resentful

6. grade

7. irritated

8. professor

9. infuriated

10. classroom

11. hostile

12. university 


\section{Appendix D}

\section{Filler Task}

For those in the sad condition:

Take a few minutes to think of something that happened in your life, or you have known to happen to someone else that made you feel very sad or depressed. Once you remember what made you feel this way, take a few minutes to write about it on this blank piece of paper.

For those in the anger condition:

Take a few minutes to think of something that happened in your life, or you have known to happen to someone else that made you feel very angry. Once you remember what made you feel this way, take a few minutes to write about it on this blank piece of paper. 
Appendix E

Emotion Rating Scale

This questionnaire consists of adjectives that may describe the way you presently feel, as you imagined yourself in the story. Using the scale below each item, please indicate how much each adjective describes how you currently feel by circling the number that most closely corresponds to your feelings.

Not at all

$\begin{array}{llllllll}\text { Hopeless } & 1 & 2 & 3 & 4 & 5 & 6 & 7 \\ \text { Frustrated } & 1 & 2 & 3 & 4 & 5 & 6 & 7 \\ \text { Worried } & 1 & 2 & 3 & 4 & 5 & 6 & 7 \\ \text { Anxious } & 1 & 2 & 3 & 4 & 5 & 6 & 7 \\ \text { Sad } & 1 & 2 & 3 & 4 & 5 & 6 & 7 \\ \text { Pleased } & 1 & 2 & 3 & 4 & 5 & 6 & 7 \\ \text { Angry } & 1 & 2 & 3 & 4 & 5 & 6 & 7 \\ \text { Alert } & 1 & 2 & 3 & 4 & 5 & 6 & 7 \\ \text { Confused } & 1 & 2 & 3 & 4 & 5 & 6 & 7 \\ \text { Relaxed } & 1 & 2 & 3 & 4 & 5 & 6 & 7 \\ \text { Hostile } & 1 & 2 & 3 & 4 & 5 & 6 & 7 \\ \text { Unhappy } & 1 & 2 & 3 & 4 & 5 & 6 & 7 \\ \text { Indifferent } & 1 & 2 & 3 & 4 & 5 & 6 & 7 \\ \text { Depressed } & 1 & 2 & 3 & 4 & 5 & 6 & 7 \\ \text { Calm } & 1 & 2 & 3 & 4 & 5 & 6 & 7 \\ \text { Infuriated } & 1 & 2 & 3 & 4 & 5 & 6 & 7 \\ \text { Happy } & 1 & 2 & 3 & 4 & 5 & 6 & 7 \\ \text { Helpless } & 1 & 2 & 3 & 4 & 5 & 6 & 7 \\ \text { Desolate } & 1 & 2 & 3 & 4 & 5 & 6 & 7\end{array}$




\section{Appendix F}

\section{Questionnaires: Study 1}

Discrimination Questionnaire

Using the scale below please answer each of the following questions honestly.

1. To what extent do you feel that the creativity task in this study accurately reflects your creative abilities

$\begin{array}{llllllllll}\text { Not at all } & 0 & 1 & 2 & 3 & 4 & 5 & 6 & 7 & \text { Very Much }\end{array}$

2. To what extent do you feel that a different story would have encouraged you to feel more creative?

$\begin{array}{llllllllll}\text { Not at all } & 0 & 1 & 2 & 3 & 4 & 5 & 6 & 7 & \text { Very Much }\end{array}$

3. To what extent do you feel that in this study creative abilities should have been evaluated using a method other than story writing?

$\begin{array}{llllllllll}\text { Not at all } & 0 & 1 & 2 & 3 & 4 & 5 & 6 & 7 & \text { Very Much }\end{array}$

4. To what extent were you personally discriminated against because you are a woman in the context of this experiment?

$\begin{array}{llllllllll}\text { Not at all } & 0 & 1 & 2 & 3 & 4 & 5 & 6 & 7 & \text { Very Much }\end{array}$

5. To what extent do you feel writing the story using the word list restricted your creativity?

$\begin{array}{llllllllll}\text { Not at all } & 0 & 1 & 2 & 3 & 4 & 5 & 6 & 7 & \text { Very Much }\end{array}$

6. To what extent do you feel given more time to create a story would have improved the creative quality of your story?

$\begin{array}{llllllllll}\text { Not at all } & 0 & 1 & 2 & 3 & 4 & 5 & 6 & 7 & \text { Very Much }\end{array}$

7. To what extent do you feel that the topic of the story restricted your creative flow? $\begin{array}{llllllllll}\text { Not at all } & 0 & 1 & 2 & 3 & 4 & 5 & 6 & 7 & \text { Very Much }\end{array}$

8. To what extent do you feel that women as a group were discriminated against in the context of this experiment?

$\begin{array}{llllllllll}\text { Not at all } & 0 & 1 & 2 & 3 & 4 & 5 & 6 & 7 & \text { Very Much }\end{array}$

9. To what extent do you feel that women in the 'career world' are discriminated against?

$\begin{array}{llllllllll}\text { Not at all } & 0 & 1 & 2 & 3 & 4 & 5 & 6 & 7 & \text { Very Much }\end{array}$ 


\section{Perceived Control Questionnaire}

Please answer the following questions honestly.

1. How good do you think you are at creative tasks like this one?

$\begin{array}{cccccccc}0 & 1 & 2 & 3 & 4 & 5 & 6 & 7 \\ \text { Not at all } & & & & & & & \text { Very Much }\end{array}$

2. How much do you think you would improve on this creative task with practice?

$\begin{array}{cccccccc}0 & 1 & 2 & 3 & 4 & 5 & 6 & 7 \\ \text { Not at all } & & & & & & & \text { Very Likely }\end{array}$

3. How likely is it that you would be placed in the high creativity group if you did this creativity task again and had the same primary experimenter read your story?

$\begin{array}{cccccccc}0 & 1 & 2 & 3 & 4 & 5 & 6 & 7 \\ \text { Not Likely } & & & & & & & \text { Very Likely }\end{array}$

4. How likely is it that you would be placed in the high creativity group if you did this creativity task again and had a different experimenter read your story?

Not Likely $\quad$ Very Likely

5. Would it be better to meet the primary experimenter before he reads your story?

Not at all

$\begin{array}{llllllll}0 & 1 & 2 & 3 & 4 & 5 & 6 & 7 \\ \text { all } & & & & & & & \text { Very Much }\end{array}$

6. Would it be better to meet the primary experimenter before he reads your story so that you can have some input into which group you should be placed in?

Not at all

$\begin{array}{llllllll}0 & 1 & 2 & 3 & 4 & 5 & 6 & 7\end{array}$

Very Much

7. If you met with the primary experimenter, how do you think you would get along?

$\begin{array}{ccccccccl}0 & 1 & 2 & 3 & 4 & 5 & 6 & 7 \\ \text { Not very well } & & & & & & \text { Very Well }\end{array}$

8. Do you think that by meeting the primary experimenter in person you could get him to judge you solely on the quality of your work?

Not at all

$$
\begin{array}{llll}
2 & 3 & 4 & 5
\end{array}
$$

$5 \quad 6 \quad 7$

Very Likely 


\section{Action and Action Efficacy Survey}

Please indicate the extent to which you would participate in the following actions if you had the opportunity to respond to your group assignment in the present study.

1. Accept the situation, that is, your assignment to either group, as is.

$\begin{array}{lcllllll}0 & 1 & 2 & 3 & 4 & 5 & 6 & 7 \\ \text { Not at all } & & & & & & \text { Very Much }\end{array}$

2. Request an individual retest of your creativity score.

$\begin{array}{lcllllll}0 & 1 & 2 & 3 & 4 & 5 & 6 & 7 \\ \text { Not at all } & & & & & & \text { Very Much }\end{array}$

To what extent do you think this action would be difficult to implement?

$\begin{array}{lccccccl}0 & 1 & 2 & 3 & 4 & 5 & 6 & 7 \\ \text { Not at all } & & & & & & \text { Very Much }\end{array}$

To what extent would this action improve your personal status in this study?

$\begin{array}{lccccccl}0 & 1 & 2 & 3 & 4 & 5 & 6 & 7 \\ \text { Not at all } & & & & & & \text { Very Much }\end{array}$

To what extent would this action improve the procedures in this study to allow other participants to be evaluated fairly?

$\begin{array}{llllllll}0 & 1 & 2 & 3 & 4 & 5 & 6 & 7 \\ \text { Not at all } & & & & & & \text { Very Much }\end{array}$

3. Confront the experimenter and demand an explanation of your particular group assignment.
$\begin{array}{lr}0 & 1 \\ \text { Not at all }\end{array}$
23
$4 \quad 5$
$5 \quad 6$
$6 \quad 7$
Not at all
Very Much

To what extent do you think this action would be difficult to implement?

$\begin{array}{lcllllll}0 & 1 & 2 & 3 & 4 & 5 & 6 & 7 \\ \text { Not at all } & & & & & & \text { Very Much }\end{array}$

To what extent would this action improve your personal status in this study?

$\begin{array}{llllllll}0 & 1 & 2 & 3 & 4 & 5 & 6 & 7\end{array}$


Not at all

Very Much

To what extent would this action improve the procedures in this study to allow other participants to be evaluated fairly?

$\begin{array}{lccccccc}0 & 1 & 2 & 3 & 4 & 5 & 6 & 7 \\ \text { Not at all } & & & & & & \text { Very Much }\end{array}$

4. Ask that all of the women be retested for their creativity.

$\begin{array}{llllllll}0 & 1 & 2 & 3 & 4 & 5 & 6 & 7 \\ \text { Not at all } & & & & & & \text { Very Much }\end{array}$

To what extent do you think this action would be difficult to implement?

$\begin{array}{lccccccl}0 & 1 & 2 & 3 & 4 & 5 & 6 & 7 \\ \text { Not at all } & & & & & & \text { Very Much }\end{array}$

To what extent would this action improve your personal status in this study?

$\begin{array}{lcccccccc}0 & 1 & 2 & 3 & 4 & 5 & 6 & 7 \\ \text { Not at all } & & & & & & \text { Very Much }\end{array}$

To what extent would this action improve the procedures in this study to allow other participants to be evaluated fairly?

$\begin{array}{lccccccl}0 & 1 & 2 & 3 & 4 & 5 & 6 & 7 \\ \text { Not at all } & & & & & & \text { Very Much }\end{array}$

5. Get together with other women to confront the experimenter, demanding an explanation for your group assignment.

$\begin{array}{lccccccl}0 & 1 & 2 & 3 & 4 & 5 & 6 & 7 \\ \text { Not at all } & & & & & & \text { Very Much }\end{array}$

To what extent do you think this action would be difficult to implement?

$\begin{array}{lccccccl}0 & 1 & 2 & 3 & 4 & 5 & 6 & 7 \\ \text { Not at all } & & & & & & \text { Very Much }\end{array}$

To what extent would this action improve your personal status in this study? 


$\begin{array}{lrllllll}0 & 1 & 2 & 3 & 4 & 5 & 6 & 7 \\ \text { Not at all } & & & & & & \text { Very Much }\end{array}$

To what extent would this action improve the procedures in this study to allow other participants to be evaluated fairly?

$\begin{array}{lccccccl}0 & 1 & 2 & 3 & 4 & 5 & 6 & 7 \\ \text { Not at all } & & & & & & \text { Very Much }\end{array}$




\section{Specific Responses}

Please indicate the extent to which you would be willing to initiate the following responses to your experience in this study:

1. I would ask volunteers to sign a petition against participating in this study.

$\begin{array}{lccccccl}0 & 1 & 2 & 3 & 4 & 5 & 6 & 7 \\ \text { Not at all } & & & & & & \text { Very Much }\end{array}$

2. I would not do anything, however if another individual initiated a response I would be willing to participate.

$\begin{array}{lcllllll}0 & 1 & 2 & 3 & 4 & 5 & 6 & 7 \\ \text { Not at all } & & & & & & \text { Very Much }\end{array}$

3. I would not do anything, and if another individual initiated a response I would not participate.

$\begin{array}{lcllllll}0 & 1 & 2 & 3 & 4 & 5 & 6 & 7 \\ \text { Not at all } & & & & & & \text { Very Much }\end{array}$

4. I would go to the chair to make a complaint about the procedures of this study.

$\begin{array}{llllllll}0 & 1 & 2 & 3 & 4 & 5 & 6 & 7 \\ \text { Not at all } & & & & & & \text { Very Much }\end{array}$

5. I would like to drop out of the experiment. In so doing, I understand that I will not be granted the chance to participate in any lottery, nor will I be eligible for future studies that pay participants for their time.

$\begin{array}{llllllll}0 & 1 & 2 & 3 & 4 & 5 & 6 & 7 \\ \text { Not at all } & & & & & & \text { Very Much }\end{array}$

6. I would like to stay in the experiment so that I can participate in the low status group's $\$ 10$ lottery and receive .5 of an experimental credit at the end of the study. $\begin{array}{llllllll}0 & 1 & 2 & 3 & 4 & 5 & 6 & 7 \\ \text { Not at all } & & & & & & \text { Very Much }\end{array}$

7. I would like to take a retest in a second attempt to become a member of the high status group. 


$\begin{array}{cccccccc}0 & 1 & 2 & 3 & 4 & 5 & 6 & 7 \\ \text { Not at all } & & & & & & & \text { Very Much }\end{array}$

8. I would like to solicit the support of other low status group members in the form of a petition that I will organize. The aim of the petition is to persuade the scorers to change their evaluation procedures.

$\begin{array}{llllllll}0 & 1 & 2 & 3 & 4 & 5 & 6 & 7\end{array}$

Not at all Very Much




\section{Appendix G}

Perceptions of the study Questionnaire

We would like to make sure that you understood the nature of this study. To do so, we'd like you to complete the following questions. Point form responses are fine.

1. In your opinion, what was this study about?

2. What do you think we hope to find?

3. Is there anything about the conduct of this study that did not make sense to you (ie. things the experimenters said or did, or questions we asked that seemed 'out of place'?)

4. To what extent do you feel this study was sexist? 


\title{
Appendix $\mathrm{H}$
}

\author{
Debriefing
}

Study:

Personal Group Discrimination Discrepancy: Moderating effects of emotions and emotional reactions.

\section{Background and Purpose of Study:}

In this study we were examining a phenomenon known as the personal group discrimination discrepancy, which asserts that members of a minority group deny personal experiences of discrimination, yet acknowledge that discrimination against their group exists. In this study we are interested in examining the effects of women's emotional reactions to situations of discrimination and on their perceptions and responses to the discrimination. In particular, we believe that if women are sad or depressed they will be more likely to be accepting of the discrimination and be more likely to attribute it to factors about themselves, and to feel helpless to change the situation. In contrast, if women's emotional response is anger, they may be less likely to attribute the discrimination to something about themselves, and to feel more empowered to take action to counter the source of discrimination. In order to assess the expectations, we want to prime women's emotional state prior to encountering the discriminatory situation.

Deception was involved in this study in that it suggests that we are concerned about creativity when it is not. In some studies, if we tell people what the purpose of the experiment is and what we predict about how they will react under certain conditions, then they might deliberately do whatever it is they think we want them to do. If that happened, their reactions would not be a good indication of how they might react in a situation in everyday life, where they didn't think they were being studied. What would be influencing them is what they thought the purpose of our study was rather than the specific conditions that we are trying to investigate. It is also possible that the opposite might occur and that people may think that if we predicted that they would do a certain thing, they might purposely not do that to show us we can't figure them out. That would also make the results invalid, because again what people would be responding to is what they thought we were looking for rather than responding naturally as they would in everyday situation. The purpose of reading and writing a short story was to induce an angry, sad, or neutral mood. Once this mood was primed, we then asked participants to complete an emotion rating scale to ensure that the desired mood was elicited. Following this, we then posed a situation of discrimination in which the male experimenter did not accept women in the high status group simply because they were women.

We then asked some participants to suppress their behavior in order to examine the potential effects of inhibition of behavior and expression on the denial of discrimination. We also encouraged some participants to freely express their views regarding the study in order to assess the effects of expression on the denial of discrimination. We also used a group that received no instruction. We then administered several questionnaires to evaluate affective, cognitive, and behavioral effects on the 
denial of personal discrimination. We asked participants to complete one questionnaire which assessed the extent to which women in this study minimized personal discrimination relative to group discrimination. Another questionnaire evaluated the extent to which participants believed 5 factors played a role in determining what group she was placed in, including her sex, luck, effort, and personal competence. Another questionnaire assessed the participants' perception of control; in other words the extent to which women felt competent about their performance (in the creativity task of creating a story) and the extent to which participants' perceived personal control over social aspects of the experiment. Finally, an 'action' survey was given to determine if participants would be willing to participate in any set of actions if they had the opportunity to respond to the treatment in the present study.

We also asked participants to read the Dennis Miller monologue to ensure that no one left the study feeling upset. The purpose of not giving credit when assigned to the low status group was to make the participants feel bad about not being assigned to the high status group and making them care about wanting to be in the high status group.

\section{Questions and Comments:}

If you have any questions about this research, or are interested in the results of this study, please feel free to contact Ritu Gill, the principal investigator (520-2600 ext. 2683) or Dr. Kim Matheson, the research supervisor (520-2600 ext. 2648). If you have any concerns about the ethics of this study, please refer them to Dr. Monique Senechal, Carleton University Research Ethics Committee for Psychological Research (520-2600 ext. 1155). Should you have any other concerns about this study please refer them to Dr. Kim Matheson, Chair of the Psychology Department (520-2600 ext. 2648). 


\section{Appendix I}

Observations by Dennis Miller (Comedian)

Please read the following script by Dennis Miller. Do not take any of the jokes seriously, they are just simple observations made by Dennis Miller and are not meant to offend anyone.

College Life Now I don't want to get off on a rant here, but is there any four-ten year period of your life more glorious than college?

Ah, college. What other institution charges you ninety grand to prepare you for a $\$ 20,000$ a year job?

And by the way, I don't think you should have to pay back college loans unless you get a job in your field. Put some pressure on the school. If I can't pay my bills, I'm not paying yours.

When I went to college, I lived on campus, and the guys I hung out with made the characters in Revenge of the Nerds look like the Rat Pack in 1962. I remember finally breaking down and trying to wash a pair of socks by shaking them around in a rinsed-out Skippy peanut butter jar full of hot water and a squeeze of Colgate Tartar Control toothpaste.

Now, my sophomore year, I had three completely different roomates: Sidney was a grade-grubber, Tom was a ladies' man, and then there was Carver. Carver was a total stoner. He smoked more bud on an average day than Ziggy Marley's entire band the night before they had to go through customs. Carver showed me that the real fun to be derived from a Frisbee was not in throwing it or catching it, but in staring at it for hours on end and marveling at 'how damn round it is man!'.

The one thing I did learn right off the bat is, never have a roomate who's really goodlooking unless you like sleeping out in the hall using a bag of Cheetos as a pillow. Fortunately, my junior year roomate Wayne and I got along really well. We each had a signal to use to let the other know we had a girl over, so don't come in. His sign was, he'd leave a belt hanging on the door knob. My sign was, Hell would freeze over. So it worked out well for both of us.

Anyway, what is the obsession with degrees? Liberal arts? That's not a degree, that's a wall hanging. Philosophy majors? The last guy to get a job out of his philosophy degree was your philosophy professor.

Bottom line: College is a way station, the last convenience store before the desert of responsibility. It's a place for people to study and move on to a fulfilling life long career. And 
not that there's anything wrong with kids who decide that college isn't for them. Look at Bill Gates. He dropped out of Harvard and then went on to become the richest man in the universe. But can you imagine how much richer he would be right now if he just had his degree? Of course, that's just my opinion, I could be wrong.

Response to Monologue:

Now that you have read the story, please write about the extent to which you found it amusing or entertaining. Your write up may be as long as you would like. 


\section{Appendix J}

\section{Informed Consent to the Use of Data}

The purpose of an informed consent is to ensure that you now understand the true purpose of the study and that you agree to allow your data to be used for research and teaching purposes. Because you were only told of the procedures and not the purpose of this study at the outset, we are now asking for your consent to allow your data to be used for research and teaching purposes.

Purpose: The true purpose of this study is to assess women's emotional and behavioral reactions to gender discrimination. This research is attempting to look at how women react to a situation of gender discrimination, and the extent to which the experience of discrimination is denied versus perceived by the women

Anonymity/Confidentiality: The data collected in this study are kept anonymous and confidential. The consent forms are kept separate from your responses.

Right to withdraw data: You have the right to indicate that you do not wish your data to be used in this study. If you indicate this is your choice, then all measures you have provided will be destroyed.

Signatures: I have read the above description of the study concerning women's responses to gender discrimination. The data in the study will be used in research publications or for teaching purposes. My signature indicates that I agree to allow the data I have provided to be used for these purposes.

Full Name (Print):

Participant Signature:

Date:

Researcher Signature:

Date: 


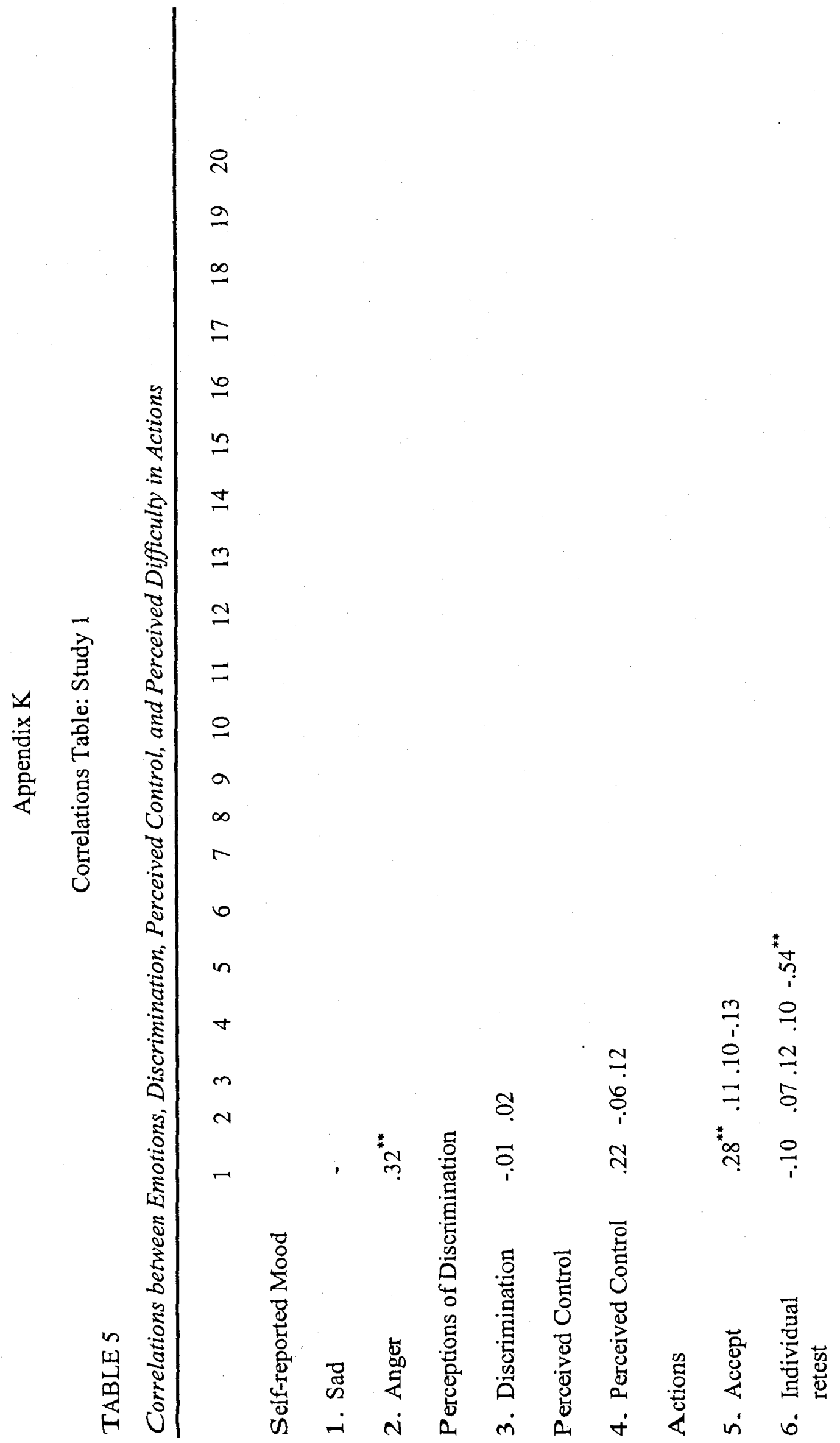


8 क

को

: अं

ชั 
I

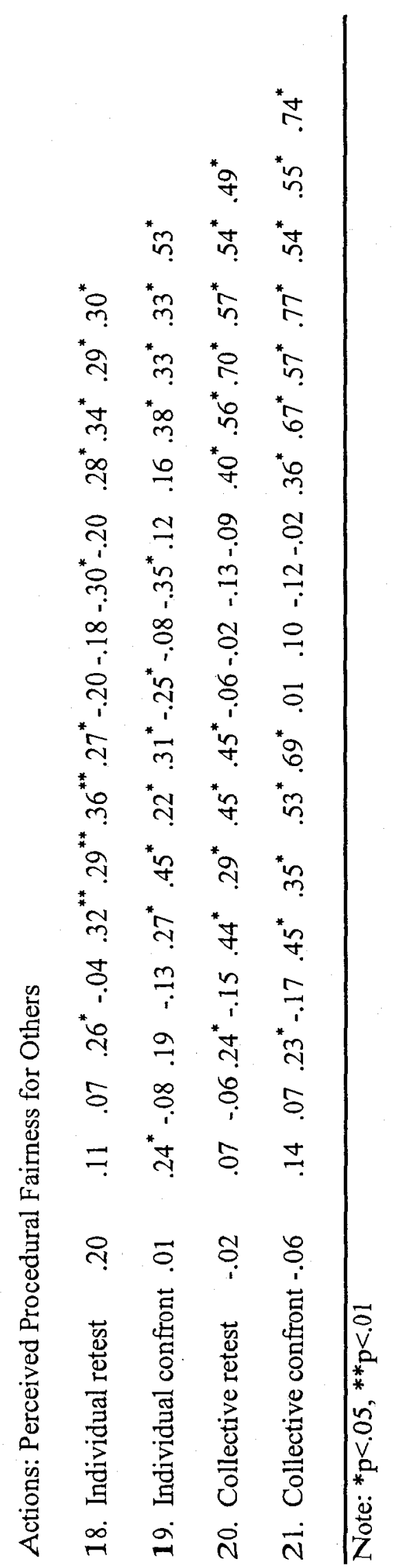


Appendix L

Informed Consent Form: Study 2

The purpose of an informed consent form is to ensure that you understand the purpose of the study and the nature of your involvement. The informed consent must provide sufficient information such that you will have the opportunity to determine whether or not you wish to participate in the study.

Research Title: Examining Creative Abilities through Storytelling

Research Personnel: The following people are involved in this research project and may be contacted at any time. Ritu Gill (Principal investigator, 520-2600 ext.7513), Dr. Kim Matheson (Faculty Investigator and Chair, Department of Psychology, 520-2684). Should you have any ethical concerns then please contact Dr. Mantler (Chair, Carleton University Research Ethics Committee for Psychological Research, 520-2600 ext. 4173).

If you have any ethical concerns about how this study was conducted, please contact

Dr. J. Mantler, Chair of the Carleton University Ethics Committee for Psychological Research , (613) 520-2600, ext. 2251

\section{If you have any other concerns about this study or how it was conducted, please contact}

Dr. M. Gick, Chair, Dept. of Psychology, Carleton University, (613) 520-2648

Purpose and Task Requirements: The purpose of this study is to examine the relation between high and low creative abilities and story writing. You will be asked to complete two creativity tasks, consisting of reading and writing a short story. You will also be asked to complete several questionnaires, some of which may ask for sensitive information, such as emotions, mood, health and medication use. The study will take approximately 1.5 hours. You will receive up to $1.5 \%$ grade increase and up to $\$ 100$ dollars in the lottery.

Potential Risk/Discomfort: There are no potential physical or psychological risks, or potential for embarrassment in this study. There may be some stress associated with personal expectations of performance.

Anonymity/Confidentiality: The data collected in this study will remain anonymous and confidential. All data will be coded such that your name is not associated with the data. In addition the coded data are made available only to researchers associated with this project. 
Right to withdraw: Your participation in this study is entirely voluntary. At any point during the study you have the right to not complete certain questions or to withdraw with no penalty whatsoever.

Signatures: I have read the above description of the study concerning creativity abilities and story writing. The data in this study will be used in research publications or for teaching purposes. My signature indicates I agree to participate in the study, and this in no way constitutes a waiver of my rights.

\section{Participant's Name:}

Participant's Signature:

Researcher's Name:

Researcher's Signature:

Date: 


\section{Demographic Questionnaire}

Please take a few moments to complete some background information about yourself. This kind of information can help to explain certain differences that may be found in creative abilities.

Sex:

Age:

Academic Major (ie. Psychology, Sociology, Biology, etc.):

What is your first language?

What is your religion, if any?

What is your ethnic/racial background? 


\section{Appendix M}

\section{Verbal Instructions: Study 2}

Hello, my name is and I am a graduate student working on a project concerned with creative abilities as they're expressed in writing and storytelling. We're attempting to determine what characteristics might be associated with people who are highly creative. Creative ability is essential to succeed in today's job market in which information is available quickly and easily and so people need to find creative ways to organize information and ideas to understand it. We've found that employers are interested in identifying the characteristics associated with these highly creative individuals so that they can hire the best people. We're also looking at creativity in terms of how it differs across academic background, for instance, psychology vs computer science vs English vs engineering etc.

The study will take approximately 1.5 hours. Before we begin I will ask you to complete these 2 items: an informed consent form, which states what the study is about, that we have your permission to use the results in research publications, you have the right to withdraw etc, and a demographic questionnaire. If you excuse me for a moment, I have to explain this to other students participating in the rooms next door.

\section{Experimenter leaves and returns a few minutes later. Items are collected.}

Now you will be asked to read a short story. While reading this story I would like for you to pretend that you are the student in the story; in other words, whatever the student is thinking/feeling, you are also thinking/feeling. After reading the story, we'll ask you to write/respond to the short story using 12 words we give you as though you are the student in the story. We will want you to be as creative in your response and your ability to work with the 12 words as you can. After completing this task, your story will be scored by one of five male students from engineering that we currently have working in this lab, as we're collaborating on some parts of this research, as you will find out later on in the study. Based on the score given by this engineering student you'll be placed in the high creativity group if you achieve a passing grade, or if your score is low, we'll be putting you in the low creativity group. Those who qualify for the high creativity group are viewed as possessing superior, more advanced creative abilities. You will have to obtain a minimum cut-off mark of $80 \%$ on the creativity task, in order to be considered for as a highly creative individual. If you fail to meet this score then you will be placed in the low status creativity group.

Those who make it to the high creativity group will work with the engineering student to try to improve the stories written by those in the low creativity group. However, those in the low creativity group will be working with me and I will ask them to complete a basic skills task which includes sentence completion and alphabetizing. The purpose of the low creativity group completing these tasks is to allow us to assess the 
relation between poor language and writing skills and lack of creativity. Clearly though their work isn't as important here or in real life, those in the low creativity group will qualify for the $\$ 10$ lottery, while those who are in the high creativity group are eligible for the $\$ 100$. Also, considering that those placed in the low status group are not viewed as competent, they will only receive half of a grade increase as opposed to 1 full grade increase as the task was not successfully completed.

Participants are given 20-25 minutes to complete the task.

Before the experimenter exits the room, in front of the participant she writes the name of the participant on the front of the story. After 20-25 minutes the experimenter returns and collects the story.

Now we're moving on to the second creativity task. This part of the creativity task will be used for those in the high creative group. (For those in the sad condition): Take a few minutes to think of something that happened in your life, or you have known to happen to someone else that made you feel very sad or depressed. Once you remember what made you feel this way, take a few minutes to write about it on this blank piece of paper. (For those in the anger condition): Take a few minutes to think of something that happened in your life, or you have known to happen to someone else that made you feel very angry. Once you remember what made you feel this way, take a few minutes to write about it on this blank piece of paper. (For those in the control condition): Take a few minutes to think of something that happened in your life, or you have known to happen to someone else that inspired a creative moment within you; it could be reading a short story, watching a movie or play. Once you remember what made you feel this way, take a few minutes to write about it on this blank piece of paper. While you are completing this task I'll hand your story to one of the judges to grade.

Following the completion of this task, subjects will be asked to complete an emotion rating scale.

After a 3-5 minutes a male experimenter knocks on the door and says, 'Here is the story that we graded', and then leaves. The female experimenter then says, 'you have been assigned to the low status group consequently you are in the low status group and do not qualify for credits'. She then marks a tally under a 'fail' column on a blackboard that shows the number of participants who had failed or passed the task so far, emphasizing that only men were being passed into the high status group providing a basis for gender discrimination.

At this point the female experimenter closes the door and tells the participant in a secretive manner, 'Something is not right with this study. The male judges do not seem to be doing a fair job as evidenced by the tally board. Because of this, I am trying to gather some hard data to present to the chair of the department. I'll share with you how other participants have been responding to this study: (This is not said to control condition)

Those in the strong ingroup strength condition will be presented with hand written statements from previous female participants, 16 of which support the ingroup (women) (e.g., If the girls in this study were to share our experience in this study with other people I think they would listen to us and take us seriously; I would get together with other 
women and talk about my experience in this study. I think we would all be supportive of each other; If we want, women in this study have the ability to improve the study by voicing our concern) and only 3 do not support the ingroup (e.g., Most women in this study don't care enough to do anything; I wouldn't be willing to get together with other girls in this study, and I don't think the other girls would want to do anything anyway; It's unlikely that the women in this study will even be listened to if they say anything).

In the weak ingroup strength condition, 16 statements will support the outgroup and only 3 support the ingroup. To reinforce the manipulation and as a manipulation check participants will indicate if each statement made reflects women's support for one another to take action, because the experimenter wants to get their opinions of these statements before drawing conclusions from them. In the control group, participants will not read and rate any statements (Mackie et al., 2000).

Female experimenter: Now we ask you to state what you think of doing something about this, and then to complete some questionnaires that I will compile and present to my supervisor.

Participants will be told that they will get to the actual study after these are completed. They will then complete a suspicion questionnaire to determine the extent to which they believed the manipulations), followed by an oral debriefing.. To alleviate anger, a second mood induction procedure will be included that is intended to provide humor. Participants will be shown a 'Mr. Bean' video clip approximately 2-5 minutes in length and asked how entertaining they found it. Given that participants are deceived about the purposes of the study at the beginning, once they are informed of the true purpose of the study following debriefing, they will complete a second informed consent delineating the true intent of the experiment that allows the use of their data. 
Appendix $\mathrm{N}$

Mood Manipulation Check

Using the rating scale beside each item, please indicate how much each adjective describes how you feel at the moment in response to the story you read \& wrote (e.g, if those events really happened to you). There are no right or wrong answers.

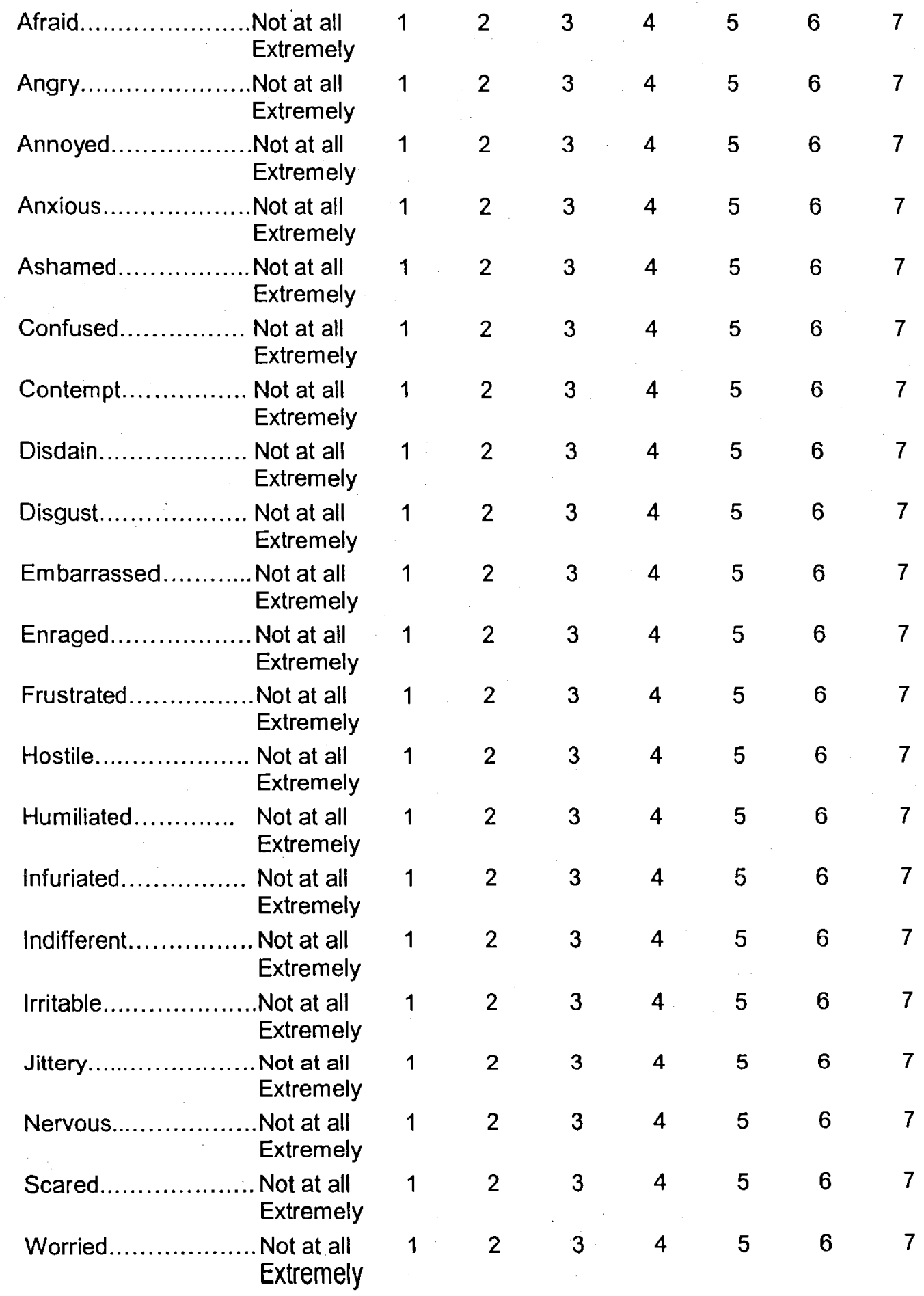




\section{Appendix $\mathrm{O}$}

\section{Strong Ingroup Condition}

\section{Strong Statements:}

1. I think together the women in this study can change this situation for the better

2. I think the women in this study can support one another and be helpful to each other

3. We girls can all get together and find a way to make it to the other group

4. This study can be improved if women get together and do something

5. Women in this study can get together and find a good solution to help us get to the better group

6. Women are actually good at these types of creativity tasks, and so if we actually raise our voices, they have to listen to us!

7. If we women band together and voice our concerns about the study I'm sure we will be heard and taken seriously.

8. I think most women in this study would care enough to share their concerns (including myself).

9. I think that me, and other women in this study, can help each other understand why we didn't make it to the other group and help each other do something to make us feel better. 10. I think women in this study can get together and voice our objection to this study. 11. By getting together with other women in this study and voicing our opinions and experiences with this study, we can help other women who do this study make it to the high status group 
12. If the girls in this study were to share our experience in this study with other people I think they would listen to us and take us seriously.

13. I would be willing to get together with other women in the study and help support each other in our experience in this study.

14. I would get together with other women and talk about my experience in this study. I think we would all be supportive of each other.

15. If we want, women in this study have the ability to improve the study by voicing our concern.

16. Girls in this study can get together and figure out a way to address the study and I'd be willing to get together with the girls and have our concerns heard (girl power!)

Weak Statements:

1. Most women in this study don't care enough to do anything

2. I wouldn't be willing to get together with other girls in this study, and I don't think the other girls would want to do anything anyway.

3. It's unlikely that the women in this study will even be listened to if they say anything.

Add own statement.

Each statement ends with:

1. Does this statement indicate women's support for doing something together to try to change the procedures of this study?

$\begin{array}{lllllllll}\text { Not at all } & 1 & 2 & 3 & 4 & 5 & 6 & 7 & \text { Very Much }\end{array}$


2. Is this statement indicating women's support of each other in this study?

$\begin{array}{lllllllll}\text { Not at all } & 1 & 2 & 3 & 4 & 5 & 6 & 7 & \text { Very Much }\end{array}$

3. Does this statement suggest that the women in this study are supportive of each other and are willing to help each other out by getting together, addressing the situation, and/or having their voices heard?

$\begin{array}{lllllllll}\text { Not at all } & 1 & 2 & 3 & 4 & 5 & 6 & 7 & \text { Very Much }\end{array}$




\section{Appendix P \\ Weak Ingroup Condition}

Weak Statements:

1. Most women in this study don't care enough to do anything

2. I wouldn't be willing to get together with other girls in this study, and I don't think the other girls would want to do anything anyway.

3. It's unlikely that the women in this study will even be listened to if they say anything.

4. It's unlikely that the women in this study will even be listened to if they say anything.

5. Even if the girls get together and voice our concerns about the study I'm sure we no one will take us seriously.

6. I think most women in this study wouldn't care enough to share their concerns (including myself!).

7. I wouldn't get together with other girls in this study (and I don't think they would want to either) to talk about the study. Besides, I don't think if we voice our concerns about the study anyone will take us seriously.

8. I think the women in this study wouldn't be supportive of one another or helpful to each other (I know I wouldn't!)

9. I wouldn't get together with other women and talk about my experience in this study. I think we would all be unsupportive of each other.

10. Women in this study do not have the ability to improve the study by voicing our concern. 
11. I don't think that by girls in this study getting together and talking would be helpful in helping us understand why we didn't make it to the other group, and we certainly wouldn't be able to help each other feel better!

12. I don't think girls in this study can change this situation for the better

13. I think the women in this study can't support one another and can't be helpful to each other

14. We girls wouldn't be able to get together and find a way to make it to the other group 15. This study can't be improved if women get together and do something because no one will care enough to listen to us

16. Women in this study can't get together and find solution to help us get to the 'better' group

Strong statements:

1. If the girls in this study were to share our experience in this study with other people I think they would listen to us and take us seriously.

2. I would get together with other women and talk about my experience in this study. I think we would all be supportive of each other.

3. If we want, women in this study have the ability to improve the study by voicing our concern.

Add own statement.

Each statement ends with: 
1. Does this statement indicate women's support for doing something together to try to change the procedures of this study?

$\begin{array}{lllllllll}\text { Not at all } & 1 & 2 & 3 & 4 & 5 & 6 & 7 & \text { Very Much }\end{array}$

2. Is this statement indicating women's support of each other in this study?

$\begin{array}{lllllllll}\text { Not at all } & 1 & 2 & 3 & 4 & 5 & 6 & 7 & \text { Very Much }\end{array}$

3. Does this statement suggest that the women in this study are supportive of each other and are willing to help each other out by getting together, addressing the situation, and/or having their voices heard?

$\begin{array}{lllllllll}\text { Not at all } & 1 & 2 & 3 & 4 & 5 & 6 & 7 & \text { Very Much }\end{array}$




\section{Appendix Q}

\section{Questionnaires}

Please answer the following questionnaires as honestly as possible as I am using this to present to the Chair of the Department of Psychology. All of your responses will be anonymous and confidential.

\section{Mood}

Using the rating scale beside each item, please indicate how much each adjective describes how you feel at the moment. There are no right or wrong answers, we just want you to be as honest as possible in indicating how you're feeling right now.

\begin{tabular}{|c|c|c|c|c|c|c|c|}
\hline Active................. Not at all & 1 & 2 & 3 & 4 & 5 & 6 & 7 Extremely \\
\hline Afraid...................... at all & 1 & 2 & 3 & 4 & 5 & 6 & 7 Extremely \\
\hline Alert...................... at all & 1 & 2 & 3 & 4 & 5 & 6 & 7 Extremely \\
\hline Angry.................... Not at all & 1 & 2 & 3 & 4 & 5 & 6 & 7 Extremely \\
\hline Annoyed................Not at all & 1 & 2 & 3 & 4 & 5 & 6 & 7 Extremely \\
\hline Anxious................... Not at all & 1 & 2 & 3 & 4 & 5 & 6 & 7 Extremely \\
\hline Ashamed............... Not at all & 1 & 2 & 3 & 4 & 5 & 6 & 7 Extremely \\
\hline Attentive ...............Not at all & 1 & 2 & 3 & 4 & 5 & 6 & 7 Extremely \\
\hline Confused.............. Not at all & 1 & 2 & 3 & 4 & 5 & 6 & 7 Extremely \\
\hline Contempt.............. Not at all & 1 & 2 & 3 & 4 & 5 & 6 & 7 Extremely \\
\hline Depressed...............Not at all & 1 & 2 & 3 & 4 & 5 & 6 & 7 Extremely \\
\hline Determined............ Not at all & 1 & 2 & 3 & 4 & 5 & 6 & 7 Extremely \\
\hline Disdain................ Not at all & 1 & 2 & 3 & 4 & 5 & 6 & 7 Extremely \\
\hline Disgust................ Not at all & 1 & 2 & 3 & 4 & 5 & 6 & 7 Extremely \\
\hline Distressed............. Not at all & 1 & 2 & 3 & 4 & 5 & 6 & 7 Extremely \\
\hline Embarrassed........... Not at all & 1 & 2 & 3 & 4 & 5 & 6 & 7 Extremely \\
\hline Enraged............... Not at all & 1 & 2 & 3 & 4 & 5 & 6 & 7 Extremely \\
\hline Enthusiastic............... Not at all & 1 & 2 & 3 & 4 & 5 & 6 & 7 Extremely \\
\hline Excited..................... Not at all & 1 & 2 & 3 & 4 & 5 & 6 & 7 Extremely \\
\hline Frustrated............... Not at all & 1 & 2 & 3 & 4 & 5 & 6 & 7 Extremely \\
\hline Guilty ..................... at all & 1 & 2 & 3 & 4 & 5 & 6 & 7 Extremely \\
\hline Happy..................Not at all & 1 & 2 & 3 & 4 & 5 & 6 & 7 Extremely \\
\hline Helpless................ Not at all & 1 & 2 & 3 & 4 & 5 & 6 & 7 Extremely \\
\hline Hostile................ Not at all & 1 & 2 & 3 & 4 & 5 & 6 & 7 Extremely \\
\hline Humiliated............. Not at all & 1 & 2 & 3 & 4 & 5 & 6 & 7 Extremely \\
\hline Indifferent............. Not at all & 1 & 2 & 3 & 4 & 5 & 6 & 7 Extremely \\
\hline Infuriated.............. Not at all & 1 & 2 & 3 & 4 & 5 & 6 & 7 Extremely \\
\hline Inspired.................Not at all & 1 & 2 & 3 & 4 & 5 & 6 & 7 Extremely \\
\hline Interested............ Not at all & 1 & 2 & 3 & 4 & 5 & 6 & 7 Extremely \\
\hline
\end{tabular}




\begin{tabular}{|c|c|c|c|c|c|c|c|}
\hline Irritable................ Not at all & 1 & 2 & 3 & 4 & 5 & 6 & 7 Extremely \\
\hline Jittery................... Not at all & 1 & 2 & 3 & 4 & 5 & 6 & 7 Extremely \\
\hline Nervous.............. Not at all & 1 & 2 & 3 & 4 & 5 & 6 & 7 Extremely \\
\hline Proud.................. Not at all & 1 & 2 & 3 & 4 & 5 & 6 & 7 Extremely \\
\hline Regretful............... Not at all & 1 & 2 & 3 & 4 & 5 & 6 & 7 Extremely \\
\hline Responsible............. Not at all & 1 & 2 & 3 & 4 & 5 & 6 & 7 Extremely \\
\hline Sad .................... Not at all & 1 & 2 & 3 & 4 & 5 & 6 & 7 Extremely \\
\hline Scared................... Not at all & 1 & 2 & 3 & 4 & 5 & 6 & 7 Extremely \\
\hline Strong .................... at all & 1 & 2 & 3 & 4 & 5 & 6 & 7 Extremely \\
\hline Unhappy.................Not at all & 1 & 2 & 3 & 4 & 5 & 6 & 7 Extremely \\
\hline Upset..................Not at all & 1 & 2 & 3 & 4 & 5 & 6 & 7 Extremely \\
\hline Worried................ Not at all & 1 & 2 & 3 & 4 & 5 & 6 & 7 Extremely \\
\hline
\end{tabular}


Discrimination Questionnaire

Using the scale below please answer each of the following questions honestly.

1. To what extent do you feel that the creativity task in this study accurately reflects your creative abilities

$\begin{array}{lllllllll}\text { Not at all } & 1 & 2 & 3 & 4 & 5 & 6 & 7 & \text { Very Much }\end{array}$

2. To what extent do you feel that a different story would have encouraged you to feel more creative?

$\begin{array}{lllllllll}\text { Not at all } & 1 & 2 & 3 & 4 & 5 & 6 & 7 & \text { Very Much }\end{array}$

3. To what extent do you feel that in this study creative abilities should have been evaluated using a method other than story writing?

$\begin{array}{lllllllll}\text { Not at all } & 1 & 2 & 3 & 4 & 5 & 6 & 7 & \text { Very Much }\end{array}$

4. To what extent were you personally discriminated against because you are a woman in the context of this experiment?

$\begin{array}{lllllllll}\text { Not at all } & 1 & 2 & 3 & 4 & 5 & 6 & 7 & \text { Very Much }\end{array}$

5. To what extent do you feel writing the story using the word list restricted your creativity?

$\begin{array}{lllllllll}\text { Not at all } & 1 & 2 & 3 & 4 & 5 & 6 & 7 & \text { Very Much }\end{array}$

6. To what extent do you feel given more time to create a story would have improved the creative quality of your story?

$\begin{array}{lllllllll}\text { Not at all } & 1 & 2 & 3 & 4 & 5 & 6 & 7 & \text { Very Much }\end{array}$

7. To what extent do you feel that the topic of the story restricted your creative flow?

$\begin{array}{lllllllll}\text { Not at all } & 1 & 2 & 3 & 4 & 5 & 6 & 7 & \text { Very Much }\end{array}$

8. To what extent do you feel that women as a group were discriminated against in the context of this experiment?

$\begin{array}{lllllllll}\text { Not at all } & 1 & 2 & 3 & 4 & 5 & 6 & 7 & \text { Very Much }\end{array}$

9. To what extent do you feel that women in the 'career world' are discriminated against?

$\begin{array}{lllllllll}\text { Not at all } & 1 & 2 & 3 & 4 & 5 & 6 & 7 & \text { Very Much }\end{array}$ 
Perceived Control Questionnaire

Below are a series of statements. Reach statement, decide if you agree or disagree and the strength of your opinion, and then circle the appropriate number according to how you feel at this moment in the context of this study.

$\begin{array}{ccccccc}1 & 2 & 3 & 4 & 5 & 6 & 7 \\ \begin{array}{c}\text { Disagree } \\ \text { strongly }\end{array} & \begin{array}{c}\text { Disagree } \\ \text { somewhat }\end{array} & \begin{array}{c}\text { Disagree } \\ \text { a little }\end{array} & \begin{array}{c}\text { Don't } \\ \text { know }\end{array} & \begin{array}{c}\text { Agree } \\ \text { a little }\end{array} & \text { Agree } & \begin{array}{c}\text { Agree } \\ \text { somewhat }\end{array} \\ \text { strongly } & & & & & & \end{array}$

1. I have little control over the things that happen to me.

$\begin{array}{llllllll}1 & 2 & 3 & 4 & 5 & 6 & 7\end{array}$

2. What happens to me in the future mostly depends on me.
1
2
3
4
5
6
7

3. There is really no way I can solve all of the problems I have.
1
2
3
4
56
7

4. There is little I can do to change many of the important things in my life.
1
2
3
4.5
6
7

5. I can do just about anything I really set my mind to.
1
2
3
4
5
6
7

6. I often feel helpless in dealing with the problems of life.
1
2
3
4
5
6
7

7. Sometimes I feel that I'm being pushed around in life.
1
2
3
4
5
6
7

8. When I really want to do something, I usually find a way to succeed at it.
1
2
3
5
6
7

9. Whether or not I am able to get what I want is in my own hands.
1
2
3
4
5
6
7

10. Other people determine most of what I can and cannot do.
1
2
3
4
5
6
7

11. What happens in my life is often beyond my control.
1
2
3
4
5
6
7

12. There are many things that interfere with what I want to do.
1
2
3
4
5
6 
Action Survey

Please indicate the extent to which you would participate in the following actions if you had the opportunity to respond to your group assignment in the present study.

1. Accept the situation, that is, your assignment to either group, as is.

$\begin{array}{lclllll}1 & 2 & 3 & 4 & 5 & 6 & 7 \\ \text { Not at all } & & & & & \text { Very Much }\end{array}$

2. Request an individual retest of your creativity score.

$\begin{array}{lclllll}1 & 2 & 3 & 4 & 5 & 6 & 7 \\ \text { Not at all } & & & & & \text { Very Much }\end{array}$

3. Confront the experimenter and demand an explanation of your particular group assignment.

$\begin{array}{lclllll}1 & 2 & 3 & 4 & 5 & 6 & 7 \\ \text { Not at all } & & & & & \text { Very Much }\end{array}$

4. Ask that all of the women be retested for their creativity.

$\begin{array}{lclllll}1 & 2 & 3 & 4 & 5 & 6 & 7 \\ \text { Not at all } & & & & & \text { Very Much }\end{array}$

5. Get together with other women to confront the experimenter, demanding an explanation for your group assignment.

$\begin{array}{lclllll}1 & 2 & 3 & 4 & 5 & 6 & 7 \\ \text { Not at all } & & & & & \text { Very Much }\end{array}$


Please indicate the extent to which you believe each action could be implemented if you had the opportunity to respond to your group assignment in the present study.

\section{Request an individual retest of your creativity score.}

To what extent do you think this action would be difficult to implement?
$1 \quad 2$
45
6
7
Very Much

To what extent would this action improve your personal status in this study?

$\begin{array}{lclllll}1 & 2 & 3 & 4 & 5 & 6 & 7 \\ \text { Not at all } & & & & & \text { Very Much }\end{array}$

To what extent would this action improve the procedures in this study to allow other participants to be evaluated fairly?

$\begin{array}{lclllll}1 & 2 & 3 & 4 & 5 & 6 & 7 \\ \text { Not at all } & & & & & \text { Very Much }\end{array}$

\section{Confront the experimenter and demand an explanation of your particular group assignment.}

To what extent do you think this action would be difficult to implement?

$\begin{array}{lcccccl}1 & 2 & 3 & 4 & 5 & 6 & 7 \\ \text { Not at all } & & & & & \text { Very Much }\end{array}$

To what extent would this action improve your personal status in this study?

$\begin{array}{lcccccl}1 & 2 & 3 & 4 & 5 & 6 & 7 \\ \text { Not at all } & & & & & \text { Very Much }\end{array}$

To what extent would this action improve the procedures in this study to allow other participants to be evaluated fairly?

$\begin{array}{lclllll}1 & 2 & 3 & 4 & 5 & 6 & 7 \\ \text { Not at all } & & & & & \text { Very Much }\end{array}$


3. Ask that all of the women be retested for their creativity.

To what extent do you think this action would be difficult to implement?

$\begin{array}{lclllll}1 & 2 & 3 & 4 & 5 & 6 & 7 \\ \text { Not at all } & & & & & \text { Very Much }\end{array}$

To what extent would this action improve your personal status in this study?

$\begin{array}{lclllll}1 & 2 & 3 & 4 & 5 & 6 & 7 \\ \text { Not at all } & & & & & \text { Very Much }\end{array}$

To what extent would this action improve the procedures in this study to allow other participants to be evaluated fairly?

$\begin{array}{lrlllll}1 & 2 & 3 & 4 & 5 & 6 & 7 \\ \text { Not at all } & & & & & \text { Very Much }\end{array}$

\section{Get together with other women to confront the experimenter, demanding an explanation for your group assignment.}

To what extent do you think this action would be difficult to implement?

$\begin{array}{lrlllll}1 & 2 & 3 & 4 & 5 & 6 & 7 \\ \text { Not at all } & & & & & \text { Very Much }\end{array}$

To what extent would this action improve your personal status in this study?

$\begin{array}{lrlllll}1 & 2 & 3 & 4 & 5 & 6 & 7 \\ \text { Not at all } & & & & & \text { Very Much }\end{array}$

To what extent would this action improve the procedures in this study to allow other participants to be evaluated fairly?

$\begin{array}{lclllll}1 & 2 & 3 & 4 & 5 & 6 & 7 \\ \text { Not at all } & & & & & \text { Very Much }\end{array}$


Entativity

1. I consider women to be a cohesive group

123

Strongly Disagree

4

5

6

7

Strongly Agree

2. I think of women as being a singular unit.

132

4

5

6

7

Strongly Disagree

Strongly Agree

3. All women are interconnected.

123

Strongly Disagree
4

5

6

7

Strongly Agree 
Appendix R

\section{Identification Scale}

Using the scale below, please rate the extent to which you agree or disagree with each of the statements below on a scale of 0 (strongly disagree) to 5 (strongly agree) according to how you feel at the moment.

$\begin{array}{lrrrrrr}1 & 2 & 3 & 4 & 5 & 6 & 7 \\ \text { Strongly } & & & & & \begin{array}{l}\text { Strongly } \\ \text { Agree }\end{array} \\ \text { Disagree } & & & & & \end{array}$

1) I have a lot in common with other woman.

2) I often think about the fact that I am a woman.

3) In general, I'm glad to be a woman.

4) The fact that I am a woman rarely enters my mind.

5) Generally, I feel good when I think about myself as a woman

6) I feel strong ties to other woman.

7) I often regret that I am a woman.

8) Overall, being a woman has very little to do with how I feel about myself.

9) I don't feel good about being a woman.

10) I find it difficult to form a bond with other woman.

11) In general, being a woman is an important part of my self-image.

12) I don't feel a sense of being "connected" with other women. 


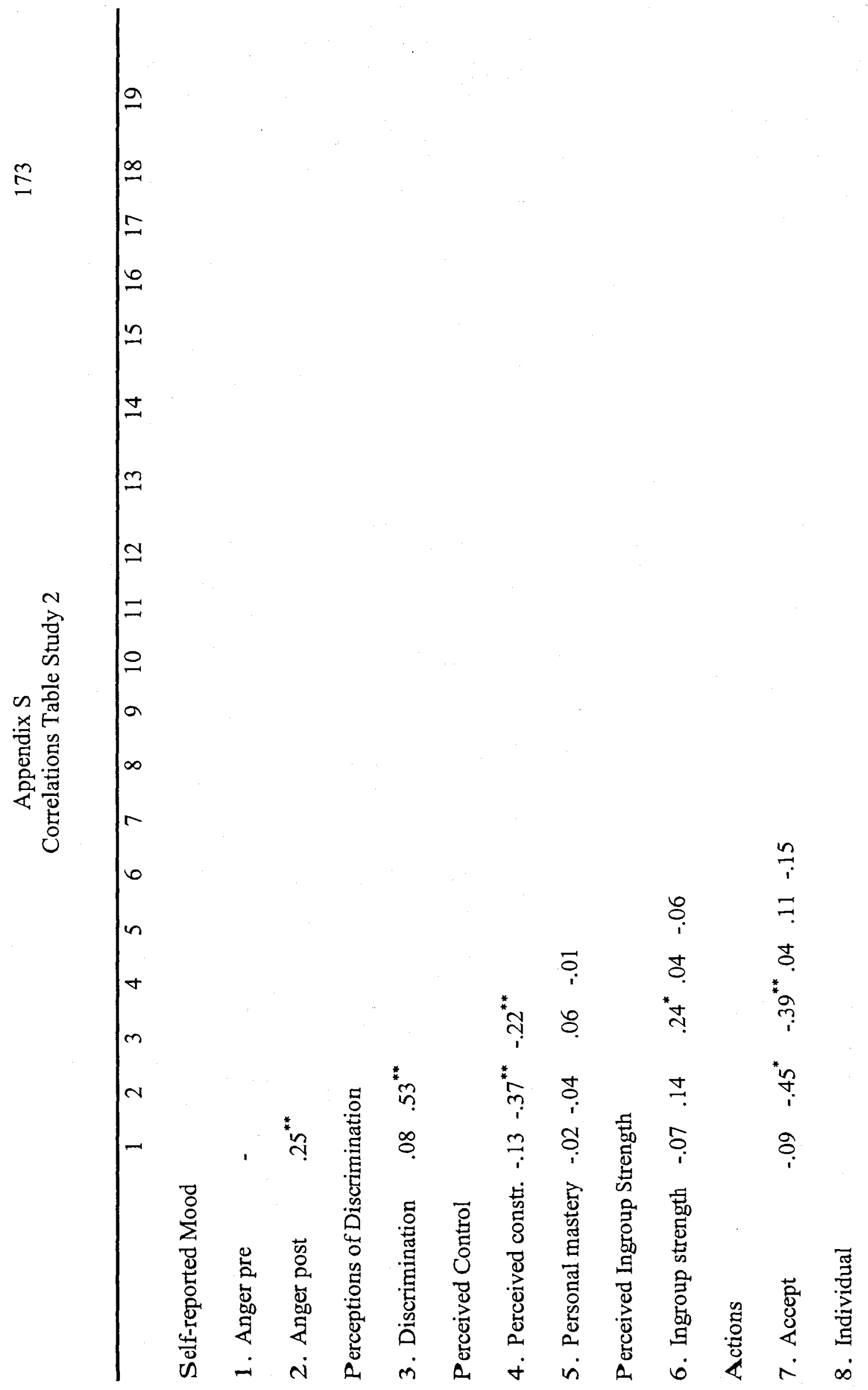


$\stackrel{ \pm}{ \pm}$

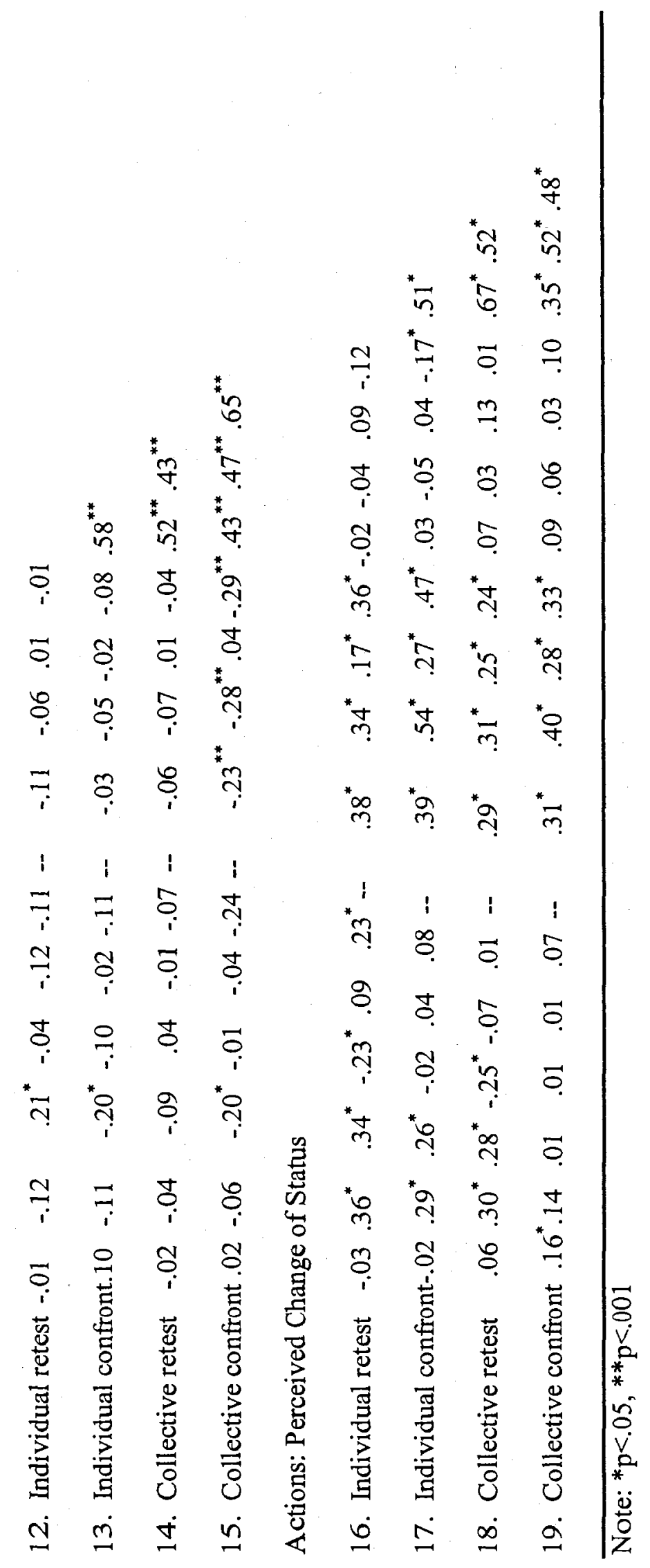


Appendix T

Debriefing

Study:

Discrimination: The effects of Anger and Ingroup Strength

\section{Background and Purpose of Study:}

In this study we are interested in examining the effects of women's emotional reactions to situations of discrimination and on their perceptions and responses to the discrimination. In particular, we believe that if women's emotional response is anger, they may be less likely to attribute the discrimination to something about themselves, and to feel more empowered to take action to counter the source of discrimination. In order. to assess the expectations, we want to prime women's emotional state prior to encountering the discriminatory situation. We also wanted to assess the extent to which one's perceptions of ingroup strength (e.g., how strong you perceive your group, such as women as opposed to the judges, to be) affected responses to and perceptions of discrimination. We believe that women who appraise their group (e.g., women) as being strong are more inclined to perceive and respond to discrimination.

Deception was involved in this study in that it suggests that we are concerned about creativity when it is not. In some studies, if we tell people what the purpose of the experiment is and what we predict about how they will react under certain conditions, then they might deliberately do whatever it is they think we want them to do. If that happened, their reactions would not be a good indication of how they might react in a situation in everyday life, where they didn't think they were being studied. What would be influencing them is what they thought the purpose of our study was rather than the specific conditions that we are trying to investigate. It is also possible that the opposite might occur and that people may think that if we predicted that they would do a certain thing, they might purposely not do that to show us we can't figure them out. That would also make the results invalid, because again what people would be responding to is what they thought we were looking for rather than responding naturally as they would in everyday situation. The purpose of reading and writing a short story was to induce an angry mood. Once this mood was primed, we then asked participants to complete an emotion rating scale to ensure that the desired mood was elicited. Following this, we then posed a situation of discrimination in which the male experimenter did not accept women in the high status group simply because they were women. We then asked women to read statements that indicated strong ingroup, weak ingroup, or a control group where no statements were read. We then administered several questionnaires to evaluate affective, cognitive, and behavioral effects on perceptions and responses to discrimination. We asked participants to complete one questionnaire which assessed the extent to which women in this study minimized personal discrimination relative to group discrimination. Another questionnaire evaluated the extent to which women identified with other women in general. Another questionnaire assessed the participants' perception 
of control. Finally, an 'action' survey was given to determine if participants would be willing to participate in any set of actions if they had the opportunity to respond to the treatment in the present study. We also asked participants to view Mr. Bean acts to ensure that no one left the study feeling upset. The purpose of not giving credit when assigned to the low status group was to make the participants feel bad about not being assigned to the high status group and making them care about wanting to be in the high status group.

\section{Questions and Comments:}

If you have any questions about this research, or are interested in the results of this study, please feel free to contact Ritu Gill, the principal investigator (520-2600 ext. 7513 ) or Dr. Kim Matheson, the research supervisor (520-2600 ext. 2684). If you have any concerns about the ethics of this study, please refer them to Dr. Janet Mantler, Carleton University Research Ethics Committee for Psychological Research (520-2600 ext. 4173). Should you have any other concerns about this study please refer them to Dr. Mary Gick, Chair of the Psychology Department (520-2600 ext. 2684). 
Appendix U

Informed Consent to the Use of Data: Study 2

The purpose of an informed consent is to ensure that you now understand the true purpose of the study and that you agree to allow your data to be used for research and teaching purposes. Because you were only told of the procedures and not the purpose of this study at the outset, we are now asking for your consent to allow your data to be used for research and teaching purposes.

Purpose: The true purpose of this study is to assess women's emotional and behavioral reactions to gender discrimination. This research is attempting to look at how women react to a situation of gender discrimination, and the extent to which the experience of discrimination is denied versus perceived by the women

Anonymity/Confidentiality: The data collected in this study are kept anonymous and confidential. The consent forms are kept separate from your responses.

Right to withdraw data: You have the right to indicate that you do not wish your data to be used in this study. If you indicate this is your choice, then all measures you have provided will be destroyed.

Signatures: I have read the above description of the study concerning women's responses to gender discrimination. The data in the study will be used in research publications or for teaching purposes. My signature indicates that I agree to allow the data I have provided to be used for these purposes.

Full Name (Print):

Participant Signature:

Date:

Researcher Signature:

Date: 